\section{Pacific Northwest}

National Laboratory

Operated by Battelle for the

U.S. Department of Energy

\title{
Proposed Occupational Exposure Limits for Non-Carcinogenic Hanford Waste Tank Vapor Chemicals
}

TS Poet

C Timchalk

March 2006

Prepared for the U.S. Department of Energy under Contract DE-AC05-76RL01830 


\title{
DISCLAIMER
}

This report was prepared as an account of work sponsored by an agency of the United States Government. Neither the United States Government nor any agency thereof, nor Battelle Memorial Institute, nor any of their employees, makes any warranty, express or implied, or assumes any legal liability or responsibility for the accuracy, completeness, or usefulness of any information, apparatus, product, or process disclosed, or represents that its use would not infringe privately owned rights. Reference herein to any specific commercial product, process, or service by trade name, trademark, manufacturer, or otherwise does not necessarily constitute or imply its endorsement, recommendation, or favoring by the United States Government or any agency thereof, or Battelle Memorial Institute. The views and opinions of authors expressed herein do not necessarily state or reflect those of the United States Government or any agency thereof.

\author{
PACIFIC NORTHWEST NATIONAL LABORATORY \\ operated by \\ BATTELLE \\ for the \\ UNITED STATES DEPARTMENT OF ENERGY \\ under Contract DE-AC05-76RL01830
}

Printed in the United States of America
Available to DOE and DOE contractors from the Office of Scientific and Technical Information,
P.O. Box 62, Oak Ridge, TN 37831-0062;
ph: (865) 576-8401
fax: (865) 576-5728
email: reports@adonis.osti.gov

\author{
Available to the public from the National Technical Information Service, \\ U.S. Department of Commerce, 5285 Port Royal Rd., Springfield, VA 22161 \\ ph: (800) 553-6847 \\ fax: (703) 605-6900 \\ email: orders@ntis.fedworld.gov \\ online ordering: http://www.ntis.gov/ordering.htm
}

This document was printed on recycled paper. 


\section{Proposed Occupational Exposure Limits for Non-Carcinogenic Hanford Waste Tank Vapor Chemicals}

TS Poet

C Timchalk

March 2006

Prepared for

the U.S. Department of Energy

under Contract DE-AC05-76RL01830

Pacific Northwest National Laboratory

Richland, Washington 99352 


\section{Summary}

A large number of volatile chemicals have been identified in the headspaces of tanks used to store mixed chemical and radioactive waste at the U.S. Department of Energy (DOE) Hanford Site, and there is concern that vapor releases from the tanks may be hazardous to workers. The tank farm operations contractor, CH2M Hill Hanford Group, Inc., is contractually obligated to meet occupational exposure limits (OELs) established by the Occupational Safety and Health Administration (OSHA) and American Conference of Governmental Industrial Hygienists (ACGIH). Some of the vapors detected in the tank headspaces have OSHA and/or ACGIH OELs, but not all. To address the need for worker exposure guidelines for those chemicals that lack OSHA or ACGIH OELs, a procedure for assigning Acceptable Occupational Exposure Limits (AOELs) for Hanford Site tank farm workers has been developed and applied to a selected group of 57 headspace chemicals.

The 57 chemicals considered in this report were identified by a toxicological screening process (Poet et al. 2006) and reviews of the analytical data on which the existence of the chemicals in the tanks were based (e.g., Sklarew and Mitroshkov 2006). AOELs developed by this report are considered "proposed" until reviewed and formally adopted by the Environmental Exposure Assessment Review Group.

The proposed AOELs were preferentially based on OELs established by U.S. or foreign agencies and organizations other than OSHA and ACGIH. When other such OELs were available, they were evaluated for use as AOELs. Four chemicals were assigned AOELs on this basis (Table S.1). For the remaining 53 chemicals without established OELs, epidemiological and toxicological information was reviewed to identify potential hazards, select critical effects, and estimate dose-response to determine exposure levels expected to be safe. When information on the chemical itself was insufficient to develop an AOEL, the proposed AOEL was based on one or more structurally related chemicals (surrogates) for which sufficient data were available. Surrogates with close structural and pharmacological activity with established OELs (ACGIH or OSHA) were preferentially selected. Of these 53 chemicals, 47 were assigned proposed AOELs (Table S.2), and six were determined to not warrant complete AOEL development (Table S.3).

Table S.1. OELs for Chemicals with Limits from NIOSH, AIHA or MAK

\begin{tabular}{|c|c|c|c|}
\hline Chemical & $\begin{array}{l}\text { CAS }^{(a)} \\
\text { Number }\end{array}$ & $\begin{array}{l}\text { Proposed AOEL } \\
\text { (ppm) }\end{array}$ & OEL Source \\
\hline Propanenitrile & $107-12-0$ & 6 & $\mathrm{REL}^{(\mathrm{b})}$ \\
\hline 2-Ethyl-1-hexanol & $104-76-7$ & 20 & MAK $^{(\mathrm{c})}$ \\
\hline Butanal & $123-72-8$ & 25 & WEEL $^{(\mathrm{d})}$ \\
\hline Butanenitrile & $109-74-0$ & 8 & REL \\
\hline \multicolumn{4}{|c|}{$\begin{array}{l}\text { (a) CAS = Chemical Abstracts Service. } \\
\text { (b) REL - Recommended Exposure Limits, National Institute for Occupational Safety and Health } \\
\text { (NIOSH) } \\
\text { (c) MAK- Maximum Arbeitsplatz Konzentration, German Commission for the Investigation of Health } \\
\text { Hazards of Chemical Compounds in the Work Area (MAK Commission) } \\
\text { (d) WEEL - Workplace Environmental Exposure Limits, American Industrial Hygiene Association } \\
\text { (AIHA) }\end{array}$} \\
\hline
\end{tabular}


Table S.2. Summary of Proposed AOELs

\begin{tabular}{|c|c|c|}
\hline Chemical & $\begin{array}{l}\mathrm{CAS}^{(\mathrm{a})} \\
\text { Number } \\
\end{array}$ & $\begin{array}{c}\text { Proposed AOEL } \\
(\mathrm{ppm})\end{array}$ \\
\hline \multicolumn{3}{|l|}{ HALOCARBONS } \\
\hline 2-Fluoropropene & $1184-60-7$ & 0.1 \\
\hline \multicolumn{3}{|l|}{ ALCOHOLS } \\
\hline Cyclopentanol & $96-41-3$ & 5 \\
\hline \multicolumn{3}{|l|}{ ETHERS } \\
\hline 1-Methoxybutane & $628-28-4$ & 17 \\
\hline \multicolumn{3}{|l|}{ ALDEHYDES } \\
\hline 2-Methylbut-2-enal & $1115-11-3$ & 0.03 \\
\hline 2-Ethylhex-2-enal & $645-62-5$ & 0.1 \\
\hline \multicolumn{3}{|l|}{ KETONES } \\
\hline 4-Methyl-2-hexanone & $105-42-0$ & 0.5 \\
\hline 3-Hexanone & $589-38-8$ & 67 \\
\hline 6-Methyl-2-heptanone & $928-68-7$ & 8 \\
\hline 2-Nonanone & $821-55-6$ & 17 \\
\hline 3-Dodecanone & $1534-27-6$ & 17 \\
\hline 2-Tridecanone & $593-08-8$ & 17 \\
\hline 3-Tridecanone & $1534-26-5$ & 17 \\
\hline 5-Methyl-2-(1-methylethenyl)cyclohexanone & 89-82-7 & 2.5 \\
\hline 4,7,7-Trimethylbicyclo[4.1.0]heptan-3-one & $4176-04-9$ & 0.7 \\
\hline 3-Methyl-3-buten-2-one & $814-78-8$ & 0.02 \\
\hline \multicolumn{3}{|l|}{ ESTERS } \\
\hline Dibutyl butylphosphonate & $78-46-6$ & 0.02 \\
\hline \multicolumn{3}{|l|}{ NITRILES } \\
\hline 2-Methylene butanenitrile & $1647-11-6$ & 0.3 \\
\hline Pentanenitrile & $110-59-8$ & 6 \\
\hline Hexanenitrile & $628-73-9$ & 6 \\
\hline Heptanenitrile & $629-08-3$ & 6 \\
\hline Octanenitrile & $124-12-9$ & 6 \\
\hline Nonanenitrile & $2243-27-8$ & 6 \\
\hline Decanenitrile & $1975-78-6$ & 6 \\
\hline 3-Butenenitrile & $109-75-1$ & 1 \\
\hline 2,4-Pentadienenitrile & $1615-70-9$ & 0.3 \\
\hline \multicolumn{3}{|l|}{ AMINES \& AMIDES } \\
\hline N-Methylaziridine & $1072-44-2$ & 0.05 \\
\hline \multicolumn{3}{|l|}{ NITRITES \& NITRATES } \\
\hline Methyl nitrite & $624-91-9$ & 0.1 \\
\hline Ethyl nitrite & 109955 & 0.1 \\
\hline Butyl nitrite & 544-16-1 & 0.1 \\
\hline Methyl nitrate & $598-58-3$ & 8 \\
\hline Ethyl nitrate & $625-58-1$ & 8 \\
\hline Butyl nitrate & $928-45-0$ & 8 \\
\hline 1,3-Propanediol, dinitrate & $3457-90-7$ & 0.05 \\
\hline 1,4-Butanediol, dinitrate & $3457-91-8$ & 0.05 \\
\hline 1,5-Pentanediol, dinitrate & $3457-92-9$ & 0.05 \\
\hline 1,2,3-Propanetriol, 1,3-dinitrate & 623-87-0 & 0.05 \\
\hline
\end{tabular}


Table S.2. (contd)

\begin{tabular}{|l|c|c||}
\hline \multicolumn{1}{|c|}{ Chemical } & $\begin{array}{c}\text { CAS } \\
\text { Number }\end{array}$ & $\begin{array}{c}\text { Proposed AOEL } \\
\text { (ppm) }\end{array}$ \\
\hline \hline 1,2,3-Propanetriol, 1-nitrate & $624-43-1$ & 8 \\
\hline NITRO COMPOUNDS & & 0.8 \\
\hline 2-Nitro-1-propanol & $2902-96-7$ & 0.3 \\
\hline 2-Nitro-2-methylpropane & $594-70-7$ & 2.5 \\
\hline 1-Nitrobutane & $627-05-4$ & 0.001 \\
\hline HETEROCYCLICS & & 0.001 \\
\hline Furan & $110-00-9$ & 0.001 \\
\hline 2-Methylfuran & $534-22-5$ & 0.001 \\
\hline 2-Propylfuran & $4229-91-8$ & 0.001 \\
\hline 2-Ethyl-5-methylfuran & $1703-52-2$ & 0.001 \\
\hline 2,5-Dihydrofuran & $1708-29-8$ & 0.5 \\
\hline alpha-Propylfuranacetaldehyde & $31681-26-2$ & \\
\hline 2,4-Dimethylpyridine & $108-47-4$ & \\
\hline (a) CAS = Chemical Abstracts Service. & & \\
\hline
\end{tabular}

Table S.3. Chemicals For Which No AOEL is Recommended

\begin{tabular}{|l|c||}
\hline \multicolumn{1}{|c|}{ Chemical } & $\begin{array}{c}\text { CAS }^{(a)} \\
\text { Number }\end{array}$ \\
\hline \hline 1-Hexadecanol & $36653-82-4$ \\
\hline 1-Octadecanol & $112-92-5$ \\
\hline 1-Methylethyl tetradecanoate & $110-27-0$ \\
\hline Butyl tetradecanoate & $110-36-1$ \\
\hline 1-Methylethyl hexadecanoate & $142-91-6$ \\
\hline Acetamide & $60-35-5$ \\
\hline (a) CAS = Chemical Abstracts Service. \\
\hline
\end{tabular}




\section{Contents}

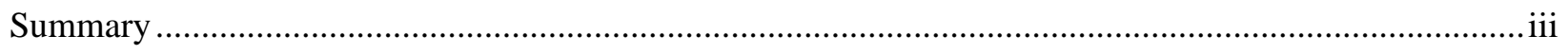

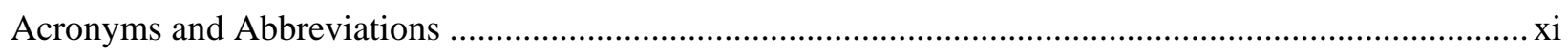

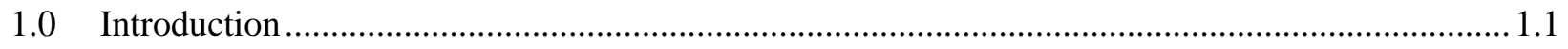

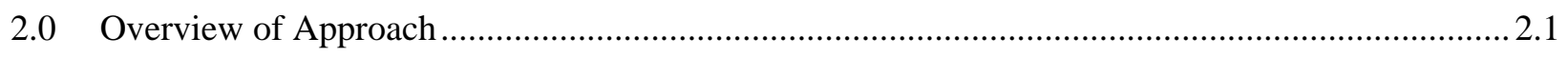

2.1 Data Base and Literature Evaluation.......................................................................... 2.2

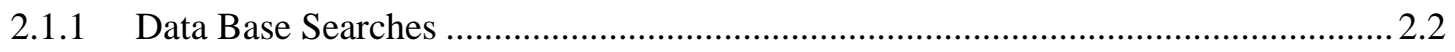

2.1.2 Literature Evaluation of Published Exposure Guidelines......................................... 2.3

2.1.3 Use of Surrogate OELs............................................................................................ 2.3

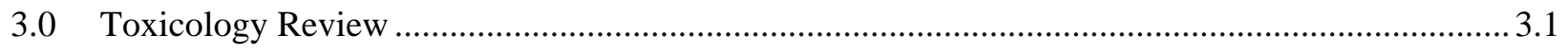

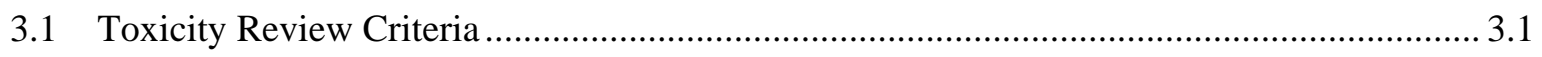

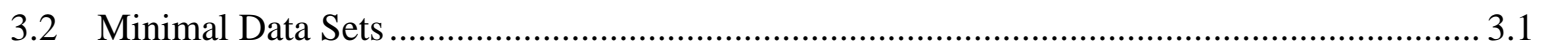

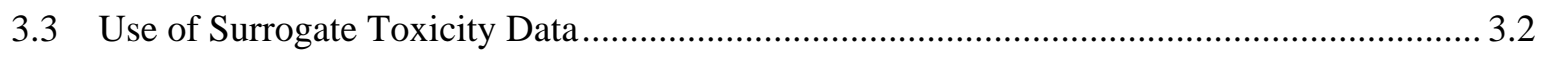

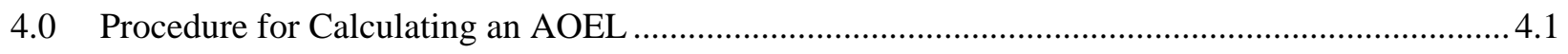

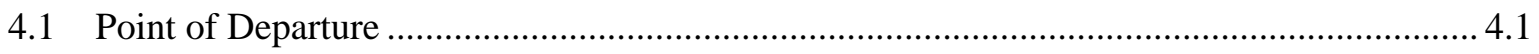

4.2 Approach for Developing Exposure Limits for Non-Cancer Effects ................................. 4.1

4.3 Establishing a NOEL Using Benchmark Dose............................................................. 4.2

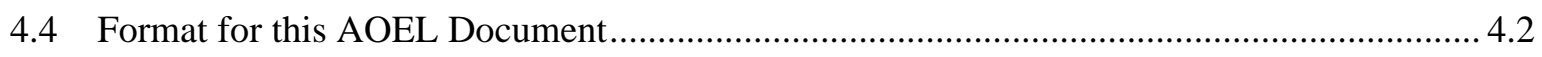

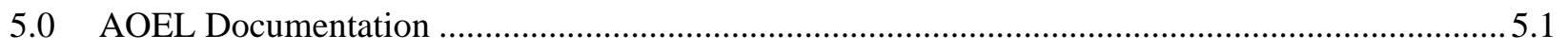

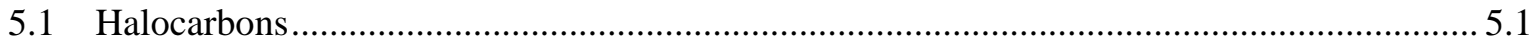

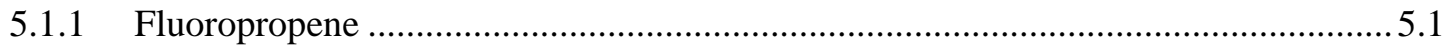

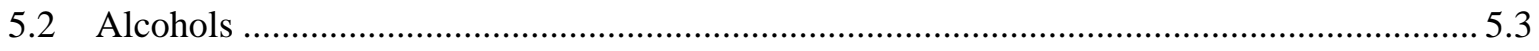

5.2.1 1-Hexadecanol, 1-Octadecanol .............................................................................. 5.3

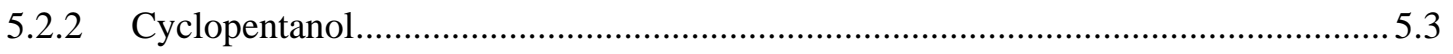

5.2.3 2-Ethyl-1-hexanol................................................................................................. 5.4

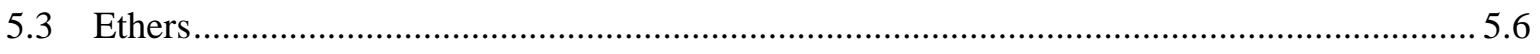

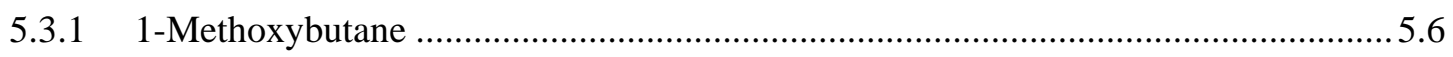

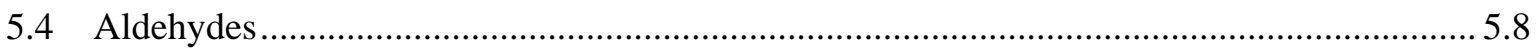

5.4.1 2-Methylbut-2-enal and 2-ethylhex-2-enal........................................................... 5.8 


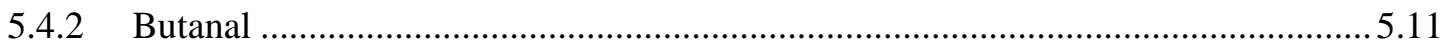

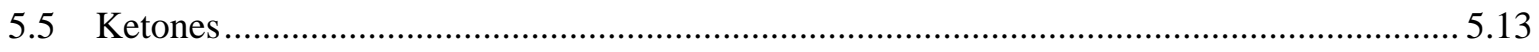

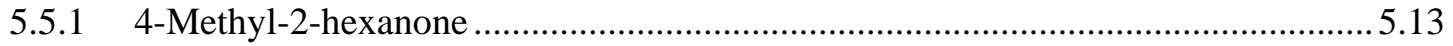

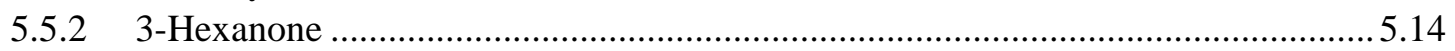

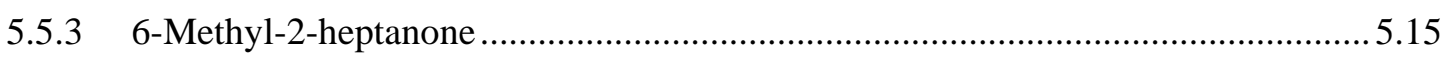

5.5.4 2-Nonanone, 3-Dodecanone, 2-Tridecanone, 3-Tridecanone .................................. 5.16

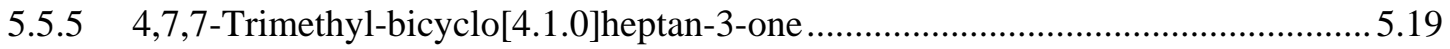

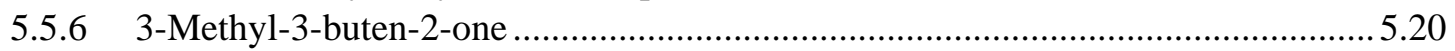

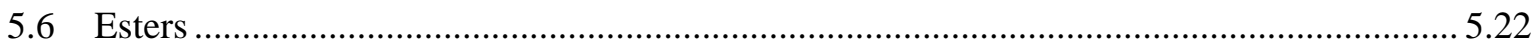

5.6.1 1-Methylethyl tetradecanoate, Butyl tetradecanoate, and 1-Methylethyl

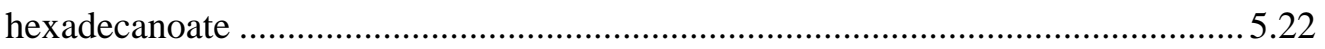

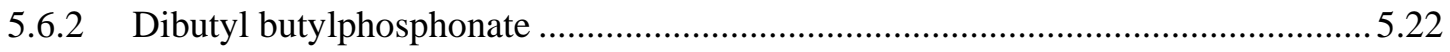

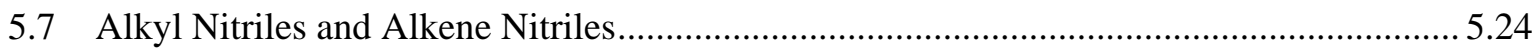

5.7.1 Propanenitrile, Butanenitrile, 2-Methylene butanenitrile, Pentanenitrile, Hexanenitrile, Heptanenitrile, Octanenitrile, Nonanenitrile, Decanenitrile and 3-Butenenitrile, and 2,-4-Pentadienenitrile ....................................................... 5.24

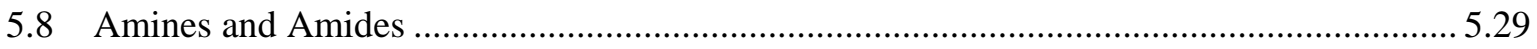

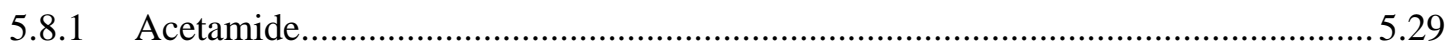

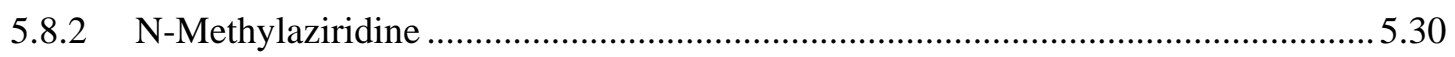

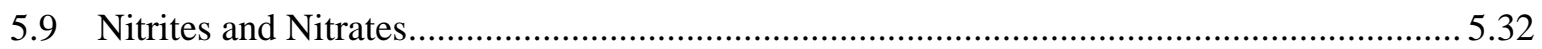

5.9.1 Short-Chain Alkyl Nitrites: n-Butyl nitrite, Ethyl nitrite, and Methyl nitrite.......... 5.32

5.9.2 Short-Chain Alkyl Nitrates Methyl Nitrate, Ethyl Nitrate, Butyl Nitrate, and Propyl Nitrate ................................................................................................. 5.33

5.9.3 Dinitrates: 1,3-Propanediol, dinitrate, 1,4-Butanediol, dinitrate, 1,5-Pentanediol,

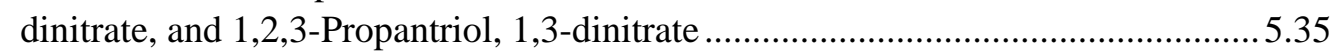

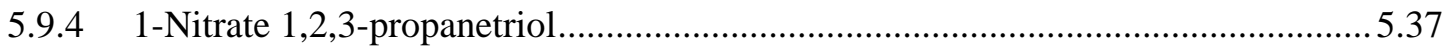

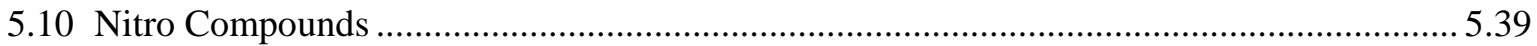

5.10.1 2-Nitro-1-propanol, 2-nitro-methylpropane, and 1-nitrobutane ............................... 5.39

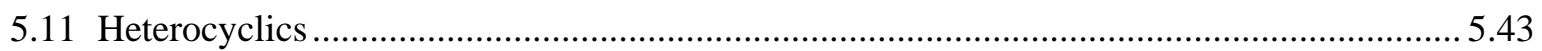

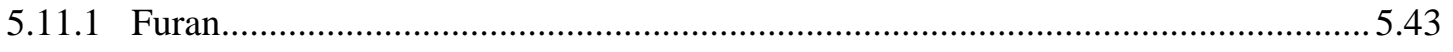

5.11.2 Furan Family: Substituted Furans 2-methylfuran, 2-5-dihydrofuran and 2-

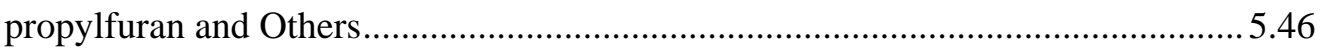

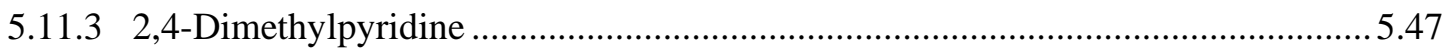

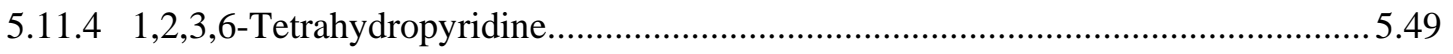

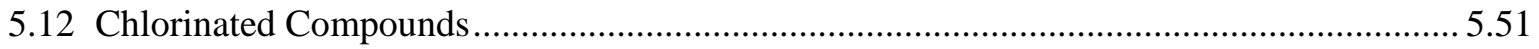

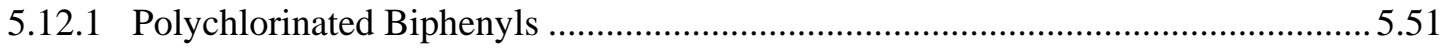

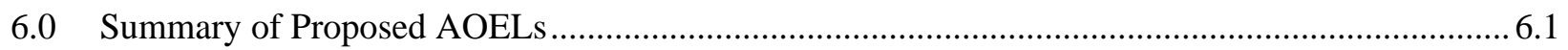

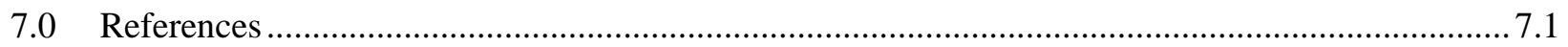




\section{Figures}

2.1 Flow Diagram Outlining Processes for Establishing an AOEL .................................................... 2.1

5.1 Comparison of Mice LD $_{50}$ Values (Tanii and Hashimoto 1984a) Based on Carbon Length......... 5.27

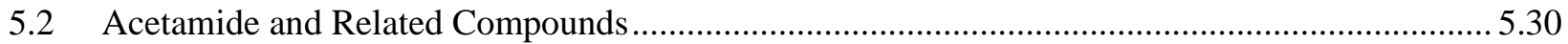




\section{Tables}

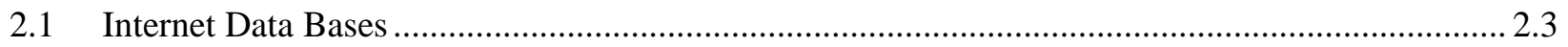

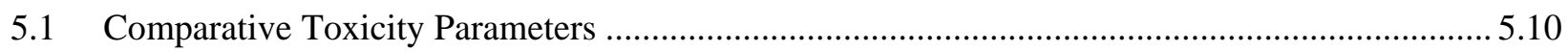

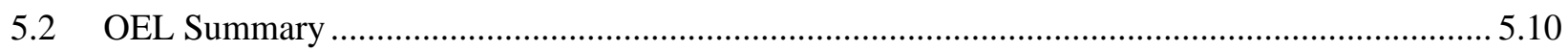

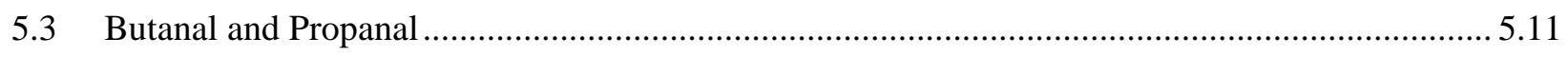

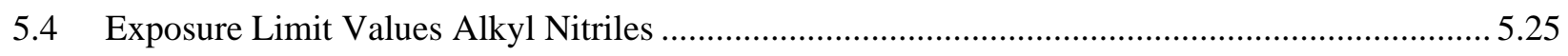

5.5 Acute or Subchronic $\mathrm{LD}_{50} \mathrm{~s}$ and OELs for Alkene Nitriles.................................................... 5.25

5.6 Acute or Subchronic NOELs and $\mathrm{LC}_{50}$ s for Alkyl Nitriles................................................... 5.26

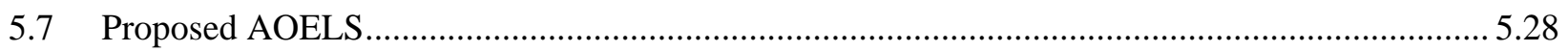

5.8 Incidence of Cancers in Rats and Mice Fed Diets Containing Acetamide .................................. 5.29

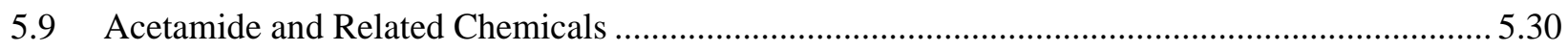

5.10 Exposure Limit Values for Propyl Nitrate .............................................................................. 5.34

5.11 Structure and Proposed OELS for Nitro Compounds .......................................................... 5.40

5.12 Comparative Toxicity Parameters for Nitro Compound Surrogates............................................ 5.41

5.13 Hepatic Non-Neoplastic Response: Number of Animals with Lesion/Total Number

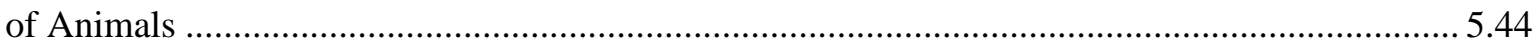

5.14 Tumor Response: Number of Animals with Tumors/Total Number of Animals ........................ 5.44

5.15 Relative Toxicities of PCB Congeners in the Tank Waste Head Space ..................................... 5.52

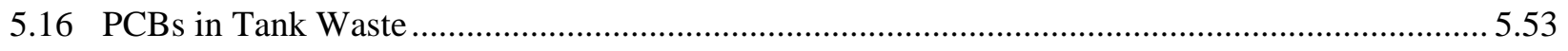

6.1 Proposed AOELs for Chemicals with Limits from NIOSH, AIHA or MAK............................... 6.1

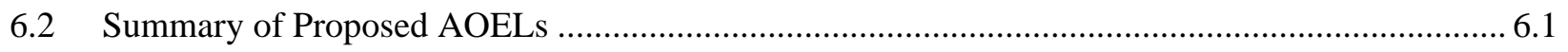

6.3 Chemicals For Which No AOEL is Recommended .............................................................. 6.3 


\section{Acronyms and Abbreviations}

AEGL $\quad$ Acute Exposure Guideline Levels (EPA)

ACGIH American Conference of Governmental Industrial Hygienists

AIHA American Industrial Hygienist Association

AOEL Acceptable Occupational Exposure Limit

BMD Benchmark dose

BMDL BMD limit

CAS Chemical Abstracts Service

CSF cancer slope factor

DOE U.S. Department of Energy

EPA U.S. Environmental Protection Agency (references to particular U.S. state or foreign country EPAs are so noted)

HSDB $^{\circledR} \quad$ Hazardous Substances Data Bank

IARC International Agency for Research on Cancer

IDLH Immediately Dangerous to Life or Health

$\mathrm{LC}_{50} \quad$ lethal concentration for $50 \%$ of test population

$\mathrm{LD}_{50} \quad$ lethal dose for $50 \%$ of test population

LClo lethal Concentration low; the lowest concentration at which death occurred

MAK 1) German Commission for the Investigation of Health Hazards of Chemical Compounds in the Work Area (MAK Commission), 2) the maximum permissible concentration of a chemical compound present in the air within a working area, which according to current knowledge, does not impair the health of the employee or cause undue annoyance.

MF modifying factors

NIEHS National Institute of Environmental Health Sciences

NIH National Institutes of Health

NIOSH National Institute for Occupational Safety and Health

NLM National Library of Medicine

NOELs No-Observed-Effect Levels 
OEL(s) Occupational Exposure Limit(s)

OSHA Occupational Safety and Health Administration

PCBs polychlorinated biphenyls

PEL Permissible Exposure Limit

POD point of departure

ppm parts per million

REL Recommended Exposure Limits

RfC reference concentration

RfD reference dose

RTECS $^{\circledR} \quad$ Registry of Toxic Effects of Chemical Substances

SCAPA DOE Subcommittee on Consequence Assessment and Protective Actions

STEL short-term exposure limit

TClo lowest published toxic concentration

TEEL Temporary Exposure Limit

$\mathrm{TLV}^{\circledR} \quad$ threshold limit value (ACGIH-specific)

TWA time-weighted average

TOXNET $^{\circledR} \quad$ The Toxicology Data Network

TWINS Tank Waste Information Network System

UF Uncertainty factor

WEEL Workplace Environmental Exposure Limit

WHO World Health Organization 


\subsection{Introduction}

A large number of volatile compounds have been identified in the headspaces of single- and doubleshelled tanks used to store mixed chemicals and radioactive waste at the U.S. Department of Energy (DOE) Hanford Site. Concern about potential exposure of tank farm workers to vapors has prompted efforts to evaluate the potential heath risk associated with exposure to these chemicals. However, occupational exposure limits (OELs) have not been established for many of these chemicals.

This report describes the process that was used to assign Acceptable Occupational Exposure Limits (AOELs) to non-carcinogenic chemicals and families of chemicals that had no previously established OELs but were identified in the tank waste headspace at or above preliminary screening values. An AOEL is defined as the concentration in air expected to lead to no adverse health effects that is acceptable to management, industrial hygiene professionals, and workers at the Hanford Site. These chemicals are listed and discussed in Section 5.0.

Permissible Exposure Limits (PELs) are established by the Occupational Health and Safety Administration (OSHA) of the U.S. Department of Labor and are legal obligations for defined industries. The National Institute for Occupational Safety and Health (NIOSH) is an arm of the Centers for Disease Control (CDC) and makes recommendations to OSHA regarding OEL values. The American Conference of Governmental Industrial Hygienists (ACGIH) is a private organization that recommends Threshold Limit Values (TLVs) to industry for voluntary application. Other human exposure standards have been published, e.g., Emergency Response Planning Guidelines and Workplace Environmental Exposure Levels (WEELs) have been established by the American Industrial Hygiene Association (AIHA), and Acute Exposure Guideline Levels have been developed by the U.S. Environmental Protection Agency (EPA). However, their applicability to occupational exposures must, in each case, be evaluated. The DOE mandates the need to comply with the OSHA and ACGIH standards in its contract with CH2M HILL Hanford Group, Inc.

The 57 chemicals considered in this report were identified by a toxicological screening process (Poet et al. 2006) and reviews of the analytical data on which the existence of the chemicals in the tanks were based (e.g., Sklarew and Mitroshkov 2006). AOELs developed by this report are considered "proposed" until reviewed and formally adopted by the Environmental Exposure Assessment Review Group. 


\subsection{Overview of Approach}

The National Academy of Sciences (NAS 1983, 1994; GAO 2001) has provided overall guidance for chemical risk assessment as further developed and applied by U.S. regulatory agencies. The process for establishing an AOEL for tank waste chemical exposure was modeled upon the generalized scientific approaches used by OSHA and ACGIH to establish OELs for worker exposure. In addition, where appropriate, the scientific approach used by other regulatory agencies, such as the EPA, to establish reference concentrations (RfC) for airborne pollutants were considered.

The key steps in the assessment process are shown in Figure 2.1. The approach first required identifying specific chemical agents or classes of chemical agents that were detected in the tank headspace at or above previously established screening values. Chemical agents that exceed the screening values underwent a more extensive evaluation to establish an AOEL for tank farms operations. First, relevant OELs were reviewed in detail. Without appropriate exposure guidelines, available epidemiology and toxicology information on a given chemical or chemical class were reviewed to identify potential hazards, select critical effects, and estimate a dose-response to determine suitable exposure levels

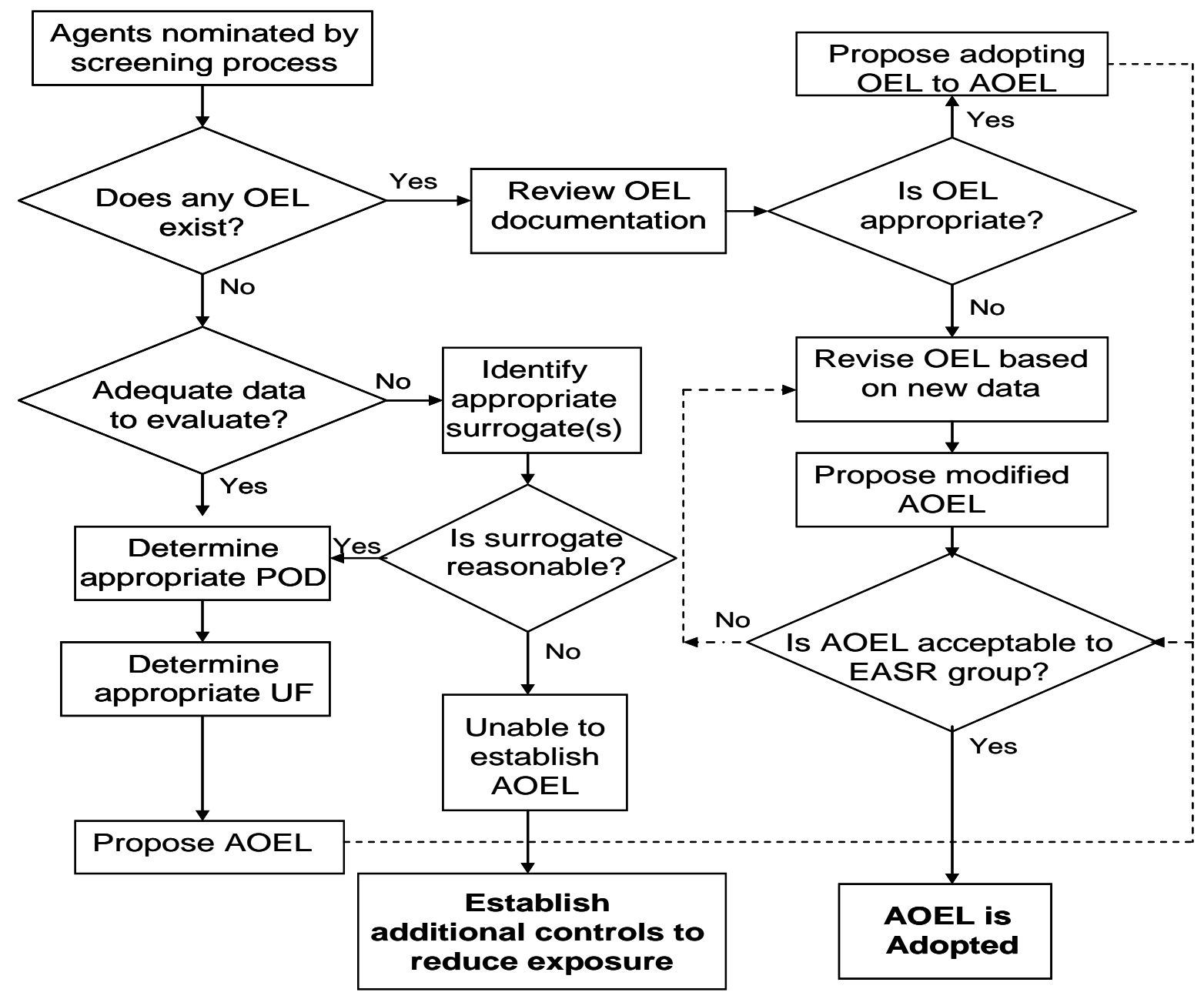

Figure 2.1. $\quad$ Flow Diagram Outlining Processes for Establishing an AOEL 
(Haber and Maier 2002). Consistent with the technical approaches ACGIH uses for establishing a Threshold Limit Value (TLV), the AOEL was based on the best scientific information available and included a critical evaluation of all supporting information (ACGIH 2005a). The AOEL review delineated the most important adverse effects. In evaluating the health effects, human data such as epidemiology studies are of prime importance; however, many of the chemicals of concern had little, if any, available human data. The second tier evaluation focused on the most relevant and sensitive animal toxicity data for the chemical and/or chemical class. Here, the basis for the AOEL is the dose-response relationship for the toxic effects of greatest concern, and the point of departure (POD) for calculating the AOEL is the associated no-observed-effect-level/lowest-observed-effect-levels (NOEL/LOEL). The rationale for the selection of a given toxic effect for the AOEL is documented.

For setting an AOEL, an appropriate risk assessment approach was used that was selected based on the critical toxicological effect, the observed dose-response, and the quality of the data used for the assessment (ACGIH 2005a). This included the use of quantitative dose-response models such as the benchmark dose (BMD) and/or the application of added factors to a NOEL/LOEL to address uncertainty.

Before establishing and implementing a formal AOEL for worker protection in the tank farms, the proposed exposure level for a given chemical and/or chemical class was submitted to the Exposure Assessment Strategy Review Group for peer review. The peer reviewers included a range of health and science professionals, including representatives from occupational medicine, toxicology, risk assessment, industrial hygiene, health physics, and worker groups. The review critically assessed the rationale for establishing the AOEL, provided the broad base of stakeholders an understanding of the rationale for the AOEL, and provided stakeholders an opportunity to submit appropriate input in the assessment.

\subsection{Data Base and Literature Evaluation}

\subsubsection{Data Base Searches}

It is imperative to consider relevant human exposure, epidemiology, and toxicological information in establishing AOELs. A methodical analysis of the available literature as it relates to hazard identification and quantitative dose-response toxicity evaluation is central to the AOEL assessment process. Internet data bases such as The Toxicology Data Network $\left(\right.$ TOXNET $\left.^{\circledR}\right)$, TOMES $\left.^{\circledR}\right)$, PUBMED $^{\circledR}$, the International Agency for Research on Cancer (IARC), and/or STN ${ }^{\circledR}$, were utilized as primary sources for initiating searches, which include both the name and Chemical Abstracts Service registry number of the compound of interest (See Table 2.1). These data bases contain information applicable to toxicological assessment of chemicals, and the information they provide may overlap. For example, both TOXNET and TOMES contain the Registry of Toxic Effects of Chemical Substances $\left(\right.$ RTECS $^{\circledR)}$ ) and Hazardous Substances Data Bank $\left(\right.$ HSDB $^{\circledR)}$ ) files. When no RTECS and/or HSDB files existed for a compound or were considered insufficient, the TOXNET literature and/or PUBMED databases were searched and the original literature evaluated for any relevant information. If relevant information was not located in this manner, PUBMED was searched directly and/or the chemical abstracts database was searched through STN. If information was found in one or more of the above sources but was incomplete, conflicting or considered insufficient, other sources such as National Institute of Environmental Health Sciences (NIEHS) National Toxicology Program (NTP), IARC, the U.S. EPA and the Agency for Toxic Substances and Disease Registry 
Table 2.1. $\quad$ Internet Data Bases

\begin{tabular}{|c|c|}
\hline TOXNET $^{\circledR)}$ & $\begin{array}{l}\text { The Toxicology Data Network, a set of data bases covering toxicology, hazardous } \\
\text { chemicals, and related areas; it is maintained by the National Library of Medicine } \\
\text { (NLM). (http://toxnet.nlm.nih.gov/) }\end{array}$ \\
\hline $\mathrm{HSDB}^{\circledR)}$ & $\begin{array}{l}\text { Hazardous Substances Data Bank. Accessible through TOXNET. Provided by the } \\
\text { NLM. }\end{array}$ \\
\hline PUBMED $^{\circledR)}$ & $\begin{array}{l}\text { PubMed, provided by the NLM, contains citations for biomedical articles back to the } \\
\text { 1950s; sources include MEDLINE and additional life science journals. } \\
\text { (http://www.ncbi.nlm.nih.gov/entrez/query.fcgi?db=PubMed). }\end{array}$ \\
\hline RTECS $^{\circledR)}$ & $\begin{array}{l}\text { Registry of Toxic Effects of Chemical Substances, provided by Thomson Micromedex, } \\
\text { Inc. Accessed through TOMES }{ }^{\circledR} \text {, which has the same provider. }\end{array}$ \\
\hline $\mathrm{STN}^{\circledR)}$ & $\begin{array}{l}\text { The Scientific \& Technical Information Network, provided by FIZ Karlsruhe, the } \\
\text { American Chemical Society, and the Japan Science and Technology Corporation. It } \\
\text { links to published research in the world's journal and patent literature back to the } \\
\text { beginning of the 20th century. }\end{array}$ \\
\hline TOMES $^{()}$ & $\begin{array}{l}\text { Registry of Toxic Effects of Chemical Substances, provided by Thomson- } \\
\text { Micromedex, Inc. }\end{array}$ \\
\hline
\end{tabular}

Monographs were also searched. Frequently, more in-depth information of the chemical of interest or its surrogate was located in this way and was useful in assigning an AOEL.

\subsubsection{Literature Evaluation of Published Exposure Guidelines}

Initial efforts focused on a comprehensive evaluation of the available literature to identify any published exposure guidelines for the chemical of interest or for a reasonable surrogate. The summary documentation used to support the establishment of the OEL was reviewed to ascertain its relevance, and any AOEL adopted based on these published OELs included appropriate documentation justifying the scientific rationale for it use.

\subsubsection{Use of Surrogate OELs}

If there were no appropriate exposure guidelines for the chemical of interest, it was deemed reasonable to identify and assign an OEL based on a structurally related chemical (surrogate). In addition to being structurally related, ideal surrogates also had a similar toxicological profile (i.e., similar target organs and response), although they may display greater or lesser potency than the chemical of concern. 


\subsection{Toxicology Review}

\subsection{Toxicity Review Criteria}

In evaluating the toxicity profile for a chemical or chemical class, the assessment was prioritized based on identification of toxic effects that are particularly relevant for occupational exposure. This would include:

- Identifying chemical agents that have a high acute toxicity potential such as Category 1 chemicals as defined by the Organization for Economic Co-operation and Development (OECD 2004).

Chemicals in Category 1, considered by OECD to have high acute toxicity potential, have $\mathrm{LD}_{50}$ and $\mathrm{LC}_{50}$ values of $\leq 5 \mathrm{mg} / \mathrm{kg}$ oral or $\leq 100 \mathrm{ppm}$ inhalation, respectively. Headspace chemicals such as these are of particular concern if the $\mathrm{LD}_{50} / \mathrm{LC}_{50}$ values do not have large safety margins $(<100)$ between observed toxicity and potential exposure levels.

- Giving priority to the evaluation of studies that utilize the most relevant occupational exposure routes (inhalation $>$ oral $>$ dermal $>$ others [intravenous/ intraperitoneal]).

- Giving priority to well-characterized dose-response toxicity studies, particularly those that included a more comprehensive evaluation of the toxicity, which includes quantitative in vivo (acute $\rightarrow$ subchronic $\rightarrow$ chronic) experiments.

The toxicity testing paradigm suggests that with increasing length of chemical exposures (i.e., acute $\rightarrow$ chronic) the effective dose levels generally decrease such that the lowest NOEL/LOEL will be determined from long-term studies. In addition, long-term chronic studies can identify chemicals that have the potential to produce a broad range of chronic health effects. An important strength of this testing paradigm is that it provided a fairly comprehensive in vivo toxicological evaluation that could be used to link dose-response results across a very broad range of exposure routes (oral vs. inhalation), doses (low vs. high), durations (sub-chronic vs. chronic), and species (rat vs. dog). The use of this type of testing data provided greater confidence (i.e., less uncertainty) in the AOEL that was established.

\subsection{Minimal Data Sets}

As discussed by Haber and Maier (2002), a number of regulatory authorities including the Health Council of the Netherlands (HCN 2000) and the EPA (1994) have established minimum data requirements based on the rationale that any value derived from data that is less than the minimum prescribed would have too much uncertainty. An alternative approach is to identify the types of data that are particularly useful and utilize a weight-of-evidence approach in the evaluation that looks at the sum total of all available information (SCOEL 1999; Haber and Maier 2002). In this regard, a weight-of-evidence review for the development of an AOEL focused on evaluating the types of studies that had greater relevance to occupational exposure and were amendable to establishing a dose-response relationship.

For this AOEL assessment process, a minimum data set was not established, and a weight-of-evidence approach was used. Due to the anticipated lack of robust toxicity data, a minimum data set was hard to achieve for the broad number of chemical agents being evaluated, particularly where there was a need to apply surrogate chemical data in the assessment, which was often the case. The AOEL documentation and the peer reviewers provided the means to assess the degree of confidence that was placed on the 
AOEL. It is important to recognize that with the unique chemistry associated with chemical/radioactive tank waste, appropriate toxicity data on the chemicals of interest or their reasonable surrogates was often absent, making the establishment of a defensible AOEL problematic. In these cases, the confidence in the AOEL was assessed and depended upon the availability of additional toxicity data from the literature.

\subsection{Use of Surrogate Toxicity Data}

When forced to use a surrogate chemical or chemical class for developing an AOEL, it was important that the surrogate had as robust a toxicology database as possible. Using a surrogate chemical with a well characterized toxicity database ensured it had a clear dose-response relationship and a clearly defined NOEL to use as a POD for establishing an AOEL. Substantially more uncertainty was assigned when utilizing surrogates that lacked a robust toxicity database. A written assessment of the overall strengths and weaknesses of the surrogate chemical was included within the AOEL documentation (Section 5). 


\subsection{Procedure for Calculating an AOEL}

\subsection{Point of Departure}

The overarching goal in evaluating the toxicity data bases is to determine a POD for developing an AOEL. Haber and Maier (2002) defined the POD as the concentration to which uncertainty factors are applied to derive an AOEL. The POD is most likely the NOEL/LOEL that was determined from the most appropriate toxicity study. In practice, this is usually the highest NOEL or lowest LOEL that was experimentally derived. It is also possible to utilize a BMD approach, as described below, to determine a POD, particularly when the experimental studies did not identify a NOEL (Fillipsson et al. 2003; Haber and Maier 2002; Crump 1984; Dourson et al. 1985).

\subsection{Approach for Developing Exposure Limits for Non-Cancer Effects}

As suggested by Bailey (2002) and others, there are numerous sources of uncertainty in the establishment of an acceptable exposure level. The approach used for identifying an acceptable exposure level for the general population or for occupational-related exposures is to adjust the NOEL or LOEL downward. The magnitude of the downward adjustment reflects the degree of uncertainty concerning the acceptable exposure limits. To address these uncertainties, empirical factors may be used to account for inadequate experimental data, interspecies variability, human variability, or extrapolation for short-term to long-term studies (EPA 2002; Dorne and Renwick 2005). In addition to uncertainty factors, additional modifying factors (MF) have been used occasionally by some regulatory agencies, such as EPA, to reflect uncertainties not addressed by other factors. Equation 1 was used to calculate the AOELs.

$$
\mathrm{AOEL}=\frac{\text { NOEL or LOEL }}{\text { UFXMF }}
$$

The application of empirical uncertainty factors to determine the AOEL was based on the methods utilized by EPA for deriving an RfC (EPA 2002). The default uncertainty factor (UF) generally covers a single order of magnitude (i.e., 101), or a value of 3 is used in place of one-half powers (i.e., 100.5). Additional factors could also be considered for inadequate data and for extrapolation from less than lifetime-to-lifetime exposures. As EPA suggest, supporting documentation included the justification used for the individual factors selected. In addition, as EPA (2002) recommends, the total UF applied to any particular chemical was limited to no more than 3000 and deriving exposure guidelines that involved the full 10-fold UF in four or more areas of extrapolation was not done. The following uncertainty and modifying factors were applied when necessary:

- Extrapolation from animal data to humans (interspecies UF). This factor is intended to account for the uncertainty in extrapolating animal data to the case of an average healthy human. It assumes that humans are more susceptible to the toxicity than the animal species evaluated.

- Variability in the human population (intraspecies UF). This factor is intended to account for the variation in sensitivity among humans.

- LOEL to NOEL UF. This factor is intended to address the uncertainty associated with extrapolation from LOELs to NOELs. 
- Sub-chronic to chronic duration UF. This factor is intended to account for the uncertainty in extrapolating from less than chronic NOELs to chronic NOELs.

- Inadequate data base UF. This factor is intended to account for the inability of any single animal study to adequately address all possible adverse outcomes in humans.

- Modifying factors (MF). This factor is intended to account for any other scientific uncertainties in the study or data bases that are not explicitly treated by other UFs. The magnitude of the MF principally depends on professional judgment.

\subsection{Establishing a NOEL Using Benchmark Dose (BMD)}

As Dorne and Renwick (2005) note, using a BMD as proposed by Crump (1984) defines a lower statistical confidence for the dose, corresponding to a predefined low-level increase in adverse effects over background. The BMD approach provides a more quantitative alternative to the first step in the dose-response assessment than the NOEL/LOEL process (EPA 2000). This is particularly useful when a NOEL has not been adequately defined from the experimental data.

The approach utilized EPA's BMD software available on the internet (http://www.epa.gov/ncea/bmds.htm). The EPA guidance document (EPA 2000) provides a detailed discussion on a number of important considerations including the types of studies that are appropriate for BMD, selection of the benchmark response values, choice of models for computing BMD, and details concerning the computation of confidence limits for the BMD. Based on the EPA criteria, a 10\% response is at or near the limit of sensitivity in most cancer and non-cancer bioassays and was used as an appropriate effective dose (ED10) for the BMD. As the EPA guidance (EPA 2000) indicates, the primary goal of the mathematical modeling is to fit a model to dose-response data, particularly at the low end of the observable dose-response range. The recommended criterion for selection of an appropriate model to obtain a Benchmark Dose Limit (BMDL) is the Akaike's Information Criterion. The Akaike's Information Criterion values were computed for each of the models used in the BMD calculation and compared the most appropriate model was selected from the analysis. Once a BMD value was selected, a lower confidence was placed on the BMDL that assured, with high confidence (95\%), the benchmark response was not exceeded. The BMDL was then used in the numerator of Equation 1 to calculate an AOEL, as described above.

\subsection{Format for this AOEL Document}

The AOEL documentation for a given chemical or chemical class is included in the following sections. An Executive Summary communicates the overall process and conclusions of the analysis. A methodology section briefly describes the approach used for developing the AOEL, and this is followed by a section describing the Available Guidelines that are particularly relevant in developing the AOEL. The Toxicology Summary section reviews pertinent human epidemiology and animal toxicology results that are directly relevant to the setting of the AOEL. Rather than describing all the available data, this section focuses on the key studies and results pertinent to the evaluation. The final Data Analysis section describes the process used for setting the AOEL. 


\subsection{AOEL Documentation}

\subsection{Halocarbons}

\subsubsection{Fluoropropene (CAS\# 1184-60-7)}

An AOEL is proposed for 2-fluoropropene based on a comprehensive review of the available toxicology and guideline literature. 2-Fluoropropene is a fluorinated propene that is similar in structure to halogenated ethylenes such as fluoroethylene (vinyl fluoride), chloroethylene (vinyl chloride), or bromoethylene (vinyl bromide). As a class of compounds, the halogenated ethylenes have been classified as known (A1) or suspected (A2) human carcinogens. Although there are no ACGIH or OSHA guidelines for 2-fluoropropene, the ACGIH has set TLV-Time Weighted Average (TWA) exposure concentrations for fluoroethylene at $1 \mathrm{ppm}\left(1.9 \mathrm{mg} / \mathrm{m}^{3}\right)$ largely based on analogy to the TLV-TWAs for chloroethylene (vinyl chloride) and bromoethylene (vinyl bromide) (ACGIH 2001bb). Based on the uncertainty associated with chemical differences between 2-fluoropropene and the halogenated ethylenes, an AOEL of $\mathbf{0 . 1} \mathbf{~ p p m}$ is proposed for 2-fluoropropene.

\subsubsection{Methodology}

The Standard Operating Procedures described in Sections 2.0 - 4.0 were used as a guide for developing this AOEL. To identify and access available toxicity data on 2-fluoropropene, a number of Internet data bases, including PUBMED ${ }^{\circledR}$, TOXNET ${ }^{\circledR}$, and TOMES ${ }^{\circledR}$, were searched and summary toxicity profiles were obtained, including the identification of primary references. In addition, ACGIH documentation was likewise reviewed for 2-fluoropropene and relevant surrogate chemicals. These toxicology summaries were then reviewed to identify the most critical data sets that could be used to establish the toxicity profile and used for the development of the AOEL.

\subsubsection{Available Guidelines}

No OEL for 2-fluoropropene has been proposed by OSHA or ACGIH. However, ACGIH has assigned a TLV-TWA for the structural surrogate fluoroethylene (ACGIH 2001n). The ACGIH documentation for fluoroethylene is based upon the structural similarity to the known human carcinogen vinyl chloride and the suspected human carcinogen vinyl bromide. However, it has been suggested that the slower relative metabolism of fluoroethylene vs. vinyl chloride to a similar toxic metabolite supports fluoroethylene being less potent than vinyl chloride (Filser and Bolt 1979). Likewise, a direct comparison of rodent bioassay results between fluoroethylene (Bogdanffy et al. 1995) and vinyl bromide (Benya et al. 1982) suggests that vinyl bromide is more than twice as potent as fluoroethylene. Therefore, ACGIH recommended a $1 \mathrm{ppm}$ TLV-TWA for fluoroethylene, which is twice the recommended TLV-TWA (0.5 ppm) for vinyl bromide.

\subsubsection{Toxicology Summary and Data Analysis}

There was no available toxicity information for 2-fluoropropene. A search of the RTECS data base found very limited and dated toxicity data on 2-chloropropene but suggested a low acute toxicity with an $\mathrm{LC}_{50}$ in mice of $267 \mathrm{~g} / \mathrm{m}^{3}$ and a lowest published concentration (TClo) in rats of $191 \mathrm{~g} / \mathrm{m}^{3}$ following repeated inhalation exposure. For the structural surrogate fluoroethylene, the acute toxicity is very low with lethal 
concentrations in rats reported to be $>800,000 \mathrm{ppm}$ for an $\sim 12$-hour exposure, and no fatalities were noted in rats exposed for 7 hours/day, 5 days/week for 30 days at 100,000 ppm fluoroethylene (Clayton 1967). A 13-week exposure of rats and mice to fluoroethylene concentrations ranging from $200-20,000^{(a)} \mathrm{ppm}$ reported a concentration-dependent increase in urinary fluoride excretion (Bogdanffy et al. 1990). The oncogenic potential of vinyl fluoride was evaluated in both rats and mice by inhalation at concentrations of 0, 25, 250 and $2500 \mathrm{ppm}$, and fluoroethylene was found to be carcinogenic at the lowest concentration (25 ppm) in both species (Bogdanffy et al. 1995). The tumorigenic response was reported to be similar to that seen with vinyl chloride and vinyl bromide (ACGIH 2001bb; Maltoni et al. 1981; Benya et al. 1982).

\subsubsection{Conclusion}

The ACGIH has set the TLV-TWA for vinyl fluoride at $1 \mathrm{ppm}\left(1.9 \mathrm{mg} / \mathrm{m}^{3}\right)$ based primarily by analogy with vinyl chloride and vinyl bromide. Based on the uncertainty associated with chemical differences between 2-fluoropropene and vinyl fluoride, an additional 10-fold factor is applied to the vinyl fluoride OEL to establish an AOEL of $\mathbf{0 . 1} \mathbf{~ p p m}$ for 2-fluoropropene.

(a) ACGIH 2001bb incorrectly identifies $2000 \mathrm{ppm}$ as the maximum vapor concentration. 


\subsection{Alcohols}

\subsection{1１-Hexadecanol (CAS \# 36653-82-4), 1-Octadecanol (CAS \# 112-92-5)}

There are currently no published exposure guidelines for 1-hexadecanol (16-carbon) or 1-octadecanol (C-18). Both these long-chain aliphatic alcohols have relatively low toxicity based on acute toxicity testing. These alcohols are common components of cosmetic compounds. Octadecanol (stearyl alcohol) is found naturally in various mammalian tissues and is readily converted to stearic acid. Octadecanol is an 18-carbon straight chain aliphatic alcohol often used as an emollient to prevent drying and chapping of skin and as a thickener and pearlizing agent in cosmetics. The common use in cosmetics and relatively low toxicity indicate an AOEL is not needed for these chemicals at this time. As additional new data become available for these compounds, it would be reasonable to reassess the appropriateness of assigning an AOEL.

\subsubsection{Cyclopentanol (CAS\# 96-41-3)}

An AOEL is proposed for cyclopentanol based on a comprehensive review of the available toxicology and guideline literature. Cyclopentanol is a cyclic (5-carbon) alcohol. Although there are no ACGIH or OSHA guidelines for cyclopentanol, the ACGIH has set TLV-TWA exposure concentrations for cyclohexanol (ACGIH 2001). The TLV-TWA for the cyclohexanol was set at $50 \mathrm{ppm}\left(206 \mathrm{mg} / \mathrm{m}^{3}\right)$ to minimize the potential for eye irritation and possible central nervous system effects including narcosis and incoordination. Based on the uncertainty associated with chemical and toxicological differences between cyclopentanol and cyclohexanol, an AOEL of $\mathbf{5}$ ppm is proposed for cyclopentanol.

\subsubsection{Methodology}

The procedures described in Sections 2.0 - 4.0 were used as a guide for developing this AOEL. To identify and access available toxicity data on cyclopentanol, a number of Internet data bases including PUBMED $^{\circledR}$, TOXNET $^{\circledR}$, and TOMES ${ }^{\circledR}$ were searched and summary toxicity profiles were obtained and primary references identified. ACGIH documentation was also reviewed for cyclohexanol, which is a relevant surrogate chemical. These toxicology summaries were then reviewed to identify the most critical data sets that could be used to establish the toxicity profile and develop the AOEL.

\subsubsection{Available Guidelines}

No OEL for cyclopentanol has been proposed by OSHA or ACGIH. However, ACGIH has assigned a TLV-TWA for the surrogate, cyclohexanol. The ACGIH documentation indicates that a TLV-TWA of 50 ppm will protect from cyclohexanol vapor irritation based on both animal and human data.

\subsubsection{Toxicology Summary and Data Analysis}

Limited toxicity evaluation has been conducted with cyclopentanol. Acute oral exposure to doses of 0.6 $1.3 \mathrm{ml} / \mathrm{kg}$ of body weight did result in mortality, and toxic response included unsteady gait and convulsion. Gross pathology indicated effects on the liver and kidneys. Acute inhalation exposure to a saturated atmosphere ( 1300 ppm) for 1 hour resulted in no mortality; however, a $\sim 3$-hour exposure at this same concentration resulted in $100 \%$ mortalities. 
The surrogate cyclohexanol has a low acute oral toxicity in rats with $\mathrm{LD}_{50} \mathrm{~S}$ at $\sim 2 \mathrm{~g} / \mathrm{kg}$ of body weight. Inhalation exposure to $1000 \mathrm{ppm}$ for 6 hours/day, 5 days/week, for 5 to 11 weeks resulted in intoxication and death in $50 \%$ of rabbits. Rabbits exposed to concentrations of 145 ppm showed only slight degeneration in the liver and kidneys (Treon et al. 1943). In humans exposed to cyclohexanol (35 minutes), an 8-hour acceptable air concentration was calculated as < 100 ppm (Nelson 1943).

\subsubsection{Conclusion}

The ACGIH has set the TLV-TWA for the cyclohexanol at $50 \mathrm{ppm}\left(206 \mathrm{mg} / \mathrm{m}^{3}\right)$ to minimize the potential for eye irritation and possible central nervous system effects including narcosis and incoordination. Based on the uncertainty associated with chemical and toxicological differences between cyclopentanol and cyclohexanol, an additional 10-fold factor is applied to the cyclohexanol OEL to establish an AOEL of 5 ppm for cyclopentanol.

\subsubsection{2-Ethyl-1-hexanol (CAS\# 104-76-7)}

An AOEL is proposed for 2-ethyl-1-hexanol based on a comprehensive review of the available toxicology and guideline literature. 2-Ethyl-1-hexanol is an aliphatic branched (8-carbon) alcohol. Although there are no ACGIH or OSHA guidelines for 2-ethyl-1-hexanol, the German Commission for the Investigation of Health Hazards of Chemical Compounds in the Work Area (MAK Commission) set a MAK of 20 ppm (MAK set in 2005). In addition, the ACGIH has set a TLV-TWA exposure concentration for isooctyl alcohol, which has the same molecular formula but a slightly different structural formula than 2-ethyl1-hexanol. The TLV-TWA for isooctyl alcohol was set at $50 \mathrm{ppm}\left(266 \mathrm{mg} / \mathrm{m}^{3}\right)^{(\mathrm{a})}$ to minimize the potential for upper respiratory tract irritation (ACGIH 2001p). The German MAK of 20 ppm will be adopted for 2-ethyl-1-hexanol.

\subsubsection{Methodology}

The procedures described in Sections 2.0 - 4.0 were used as a guide for developing this AOEL. To identify and access available toxicity data on 2-ethyl-1-hexanol, a number of Internet data bases including PUBMED, TOXNET, and TOMES were searched and summary toxicity profiles were obtained and primary references identified. In addition, ACGIH documentation was likewise reviewed for isooctyl alcohol as a relevant surrogate chemical. These toxicology summaries were then reviewed to identify the most critical data sets that could be used to establish the toxicity profile and develop the AOEL.

\subsubsection{Available Guidelines}

No OEL for 2-ethyl-1-hexanol has been proposed by OSHA or ACGIH, and the German MAK commission has recently updated their OEL for 2-ethyl-1-hexanol from $50 \mathrm{ppm}$ to $20 \mathrm{ppm}$. There is no available documentation explaining the reasons for the change (MAK set in 2005). In addition, ACGIH has assigned a TLV-TWA for a structural surrogate isooctyl alcohol (ACGIH 2001p). The ACGIH documentation indicates that a TLV-TWA of $50 \mathrm{ppm}$ will minimize the potential for upper respiratory tract irritation.

(a) ACGIH incorrectly applied units of $\mathrm{mg} / \mathrm{kg}$ to this value. 


\subsubsection{Toxicology Summary and Data Analysis}

There appears to be substantial toxicity data on 2-ethyl-1-hexanol, however no U.S. guidelines have yet been established for occupational exposure. In mice, rats, and guinea pigs, the $\mathrm{LC}_{50}$ for 2-ethyl-1-hexanol was >227 ppm (6-8 hour exposure) (Scala and Burtis 1973; Smyth et al. 1969; Treon 1963). The oral $\mathrm{LD}_{50}$ in rats reported in several studies was $\sim 3 \mathrm{~g} / \mathrm{kg}$ of body weight (Scala and Burtis 1973; Albro 1975; Treon 1963; NIOSH 1976). In these studies, the animals were observed for 24 hours prior to necropsy, and no deaths occurred during exposure or observation. All animals exhibited central nervous system depression, labored breathing, and one guinea pig had a clonic convulsion. The results of long-term oral carcinogenicity studies in both rats and mice indicate that 2-ethyl-1-hexanol is not carcinogenic (BASF 1991; 1992). Although the German MAK has established an OEL for 2-ethyl-1-hexanol (20 ppm), for comparison isooctyl alcohol was also chosen as a surrogate because it has the same molecular formula as 2-ethyl-1-hexanol, and an ACGIH TLV-TWA has been established and documented (ACGIH 2001p). An acute oral $\mathrm{LD}_{50}$ for isooctyl alcohol in rats of $1.5 \mathrm{~g} / \mathrm{kg}$ of body weight has been reported, and the principal signs of effect were central nervous system depression and labored respiration. In addition, mice, rats, and guinea pigs that inhaled 200 ppm isooctyl alcohol for 6 hours showed only moderate local irritation of the upper respiratory tract, but no signs of systemic intoxication were observed (Scala and Burtis 1973). These toxicological responses seen with isooctyl alcohol following either oral or inhalation exposure are reasonably comparable to the response seen with 2-ethyl-1-hexanol. Hence, isooctyl alcohol is a reasonable surrogate based on similar molecular structure and toxicological profile.

\subsubsection{Conclusion}

The German MAK commission has set an OEL TWA for 2-ethyl-hexanol at $20 \mathrm{ppm}$; however, we lack documentation explaining the rational for the selection of the OEL. The ACGIH has set the TLV-TWA for isooctyl alcohol at $50 \mathrm{ppm}\left(266 \mathrm{mg} / \mathrm{m}^{3}\right)$ to minimize the potential for upper respiratory tract irritation. The German MAK of $\mathbf{2 0} \mathbf{~ p p m}$ will be adopted for 2-ethyl-hexanol. For perspective, this AOEL is 2.5-fold lower than the ACGIH TLV-TWA for the surrogate isooctyl alcohol. 


\subsection{Ethers}

\subsubsection{1-Methoxybutane (CAS\# 628-28-4)}

An AOEL is proposed for 1-methoxybutane (n-butyl methyl ether) based on a comprehensive review of the available toxicology and guideline literature. 1-methoxybutane has the same molecular formula $\left(\mathrm{C}_{5} \mathrm{H}_{12} \mathrm{O}\right)$ and is similar in structure to methyl tert-butyl ether (MTBE). Although there are no ACGIH or OSHA guidelines for 1-methoxybutane, the ACGIH has set TLV-TWA exposure concentrations for MTBE at $50 \mathrm{ppm}\left(180 \mathrm{mg} / \mathrm{m}^{3}\right)$ based upon extensive animal toxicity testing and human exposure data (ACGIH 2002a). Based on the uncertainty associated with slight chemical differences between 1-methoxybutane and MTBE, an AOEL of $\mathbf{1 7} \mathbf{~ p p m}$ is proposed for 1-methoxybutane.

\subsubsection{Methodology}

The procedures described in Sections 2.0 - 4.0 were used as a guide for developing this AOEL. To identify and access available toxicity data on 1-methoxybutane, a number of Internet data bases including PUBMED, TOXNET, and TOMES were searched, and summary toxicity profiles were obtained and primary references identified. In addition, ACGIH documentation was likewise reviewed for 1-methoxybutane and relevant surrogate chemicals. These toxicology summaries were then reviewed to identify the most critical data sets that could be used to establish the toxicity profile and develop the AOEL.

\subsubsection{Available Guidelines}

No OEL for 1-methoxybutane has been proposed by OSHA or ACGIH. However, ACGIH has assigned a TLV-TWA of $50 \mathrm{ppm}\left(180 \mathrm{mg} / \mathrm{m}^{3}\right.$ ) for the structural surrogate MTBE (ACGIH 2002a). The TLV-TWA for MTBE is based upon the observance of no adverse symptoms in humans (10 subjects) exposed to up to 50 ppm MTBE (Johanson et al. 1995) and a no-observed-adverse-effect level (NOAEL) for repeated inhalation exposure in rats at 800 ppm (Daughtrey et al. 1997; Lington et al. 1997) and a NOEL of $400 \mathrm{ppm}$ in rats for a two-generation study (Bevan et al. 1997).

\subsubsection{Toxicology Summary and Data Analysis}

A search of the RTECS data base found very limited toxicity data on 1-methoxybutane but suggested a low acute toxicity with an $\mathrm{LC}_{50}$ in mice of $176 \mathrm{~g} / \mathrm{m}^{3}(48,800 \mathrm{ppm})$. The primary observed effect is general anesthesia. For the structural surrogate MTBE, acute toxicity is very low with lethal concentrations reported to be $>35,000 \mathrm{ppm}$ in both mice and rats (Marsh and Leake 1950; Conaway et al. 1985). Since MTBE is used extensively as an octane-enhancing agent in gasoline, there is substantial exposure both occupationally and to the general public (ACGIH 2002a). Rats were repeatedly exposed to MTBE vapors 6 hours/day, 5 days/week for 13 weeks at 0, 800, 4000 and 8000 ppm (Lington et al. 1997). The authors reported no treatment-related mortalities, and the NOEL for repeated exposure was $800 \mathrm{ppm}$. In addition, MTBE has not been found to induce adverse effects in fetal development (rats, mice, and rabbits) or on reproduction (ACGIH 2002a; Caprino and Togna 1998). In chronic vapor inhalation studies, rats and mice were exposed to 0, 400, 3000 and 8000 ppm MTBE for >18 months (BurleighFlayer et al. 1992; Chun et al. 1992). MTBE has been associated with an increase in hepatocellular carcinoma in female mice and increased renal cancer in male rats ( $\alpha 2 \mathrm{u}$-microglobulin nephropathy). Based upon the observed tumorigenic response in rodent studies, MTBE has been classified as an A3 
Confirmed Animal Carcinogen with Unknown Relevance to Humans. A number of human in vitro and in vivo metabolism studies have been conducted with MTBE. Johanson et al. (1995) conducted a controlled human exposure study in which 10 adult male volunteers were exposed to 5, 25, and $50 \mathrm{ppm}$ MTBE for 2 hours while conducting light exercise. This pharmacokinetic study reported that the kinetics were linear at all concentrations with no observed adverse symptoms in humans at concentrations up to $50 \mathrm{ppm}$.

\subsubsection{Conclusion}

The ACGIH has set the TLV-TWA for MTBE at $50 \mathrm{ppm}\left(180 \mathrm{mg} / \mathrm{m}^{3}\right)$. Based on the uncertainty associated with chemical differences between 1-methoxybutane and MTBE, an additional 3-fold factor is applied to the MTBE OEL to account for the limited 1-methoxybutane data to establish an AOEL of 17 ppm for 1-methoxybutane. 


\subsection{Aldehydes}

\subsubsection{2-Methylbut-2-enal (CAS\# 1115-11-3) and 2-ethylhex-2-enal (CAS\# 645-62-5)}

2-Methylbut-2-enal and 2-ethylhex-2-enal are alcrolein derivatives, which contain a branched aliphatic sidechain with a double bond and oxygen on the C-1 carbon. The principal toxic effect that stems from exposures to aldehydes and aliphatic hydrocarbons is irritation to mucous membranes. Irritation caused by similar compounds with both a double bond and a double-bonded oxygen can be severe, and the ACGIH has recommended TLV-ceilings of 0.1 and $0.3 \mathrm{ppm}$ for acrolein and crotonaldehyde, respectively. Very little information was found regarding 2-methylbut-2-enal and 2-ethylhex-2-enal, and proposed OELs were based on crotonaldehyde as a surrogate with an UF of 30 (2-methylbut-2-enal) or 100 (2-ethylhex-2-enal), depending on the availability of toxicology data. The recommended OELs for 2-methylbut-2-enal and 2-ethylhex-2-enal are 0.03 and 0.1 , respectively.

\subsubsection{Methodology}

The procedures described in Sections 2.0 - 4.0 were used as a guide for developing this AOEL. To identify and access available toxicity data on 2-methylbut-2-enal and 2-ethylhex-2-enal, a number of Internet data bases including PUBMED, TOXNET, and TOMES were searched and summary toxicity profiles were obtained and primary references identified. In addition, ACGIH documentation was likewise reviewed for crotonaldehyde, acrolein, and propionaldehyde as potentially relevant surrogate chemicals. These toxicology summaries were then reviewed to identify the most critical data sets that could be used to establish the toxicity profile and develop the AOEL.

\subsubsection{Available Guidelines}

No OELs have been proposed by OSHA or ACGIH for either 2-methylbut-2-enal or 2-ethylhex-2-enal. However, ACGIH has assigned TLV ceilings for the structural surrogates, crotonaldehyde and acrolein, and a TLV-TWA for propionaldehyde. Propionaldehyde lacks the double bond, and the ACGIH TLVTWA is 20 ppm (ACGIH 2002b). The ACGIH TLV ceilings for crotonaldehyde and acrolein are 0.3 and $0.1 \mathrm{ppm}$, respectively (ACGIH 2001e; 2001a). The toxicological endpoint of concern for all of these aldehydes is irritation of the eyes and upper respiratory tract. The irritation caused by exposures to crotonaldehyde and acrolein are rapid and can be lethal due to changes in pulmonary function. Crotonaldehyde is an animal carcinogen (hepatocellular carcinomas).

\subsubsection{Toxicology Summary}

No toxicity data were found for 2-methylbut-2-enal. 2-Methylbut-2-enal is a pheromone released in rabbit milk apparently needed by newborn rabbit pups to find the nipple (Schaal et al. 2003). The structural surrogate of 2-methylbut-2-enal lacking the double-bonded oxygen, 2-methyl-2-butene has a high LC 50 (low toxicity), and an inhalation NOEL in a 26-week study was 580 ppm (Olefins Panel 2004).

There are limited toxicity data available for 2-ethylhex-2-enal. The European Commission of the European Chemicals Bureau has collected toxicology data since 2-ethylhex-2-enal is a high-production volume chemical in Europe. All animals exposed acutely to 2-ethylhex-2-enal via inhalation at levels of $8406 \mathrm{ppm}$ died. No animals died or were grossly affected by exposures to $2425 \mathrm{ppm}$. The oral $\mathrm{LD}_{50}$ for 
2-ethylhex-2-enal is 3-4.7 g/kg (Table 5.1). 2-Ethylhex-2-enal was negative in Ames Salmonella tests for genotoxicity.

Aldehydes such as these are generally irritating to mucous membranes, especially of the eyes or upper respiratory tract. The unsaturated aldehydes such as acrolein and crotonaldehyde are much more acutely irritating than the similarly sized aldehydes (compare propionaldehyde to acrolein).

\subsubsection{Conclusion}

In reviewing the available toxicity data bases on acrolein derivatives with similar structures to 2-ethylhex2-enal and 2-methylbut-2-enal, the most robust data were found for crotonaldehyde and acrolein, which differ in that they lack branching and have smaller carbon chains. The ACGIH-recommended TWA ceilings for crotonaldehyde and acrolein are 0.3 and $0.1 \mathrm{ppm}$, respectively. An UF of 3 is recommended to extrapolate a recommended OEL for 2-ethylhex-2-enal from crotonaldehyde due to the structural differences inherent with branching of the side-chain, which may result in metabolic or toxicological differences. Thus, the recommended OEL for 2-ethylhex-2-enal is $\mathbf{0 . 1} \mathbf{~ p p m}$. An additional UF of 3 is recommended to extrapolate a recommended OEL for 2-methylbut-2-enal from crotonaldehyde due to the limited toxicological data for 2-methylbut-2-enal. Thus, the recommended OEL for 2-methylbut-2-enal is $\mathbf{0 . 0 3} \mathbf{~ p p m}$ (Table 5.2). 
Table 5.1. Comparative Toxicity Parameters

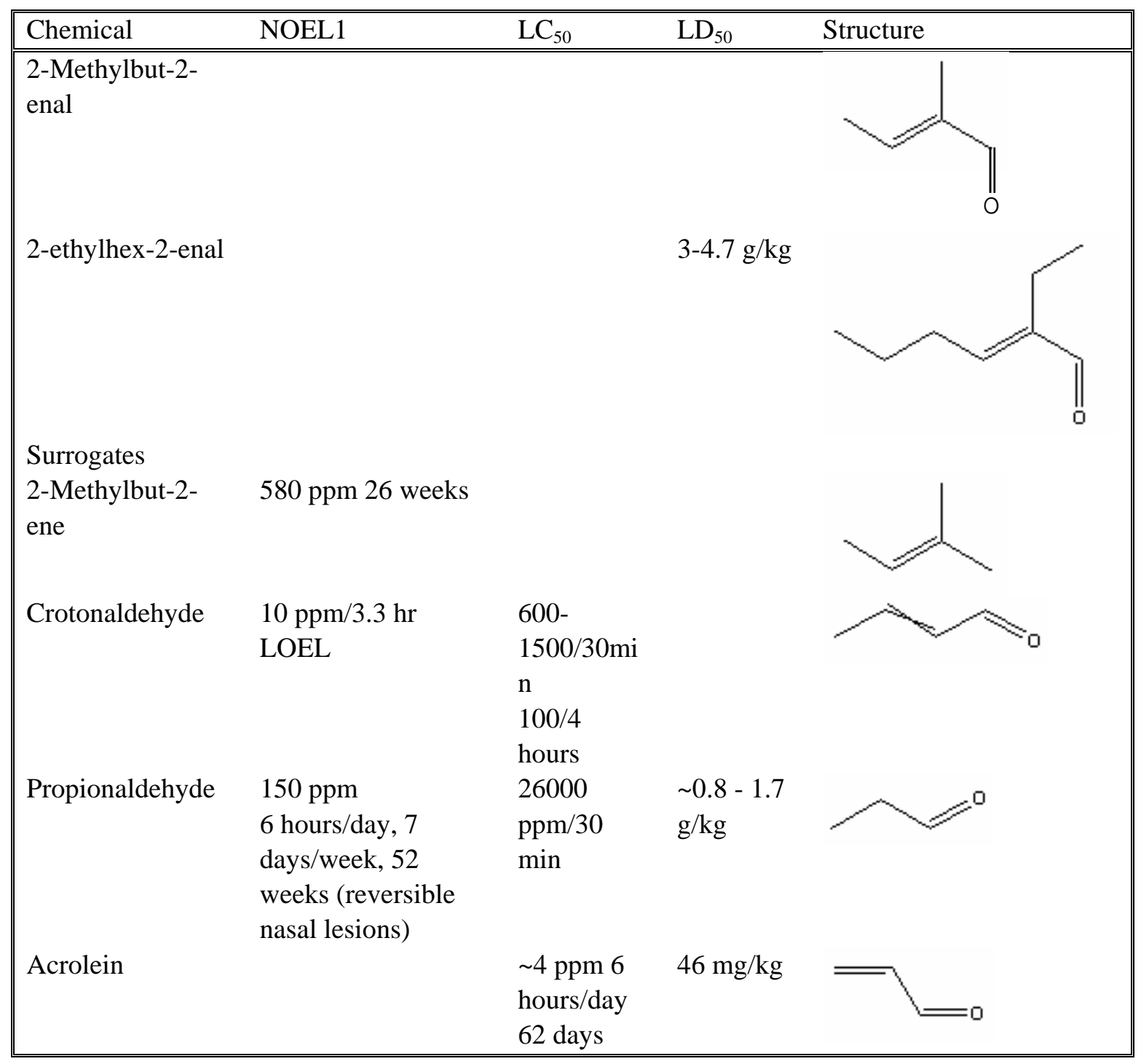

Table 5.2. OEL Summary

\begin{tabular}{|c|c|c|}
\hline & OEL & Comment \\
\hline 2-Methylbut-2-enal & 0.03 & $\begin{array}{l}\mathrm{UF}=3 \text { for ceiling adjustment, } \\
\text { and additional } 3 \text { for limited data }\end{array}$ \\
\hline $\begin{array}{l}\text { 2-ethylhex-2-enal } \\
\text { Surrogates }\end{array}$ & 0.1 & UF = 3 for ceiling adjustment \\
\hline 2-Methylbut-2-ene & NA & \\
\hline Crotonaldehyde & $0.3 \mathrm{ppm}$ & ACGIH TLV-Ceiling \\
\hline Propionaldehyde & 20 ppm & ACGIH TLV-TWA \\
\hline Acrolein & $0.1 \mathrm{ppm}$ & ACGIH TLV-Ceiling \\
\hline
\end{tabular}




\subsubsection{Butanal (CAS\# 123-72-8)}

An AOEL is proposed for butanal based on a comprehensive review of the available toxicology and guideline literature. Butanal (butyraldehyde) is an aliphatic aldehyde. Aliphatic aldehydes are generally volatile organic compounds that irritate skin, eyes, and the upper respiratory tract. Although there are no ACGIH or OSHA guidelines for butanal, the AIHA has proposed a TWA Workplace Environmental Exposure Limit (WEEL) of 25 ppm. The AIHA procedures for developing WEELs are similar to procedures described in Sections 2.0-4.0 for developing proposed AOELs for the current tank waste headspace analysis and include an assessment of the chemicals by qualified personnel, a review of the toxicological literature, and a committee assessment

(http://www.aiha.org/committees/documents/weel_procedures.doc). The proposed AOEL for butanal is $25 \mathbf{~ p p m}$ and is equivalent to the WEEL developed by the AIHA.

\subsubsection{Methodology}

To identify and access available toxicity data on butanal, a number of Internet data bases including PUBMED, TOXNET, TOMES, and IARC, were searched and summary toxicity profiles were obtained and primary references identified. These toxicology summaries were then reviewed to identify the most critical data sets that could be used to establish the toxicity profile and develop the AOEL. Primary references for the most relevant toxicology endpoints were obtained for review.

\subsubsection{Available Guidelines}

No OEL for butanal has been proposed by OSHA or ACGIH. However, the AIHA has assigned a WEEL for butanal at $25 \mathrm{ppm}$. Several aliphatic aldehydes have had TLVs and WEELS set, and values assigned by these two groups are generally the same. For comparison, basic toxicity/exposure guidelines for butanal and propanal are given in Table 5.3. The Spacecraft Maximum Allowable Concentration for butanal is 41 ppm (CLS 2000), and the Danish EPA (http://www.mst.dk/chemi/01084008.htm) has set a TLV of an average 8-hour mean limit of 25 ppm based on the WEEL.

\subsubsection{Toxicology Summary and Data Analysis}

Butanal is used in the production of resins, solvents, and plasticizers. It is metabolized to butyric acid, primarily in the liver. Acids from aliphatic aldehydes can serve as substrates for fatty acid oxidation within the Krebs cycle. The primary toxicological endpoint from butanal exposures is irritation to the skin and eyes. Acute toxicity is low (See Table 5.3). The NOEL following a 1-month inhalation exposure (6 hours/day, 5 days/week) in rats was 320 ppm (EPA 1989). No evidence has been presented

Table 5.3. Butanal and Propanal

\begin{tabular}{|l|l|c|c|c||}
\hline Chemical & Structure & LC $_{50}$ (rats, ppm) $^{(\mathrm{a})}$ & WEEL & TLV \\
\hline Butanal & 59000 & 25 & n.a. \\
\hline Propanal & 26000 & 20 & 20 \\
\hline $\begin{array}{l}\text { (a) Skog 1950, as reported in CLS 2000. } \\
\text { (http://books.nap.edu/books/0309067952/html/1.html) }\end{array}$ \\
\hline
\end{tabular}


that butanal exposures cause cancer. In humans, exposures to $200 \mathrm{ppm}$ for 30 minutes were non-irritating (CLS 2000). The odor threshold for butanal is approximately 3 ppm (Cometto-Muniz et al. 1998).

No guidelines have been established for butanal by either ACGIH or OSHA. The 8-hour TWA WEEL of $25 \mathrm{ppm}$ proposed by the AIHA is within the same range as available ACGIH TLVs given for several related aliphatic aldehydes (ACGIH 2005b), including the closely related propanal (ACGIH 2002b; Table 5.3).

\subsubsection{Conclusion}

Based on the high $\mathrm{LC}_{50}$ in rats, the lack of irritation observed in human exposures to $200 \mathrm{ppm}$, and the 320 ppm NOEL for subchronic inhalation exposures in rats, the 25 ppm WEEL is appropriate. In addition, the WEELs assigned by AIHA that are available for other aliphatic aldehydes generally match the TLVs assigned by ACGIH. Therefore, an AOEL of $\mathbf{2 5} \mathbf{~ p p m}$ is proposed for butanal. 


\subsection{Ketones}

\subsubsection{4-Methyl-2-hexanone (CAS\# 105-42-0)}

An AOEL is proposed for 4-methyl-2-hexanone based on a comprehensive review of the available toxicology and guideline literature. 4-Methyl-2-hexanone is an aliphatic branched (7-carbon) ketone that is structurally similar to 2-hexanone. Aliphatic ketones are generally volatile organic compounds that can be irritating to the skin, eyes, and upper respiratory tract. Although there are no ACGIH or OSHA guidelines for 4-methyl-2-hexanone, the ACGIH has set TLV-TWA exposure concentrations for 2hexanone which has extensive animal toxicity and human data available. 2-Hexanone is a known animal and human neurotoxicant in which the mechanism of neurotoxicity has been well studied. The TLVTWA for 2-hexanone was set at $5 \mathrm{ppm}\left(20 \mathrm{mg} / \mathrm{m}^{3}\right)$ to minimize the potential for distal peripheral neurotoxicity, primarily nerve fiber conduction, with weakness in the hands and feet and loss of coordination. Based on the uncertainty associated with chemical and toxicological differences between 4-methyl-2-hexanone and 2-hexanone, an AOEL of $\mathbf{0 . 5} \mathbf{~ p p m}$ is proposed for 4-methyl-2-hexanone.

\subsubsection{Methodology}

The procedures described in Sections 2.0 - 4.0 were used as a guide for developing this AOEL. To identify and access available toxicity data on 4-methyl-2-hexanone, a number of Internet data bases, including PUBMED, TOXNET, and TOMES, were searched and summary toxicity profiles were obtained and primary references identified. In addition, ACGIH documentation was likewise reviewed for 4-methyl-2-hexanone and relevant surrogate chemicals. These toxicology summaries were then reviewed to identify the most critical data sets that could be used to establish the toxicity profile and develop the AOEL.

\subsubsection{Available Guidelines}

No OEL for 4-methyl-2-hexanone has been proposed by OSHA or ACGIH. However, ACGIH has assigned a TLV-TWA for the structural surrogate 2-hexanone. The ACGIH documentation indicates that a TLV-TWA of 5 ppm was reasonable based on the decrements in rodent and nonhuman primate sciatictibial nerve conduction following 9 months of inhalation exposure to 2-hexanone at concentrations equivalent to an 8-hour TWA of 75 ppm (Johnson et al. 1978). The ACGIH indicated that the TLV-TWA of $5 \mathrm{ppm}$ is anticipated to include an adequate margin of safety to minimize the potential for adverse neurotoxicity.

\subsubsection{Toxicology Summary and Data Analysis}

The toxicity data base for the surrogate 2-hexanone was utilized for the assessment because no substantial information was available on 4-methyl-2-hexanone. In the case of 2-hexanone, there is very robust toxicity information particularly as it relates to neurotoxicity. Subchronic inhalation exposure to 2-hexanone at concentrations ranging from $200 \mathrm{ppm}$ to $1600 \mathrm{ppm}$ is associated with the observance of peripheral neuropathy in chickens, rats, cats, and monkeys (Abou-Donia et al. 1985; Mendell et al. 1974; Spencer et al. 1975; Duckett et al. 1974). Johnson et al. (1979) reported that rats and monkeys that inhaled $100 \mathrm{ppm}$ of 2-hexanone for 9 months developed abnormal neurophysiologic indicators, and this exposure was equivalent to a daily 8-hour TWA of $75 \mathrm{ppm}$. In addition to the observed neurotoxicity, rats that inhaled 700 ppm 2-hexanone for 11 weeks developed testicular atrophy (Katz et al. 1980); 
however, observed testicular toxicity occurs at doses that are greater than those leading to axonopathy. Extensive pharmacokinetic and metabolism investigations have identified the ultimate neurotoxic metabolite as 2,5-hexanedione, which is a metabolite of both 2-hexanone and hexane. Anthony et al. (1983) evaluated the neurotoxicity of the 3,4-dimethyl-2,5-hexanedione, and it was reported as 20-30 times more potent on a molar basis than 2,5-hexanedione. It was noted that alkyl substitution causes branched-chain compounds to cyclize more rapidly than unbranched analogs, implicating pyrrole formation in the pathogenesis of the axonopathy. Although no data were available on 4-methyl2-hexanone, it is feasible that the alkyl substitution could likewise enhance pyrrole formation.

The ACGIH documentation provides numerous examples of occupational exposure to 2-hexanone that have led to peripheral neuropathy, and the ACGIH has established a Biological Exposure Index of $0.4 \mathrm{mg} / \mathrm{L}$ for 2,5-hexanedione in urine taken at the end of a work shift (ACGIH 2003).

\subsubsection{Conclusion}

The ACGIH has set the TLV-TWA for 2-hexanone at $5 \mathrm{ppm}\left(20 \mathrm{mg} / \mathrm{m}^{3}\right)$ to minimize the potential for neurotoxic effects. Based on uncertainty associated with chemical and toxicological differences between 2-hexanone and 4-methyl-2-hexanone, an additional 10-fold factor is applied to the 2-hexanone OEL to establish an AOEL of $\mathbf{0 . 5} \mathbf{~ p p m}$ for 4-methyl-2-hexanone.

\subsubsection{3-Hexanone (CAS\# 589-38-8)}

An AOEL is proposed for 3-hexanone based on a comprehensive review of the available toxicology and guideline literature. 3-Hexanone is an aliphatic (6-carbon) ketone. Aliphatic ketones are generally volatile organic compounds that can be irritating to the skin, eyes, and the upper respiratory tract. Although there are no ACGIH or OSHA guidelines for 3-hexanone, the ACGIH has set TLV-TWA exposure concentrations for 2-pentanone and 3-pentanone (ACGIH 2001h; 2001r) with 2-pentanone having the more robust data set. The TLV-TWA for the pentanones was set at $200 \mathrm{ppm}\left(705 \mathrm{mg} / \mathrm{m}^{3}\right)$ to minimize the potential objectionable narcotic effects and significant irritation. Based on the uncertainty associated with chemical differences between 3-hexanone and 2- or 3-pentanone, an AOEL of $\mathbf{6 7} \mathbf{~ p p m}$ is proposed for 3-hexanone.

\subsubsection{Methodology}

The procedures described in Sections 2.0 - 4.0 were used as a guide for developing this AOEL. To identify and access available toxicity data on 3-hexanone, a number of Internet data bases, including PUBMED, TOXNET, and TOMES were searched, and summary toxicity profiles were obtained and primary references identified. ACGIH documentation was likewise reviewed for 3-hexanone and relevant surrogate chemicals. These toxicology summaries were then reviewed to identify the most critical data sets that could be used to establish the toxicity profile and develop the AOEL.

\subsubsection{Available Guidelines}

No OEL for 3-hexanone has been proposed by OSHA or ACGIH. However, ACGIH has assigned a TLV-TWA for the structural surrogates 2- and 3-pentanone. The ACGIH documentation indicates that occupational exposure to 1500 ppm 2-pentanone has been associated with complaints of ocular and mucous membrane irritation in humans, and high-dose exposure to 2-pentanone was associated with 
narcosis in animals. Therefore, a 200 ppm TLV-TWA was recommended by ACGIH and is believed to be low enough to protect from narcotic and irritation effects.

\subsubsection{Toxicology Summary and Data Analysis}

The lowest published lethal concentration for 3-hexanone was reported as a 4-hour inhalation exposure to $4000 \mathrm{ppm}$ in rats. No other relevant information was obtained for 3-hexanone. However, for the surrogate 2-pentanone, occupational exposure to $1500 \mathrm{ppm}$ was associated with a strong odor and ocular and upper respiratory tract irritation in humans. Inhalation exposure of guinea pigs to $5000 \mathrm{ppm}$ for 8 hours resulted in narcosis, but obvious ocular and upper respiratory tract irritation was likewise noted. The 4-hour $\mathrm{LC}_{50}$ in rats was $>2000$ ppm.

\subsubsection{Conclusion}

The ACGIH has set the TLV-TWA for the pentanones at $200 \mathrm{ppm}\left(705 \mathrm{mg} / \mathrm{m}^{3}\right)$ to minimize the potential objectionable narcotic effects and significant irritation. Based on the uncertainty associated with chemical differences between 3-hexanone and 2- or 3-pentanone, an additional 3-fold factor is applied to the pentanone OEL to establish an AOEL of $\mathbf{6 7} \mathbf{~ p p m}$ for 3-hexanone.

\subsubsection{6-Methyl-2-heptanone (CAS\# 928-68-7)}

An AOEL is proposed for 6-methyl-2-heptanone based on a comprehensive review of the available toxicology and guideline literature. 6-methyl-2-heptanone is an aliphatic branched (8-carbon) ketone. Aliphatic ketones are generally volatile organic compounds that can be irritating to the skin, eyes, and the upper respiratory tract. Although there are no ACGIH or OSHA guidelines for 6-methyl-2-heptanone, the ACGIH has set TLV-TWA exposure concentrations for 5-methyl-3-heptanone and 2-heptanone (ACGIH 2001i; 2001q) with 5-methyl-3-heptanone having available human data. The TLV-TWA for 5-methyl3-heptanone was set at $25 \mathrm{ppm}\left(131 \mathrm{mg} / \mathrm{m}^{3}\right)$ as a comfort level in unconditioned workers. Based on the uncertainty associated with chemical differences between 6-methyl-2-heptanone, 5-methyl-3-heptanone, and 2-heptanone an AOEL of $\mathbf{8} \mathbf{~ p p m}$ is proposed for 6-methyl-2-heptanone.

\subsubsection{Methodology}

The procedures described in Sections 2.0 - 4.0 were used as a guide for developing this AOEL. To identify and access available toxicity data on 3-hexanone, a number of Internet data bases including PUBMED, TOXNET, and TOMES were searched, and summary toxicity profiles were obtained and primary references identified. ACGIH documentation was likewise reviewed for 6-methyl-2-heptanone and relevant surrogate chemicals. These toxicology summaries were then reviewed to identify the most critical data sets that could be used to establish the toxicity profile and develop the AOEL.

\subsubsection{Available Guidelines}

No OEL for 6-methyl-2-heptanone has been proposed by OSHA or ACGIH. However, ACGIH has assigned a TLV-TWA for the structural surrogates 5-methyl-3-heptanone and 2-heptanone. The ACGIH documentation indicates that humans are sensitive to 5-methyl-3-heptanone vapor exposures at concentrations of $>25 \mathrm{ppm}$, which results in both eye and respiratory irritation. Therefore, a $25 \mathrm{ppm}$ 
TLV-TWA was recommended by ACGIH as a comfort level for unconditioned workers. Data for 2-heptanone was limited to animal studies, and a TLV-TWA of $50 \mathrm{ppm}$ was recommended to minimize the potential for irritant effects.

\subsubsection{Toxicology Summary and Data Analysis}

No substantial information was available for 6-methyl-2-heptanone. The ACGIH documentation indicates that unconditioned human occupational exposure to $50 \mathrm{ppm}$ 5-methyl-3-heptanone was the threshold for eye and nose irritation in 50\% of the exposed subjects, while $6 \mathrm{ppm}$ was an odor threshold. A 100-ppm exposure was reported to be irritating to the mucous membranes and produced headache and nausea that were too intense to tolerate for more than a few minutes. In rats and mice, 4-hour exposure to a saturated atmosphere $(3000 \mathrm{ppm})$ rapidly resulted in signs of eye and respiratory system irritation. Oral $\mathrm{LD}_{50} \mathrm{~S}$ ranged from 2.5 - to $3.8 \mathrm{~g} / \mathrm{kg}$ in rats, mice, and guinea pigs. There were no reported human data with 2-heptanone, although NIOSH reported that $\sim 67,000$ workers are potentially exposed. Exposure to 1500 ppm 2-heptanone produced irritation, while 2000 ppm was strongly narcotic, and 4800 ppm caused narcosis and death in $4-8$ hours in rats. The oral $\mathrm{LD}_{50}$ is $\sim 1.7 \mathrm{~g} / \mathrm{kg}$ in rats. A subchronic study conducted in both rats and monkeys found no clinical evidence of toxicity or neurological impairment following a 9-month exposure to either 131 or 1025 ppm 2-heptanone (Johnson et al. 1978). The TLV-TWA of 50 ppm was recommended by ACGIH to minimize any potential for irritant effects.

\subsubsection{Conclusion}

The ACGIH has set the TLV-TWA for 5-methyl-3-heptanone and 2-heptanone at $25 \mathrm{ppm}\left(131 \mathrm{mg} / \mathrm{m}^{3}\right)$ and $50 \mathrm{ppm}\left(233 \mathrm{mg} / \mathrm{m}^{3}\right)$, respectively, to minimize the potential irritation effects. The results observed in humans with 5-methyl-3-heptanone are the most relevant and will be the primary surrogate for establishing an AOEL for 5-methyl-2-heptanone. Based on minimal uncertainty associated with chemical differences between 5-methyl-3-heptanone and 6-methyl-2-heptanone, an additional 3-fold factor is applied to the 5-methyl-3-heptanone OEL to establish an AOEL of $8 \mathbf{~ p p m}$ for 6-methyl-2-heptanone.

\subsubsection{2-Nonanone (CAS\# 821-55-6), 3-Dodecanone (CAS\#1534-27-6), 2-Tridecanone (CAS\#593-08-8), 3-Tridecanone (CAS\#1534-26-5)}

An AOEL is proposed for 2-nonanone, 3-dodecanone, 2-tridecanone, and 3-tridecanone based on a comprehensive review of the available toxicology and guideline literature. These long-chained aliphatic ketones range from 9-carbon to 13-carbon in length with the ketone present on either the 2nd or 3rd carbon. Aliphatic ketones can be irritating to the skin, eyes and the upper respiratory tract. Although there are no ACGIH or OSHA guidelines for these long chained aliphatic ketones, the ACGIH has set TLV-TWA exposure concentrations for the structural isomers of heptanone (2-heptanone, 3-heptanone and 4-heptanone [molecular formula: $\mathrm{C}_{7} \mathrm{H}_{14} \mathrm{O}$ ]) at $50 \mathrm{ppm}\left(233 \mathrm{mg} / \mathrm{m}^{3}\right)$ to minimize the potential for eye and skin irritation (ACGIH 2001i; 2001b; 2001q). Based on the uncertainty associated with chemical differences between 2-nonanone, 3-dodecanone, 2-tridecanone, and 3-tridecanone, and the isomers of heptanone, an AOEL of $\mathbf{1 7} \mathbf{~ p p m}$ is proposed for these long (C-9 to C-13) chained aliphatic ketones.

\subsubsection{Methodology}

The procedures described in Sections 2.0 - 4.0 were used as a guide for developing this AOEL. To identify and access available toxicity data on 2-nonanone, 3-dodecanone, 2-tridecanone, and 
3-tridecanone a number of Internet data bases including PUBMED, TOXNET, and TOMES were searched, and summary toxicity profiles were obtained and primary references identified. In addition, ACGIH documentation was reviewed for 2-heptanone, 3-heptanone, 4-heptanone, and relevant surrogate chemicals. These toxicology summaries were then reviewed to identify the most critical data sets that could be used to establish the toxicity profiles and develop the AOEL.

\subsubsection{Available Guidelines}

No OELs for 2-nonanone, 3-dodecanone, 2-tridecanone, and 3-tridecanone have been proposed by OSHA or ACGIH. However, ACGIH has assigned a TLV-TWA for the structural surrogate isomers 2-heptanone, 3-heptanone, and 4-heptanone. The ACGIH documentation recommends a 50-ppm TLVTWA to minimize the potential for ocular, dermal, and mucus membrane irritation.

\subsubsection{Toxicology Summary and Data Analysis}

These higher molecular weight ketones generally have low volatility; therefore, toxicity information is more available from oral and dermal exposures. Acute oral $\mathrm{LD}_{50} \mathrm{~S}$ are high (greater than $5 \mathrm{~g} / \mathrm{kg}$ ), indicating low toxicity. For 2- nonanone, the $\mathrm{LD}_{50}$ is greater than 3 and $7 \mathrm{~g} / \mathrm{kg}$ in rats and mice, respectively (Tanii 1986). The ACGIH documentation for 2-heptanone, 3-heptanone, and 4-heptanone ketone isomers was based upon the similar toxicological response. Exposure to $1500 \mathrm{ppm}$ 2-heptanone produced irritation, while $2000 \mathrm{ppm}$ was strongly narcotic, and $4800 \mathrm{ppm}$ caused narcosis and death in 4-8 hours in rats. The oral $\mathrm{LD}_{50}$ in rats is $\sim 1.7 \mathrm{~g} / \mathrm{kg}$ (ACGIH 2001i). A report suggested that irritation potency might increase with increasing ketone carbon chain length (Specht et al. 1940). A subchronic study conducted in both rats and monkeys found no clinical evidence of toxicity or neurological impairment following a 9-month exposure to either 131 or 1025 ppm 2-heptanone (Johnson et al. 1978). Likewise, limited inhalation toxicity studies (4-hour acute exposure) with 3-heptanone resulted in no fatalities at $2000 \mathrm{ppm}$, but all animals died at $4000 \mathrm{ppm}$ (Smyth et al. 1949). Rats exposed to $700 \mathrm{ppm}$ for 24-weeks exhibited no signs of neurotoxic effects (Katz et al. 1980), even though the neurotoxic 2,5-heptanedione metabolite was detected. Katz et al (1980) concluded that even though the neurotoxic metabolite was detectable, the systemic concentration achieved was insufficient to elicit a neurotoxic response. Limited toxicity studies have also been conducted with the 4-heptanone isomer. Following a 6-hour inhalation exposure, the $\mathrm{LC}_{50}$ for 4-heptanone was $2690 \mathrm{ppm}$, with narcosis occurring at 1600 ppm, and three out of four rats killed at 3200 ppm (Krasavage et al. 1982). A 6-hours/day exposure to $1200 \mathrm{ppm}$ of 4-heptanone resulted in a slightly decreased response to stimulation during exposure, and marginal liver enlargement but no changes in clinical chemistry or pathology (Krasavage et al. 1982). Hence, for these structurally related heptanone compounds, the ACGIH recommended a TLV-TWA of $50 \mathrm{ppm}$ primarily to minimize any potential for irritant effects.

\subsubsection{Conclusion}

The ACGIH has set the TLV-TWA for 2-heptanone, 3-heptanone, and 4-heptanone ketone isomers at $50 \mathrm{ppm}\left(233 \mathrm{mg} / \mathrm{m}^{3}\right)$. Based on the uncertainty associated with chemical differences between 2nonanone, 3-dodecanone, 2-tridecanone, 3-tridecanone, and the isomers of heptanone, an additional 3fold factor is applied to the OEL to establish an AOEL of $17 \mathrm{ppm}$ for these long (C-9 to C-13) chained aliphatic ketones. 


\subsubsection{5-Methyl-2-(1-methyethenyl)cyclohexanone (CAS\# 89-82-7)}

An AOEL is proposed for 5-methyl-2-(1-methyethenyl) cyclohexanone, which is also known as Pulegone, based on a comprehensive review of the available toxicology and guideline literature. This methyl and isopropyl substituted cyclohexanone is structurally similar to cyclohexanone. Although there are no ACGIH or OSHA guidelines for pulegone, the ACGIH has set TLV-TWA exposure concentrations for cyclohexanone at $25 \mathrm{ppm}\left(100 \mathrm{mg} / \mathrm{m}^{3}\right)$ to minimize the potential for eye, skin, and throat irritation (ACGIH 2001j). Based on the uncertainty associated with chemical differences between cyclohexanone and 5-methyl-2-(1-methyethenyl) cyclohexdanone, an AOEL of $\mathbf{2 . 5} \mathbf{~ p p m}$ is proposed.

\subsubsection{Methodology}

The procedures described in Sections 2.0 - 4.0 were used as a guide for developing this AOEL. To identify and access available toxicity data on 5-methyl-2-(1-methyethenyl) cyclohexanone, a number of Internet data bases including PUBMED, TOXNET, and TOMES were searched, and summary toxicity profiles were obtained and primary references identified. In addition, ACGIH documentation was reviewed for 5-methyl-2-(1-methyethenyl) cyclohexanone and relevant surrogate chemicals. These toxicology summaries were then reviewed to identify the most critical data sets that could be used to establish the toxicity profiles and develop the AOEL.

\subsubsection{Available Guidelines}

No OELs for 5-methyl-2-(1-methyethenyl) cyclohexanone have been proposed by OSHA or ACGIH. However, ACGIH has assigned a TLV-TWA for the structural surrogate cyclohexanone at $25 \mathrm{ppm}$ to minimize the potential for eye, nose, and throat irritation.

\subsubsection{Toxicology Summary and Data Analysis}

5-Methyl-2-(1-methyethenyl) cyclohexanone, commonly known as pulegone, is a major component of oil of pennyroyal, which has been used for flavoring foods and drinks. Pennyroyal oil has also been used as a fragrance agent and as an herbal medicine. Tice (1998) prepared a detailed review of the toxicology literature on pulegone and one of its metabolites, menthofuran, in support of pulegone and its metabolite being nominated by the NTP for additional chronic testing. The rational for further testing was based on the potential for human exposure and the absence of any carcinogenicity data. The NTP bioassay on pulegone is currently ongoing, and updates on project results can be obtained from the NTP website (http://ntp-server.niehs.nih.gov/). Human exposure to pulegone is primarily through ingestion of food products, and human acute toxicity has been associated with the ingestion of high doses of pennyroyal oil. There are no available animal inhalation studies with pulegone; however, the $\mathrm{LD}_{50}$ values for subcutaneous or intraperitoneal routes ranged from $150-1700 \mathrm{mg} / \mathrm{kg}$ in mice and rats. In a 28-day oral gavage study in rats, pulegone was administered at doses of 020,60 and $160 \mathrm{mg} / \mathrm{kg} / \mathrm{day}$. The NOEL for pulegone was $20 \mathrm{mg} / \mathrm{kg} / \mathrm{day}$ (Thorup et al. 1983). In experimental animals, pulegone is metabolically transformed (CYP450 involvement) to methofuran and other metabolites. The primary toxic response at high doses is associated with hepatic effects. There are currently no published data found on chronic exposure, teratogenicity, embryotoxicity, or carcinogenicity of pulegone.

Cyclohexanone (CAS 108-94-1) is a structural surrogate for pulegone, and ACGIH (2001j) has established a TLV-TWA of $25 \mathrm{ppm}\left(100 \mathrm{mg} / \mathrm{m}^{3}\right)$ for occupational exposure, which is intended to 
minimize the potential for eye, nose, and throat irritation. The acute toxicity of cyclohexanone is low; the intraperitoneal and subcutaneous $\mathrm{LD}_{50}$ values ranged from 1130 - $1535 \mathrm{mg} / \mathrm{kg}$ (Smyth et al. 1969; Gupta et al. 1979; Deichman and LeBlanc 1943). A 6-hour exposure to 4000 ppm in guinea pigs resulted in narcosis, hypothermia, and decreased respiration (Specht et al. 1940). Rabbits were exposed to 190 to 1414 ppm cyclohexanone for 6 hours/day for 50 days. The 190-ppm exposure showed only minor degenerative changes in liver and kidney (Treon et al. 1943). A 2-year carcinogenicity study was conducted in both rats and mice, and the neoplasms in the treated groups did not differ significantly from controls (Lijinsky and Kovatch 1986). The major metabolite of cyclohexanone is a reduction to cyclohexanol and subsequent conjugation with glucuronic acid. In humans, exposure to $25 \mathrm{ppm}$ cyclohexanone was not uncomfortable for most subjects; 50 ppm was irritating to the throat, while exposure to 75 ppm for 3-5 minutes resulted in more pronounced irritation of the eyes, nose, and throat (Nelson et al. 1943).

\subsubsection{Conclusion}

The ACGIH has set the TLV-TWA for cyclohexanone at $25 \mathrm{ppm}\left(100 \mathrm{mg} / \mathrm{m}^{3}\right)$. Based on the uncertainty associated with chemical, metabolic, and toxicological differences between cyclohexanone and 5-methyl2-(1-methyethenyl) cyclohexanone, an additional 10-fold factor is applied to the cyclohexanone OEL to establish an AOEL of 2.5 ppm for 5-methyl-2-(1-methyethenyl) cyclohexanone.

\subsubsection{4,7,7-Trimethyl-bicyclo[4.1.0]heptan-3-one (CAS\# 4176-04-9)}

An AOEL is proposed for 4,7,7-trimethyl-bicyclo[4.1.0]heptane-3-one, which is also known as caranone, based on a comprehensive review of the available toxicology and guideline literature. This cyclo ketone is structurally similar to camphor (1,7,7-trimethyl-bicyclo[2.2.1]heptan-2-one). Although there are no ACGIH or OSHA guidelines for caranone, the ACGIH has set TLV-TWA exposure concentrations for the structurally similar camphor at $2 \mathrm{ppm}\left(12 \mathrm{mg} / \mathrm{m}^{3}\right)$ to minimize the potential for eye and nose irritation and loss of sense of smell (ACGIH 2001b). Based on the uncertainty associated with chemical differences between camphor and caranone, an AOEL of $\mathbf{0 . 7} \mathbf{~ p p m}$ is proposed.

\subsubsection{Methodology}

The procedures described in Sections 2.0 - 4.0 were used as a guide for developing this AOEL. To identify and access available toxicity data on 4,7,7-trimethyl-bicyclo[4.1.0]heptane-3-one (caranone), a number of Internet data bases, including PUBMED, TOXNET, and TOMES were searched, and summary toxicity profiles were obtained and primary references identified. In addition, ACGIH documentation was reviewed for camphor (1,7,7-tricmethyl-bicyclo[2.2.1]heptan-2-one), which is a relevant surrogate chemical. These toxicology summaries were then reviewed to identify the most critical data sets that could be used to establish the toxicity profiles and develop the AOEL.

\subsubsection{Available Guidelines}

No OELs for 4,7,7-trimethyl-bicyclo[4.1.0]heptane-3-one have been proposed by OSHA or ACGIH. However, ACGIH has assigned a TLV-TWA for the structural surrogate camphor (1,7,7-tricmethylbicyclo[2.2.1]heptan-2-one) at 2 ppm to minimize the potential for eye and nose irritation and loss of sense of smell. 


\subsubsection{Toxicology Summary and Data Analysis}

4,7,7-Trimethyl-bicyclo[4.1.0]heptane-3-one is commonly known as caranone. There are no available animal inhalation studies with caraonone. Camphor (CAS 76-22-2) is a structural surrogate for caranone, and ACGIH (2001b) has established a TLV-TWA of $2 \mathrm{ppm}\left(12 \mathrm{mg} / \mathrm{m}^{3}\right)$ for occupational exposure, which is intended to minimize the potential for eye and nose irritation and loss of sense of smell. The acute inhalation toxicity of camphor was evaluated; the $\mathrm{LC}_{50}$ in mice was reported as $75 \mathrm{ppm}$, and the TCLo in mice was $18 \mathrm{ppm}$ for a repeated (7-week) exposure. No tumorigenic response was reported in mice following subcutaneous or topical treatment with camphor. In humans, exposure at or below 2 ppm over a 5-day work week showed that irritation to the eyes and nose and loss of sense of smell did not occur (Gronka et al. 1969). In addition, physical examination of exposed workers failed to reveal any significant findings apart from nose and throat inflammation, with the longest exposures lasting $\sim 10$ months. High-level exposures (concentration not specified) are reported to cause nausea, anxiety, dizziness, confusion, headache, and twitching of facial muscles (Gronka et al. 1969; Proctor et al. 1988; Gosselin et al. 1984; Arnow 1976).

\subsubsection{Conclusion}

The ACGIH has set the TLV-TWA for camphor at $2 \mathrm{ppm}\left(12 \mathrm{mg} / \mathrm{m}^{3}\right)$. Based on the uncertainty associated with chemical and toxicological differences between caranone and camphor, an additional 3-fold factor is applied to the camphor OEL to establish an AOEL of $\mathbf{0 . 7} \mathbf{~ p p m}$ for 4,7,7-trimethylbicyclo[4.1.0]heptane-3-one.

\subsubsection{3-Methyl-3-buten-2-one (CAS\# 814-78-8)}

An AOEL is proposed for 3-methyl-3-buten-2-one, based on a comprehensive review of the available toxicology and guideline literature. This ketone is structurally similar to 3-butene-2-one. Although there are no ACGIH or OSHA guidelines for 3-methyl-3-buten-2-one, the American Conference of Governmental Industrial Hygienists (ACGIH $\left.{ }^{\circledR}\right)$ has set Threshold Limit Value-Ceiling (TLV ${ }^{\circledR}$-Ceiling) exposure concentrations for 3-butene-2-one at $0.2 \mathrm{ppm}\left(0.6 \mathrm{mg} / \mathrm{m}^{3}\right)$ to minimize the potential for irritation of the skin, eyes and respiratory tract and the risk of dermal sensitization or allergic type reaction (ACGIH 2001s). Based on the uncertainty associated with chemical and toxicological differences between 3-buten-2-one and 3-methyl-3-buten-2-one an AOEL of 0.02 ppm is proposed.

\subsubsection{Methodology}

The procedures described in Sections 2.0 - 4.0 were used as a guide for developing this AOEL. To identify and access available toxicity data on 3-methyl-3-buten-2-one, a number of Internet data bases, including PUBMED, TOXNET, and TOMES were searched, and summary toxicity profiles were obtained and primary references identified. In addition, ACGIH documentation was reviewed for 3-buten-2-one, which is a relevant surrogate chemical. These toxicology summaries were then reviewed to identify the most critical data sets that could be used to establish the toxicity profiles and develop the AOEL. 


\subsubsection{Available Guidelines}

No OELs for 3-methyl-3-buten-2-one have been proposed by OSHA or ACGIH. However, ACGIH has assigned a TLV-ceiling for the structural surrogate 3-buten-2-one at $0.2 \mathrm{ppm}$ to minimize the potential for irritation of the skin, eyes, and respiratory tract and the risk of dermal sensitization or allergic reaction. The German MAK commission has reported 3-methyl-3-buten-2-one as a skin sensitizing substance based on animal tests (MAK 2000).

\subsubsection{Toxicology Summary and Data Analysis}

For 3-methyl-3-buten-2-one, the lowest published lethal concentration in rats and guinea pigs ranged from 125 - 250 ppm for 4 hours. A 30 ppm, 7 hours/day exposure to rats, guinea pigs, and rabbits for a total of 20 exposures in 28 days resulted in ocular and nasal irritation in all species, death and weight loss in rats, and decreased growth in guinea pigs. In addition, 1007 hours/day exposures of 15 ppm over 140 days resulted in ocular and nasal irritation in all animals (Clayton and Clayton 1982). In humans, 3-methyl3-buten-2-one is reported to produce skin irritation upon contact. Vapors have also been reported to be highly irritating to the respiratory tract (Clayton and Clayton 1982).

The surrogate 3-buten-2-one has an odor threshold of $\sim 0.2 \mathrm{ppm}$, which corresponds to the current ACGIH TLV-ceiling. The 4-hour $\mathrm{LC}_{50}$ values for 3-buten-2-one ranged from 2.4 to $2.8 \mathrm{ppm}$ in rats and mice, and a 50\% respiratory depression of $5.3 \mathrm{ppm}$ was reported for mice (Schaper 1993). These acute results with 3-buten-2-one suggest that this surrogate may be acutely more toxic than 3-methyl-3-buten-2-one. In humans, 3-buten-2-one is a severe skin, eye, and respiratory tract irritant.

\subsubsection{Conclusion}

The ACGIH has set the TLV-ceiling for 3-buten-2-one at $0.2 \mathrm{ppm}\left(0.6 \mathrm{mg} / \mathrm{m}^{3}\right)$. Based on the uncertainty associated with chemical and toxicological differences between 3-methyl-3-buten-2-one and 3-buten2-one, an additional 3-fold factor is applied; in addition, a 3-fold factor is applied for extrapolation from the TLV-ceiling to a TWA. Hence, a net 9-fold factor is applied to the 3-buten-2-one OEL to establish an AOEL of 0.02 ppm for 3-methyl-3-buten-2-one. 


\subsection{Esters}

\subsubsection{1-Methylethyl tetradecanoate (Cas \# 110-27-0), Butyl tetradecanoate (Cas \# 110- 36-1), and 1-Methylethyl hexadecanoate (CAS \# 142-91-6)}

The screening value for these decanoic acids was obtained from a Swedish TWA of $5 \mathrm{mg} / \mathrm{m}^{3}$ for the related butyl stearate (butyl octadecanoate, CAS \# 123-95-5). The ACGIH also has established a TLVTWA for stearates of $10 \mathrm{mg} / \mathrm{m}^{3}(\sim 0.72 \mathrm{ppm})$, and OSHA has set a nuisance dust level for stearates of $5 \mathrm{mg} / \mathrm{m}^{3}$. These values are for total particulates or nuisance dusts and do not apply to vapors. These decanoic acids are common components of cosmetic compounds. They break down into innocuous metabolic products and are non-toxic, similar to the related fatty acids. The common use in cosmetics and the known and expected metabolic breakdown to non-toxic products indicates an AOEL is not needed for these chemicals at this time. As additional new data become available for these compounds, it would be reasonable to reassess the appropriateness of assigning an AOEL.

\subsubsection{Dibutyl butylphosphonate (CAS\# 78-46-6)}

An AOEL is proposed for dibutyl butylphosphonate based on a comprehensive review of the available toxicology and guideline literature. Dibutyl butylphosphonate is a phosphoric acid similar in structure to dibutyl phosphate (DBP, CAS\# 107-66-4) and tributyl phosphate (TBP, CAS\# 126-73-8). Although there are no ACGIH or OSHA guidelines for dibutyl butylphosphonate, the ACGIH has set TLV-TWA exposure concentrations for TBP at $0.2 \mathrm{ppm}\left(2.2 \mathrm{mg} / \mathrm{m}^{3}\right)$ and for DBP at $1 \mathrm{ppm}\left(8.6 \mathrm{mg} / \mathrm{m}^{3}\right)$ (ACGIH 2001aa; 2001g). Based on the uncertainty associated with chemical and toxicological differences between dibutyl butylphosphonate and DBP or TBP, an AOEL of $\mathbf{0 . 0 2} \mathbf{~ p p m}$ is proposed for dibutyl butylphosphonate by adding additional uncertainty factors to the TBP TLV-TWA.

\subsubsection{Methodology}

The procedures described in Sections 2.0 - 4.0 were used as a guide for developing this AOEL. To identify and access available toxicity data on dibutyl butylphosphonate, a number of Internet data bases including PUBMED, TOXNET, and TOMES were searched, and summary toxicity profiles were obtained and primary references identified. In addition, ACGIH documentation was reviewed for dibutyl phosphate and relevant surrogate chemicals. These toxicology summaries were then reviewed to identify the most critical data sets that could be used to establish the toxicity profile and develop the AOEL.

\subsubsection{Available Guidelines}

No OEL for dibutyl butylphosphonate has been proposed by OSHA or ACGIH. However, ACGIH has assigned a TLV-TWA for the structural surrogates DBP and TBP (ACGIH 2001aa; 2001g). The ACGIH documentation for DBP and TBP are based upon very limited toxicity information (primarily sensory irritation), and in the case of TBP, by structural analogy with triphenyl phosphate. The current TLVTWA for TBP and DBP are $0.2 \mathrm{ppm}\left(2.2 \mathrm{mg} / \mathrm{m}^{3}\right)$ and $1 \mathrm{ppm}\left(8.6 \mathrm{mg} / \mathrm{m}^{3}\right)$, respectively.

\subsubsection{Toxicology Summary and Data Analysis}

A search of the RTECS data base found very limited toxicity data on dibutyl butylphosphonate. The $\mathrm{LD}_{50}$ following intraperitoneal and intravenous dosing in the mouse were $125 \mathrm{mg} / \mathrm{kg}$ and $56 \mathrm{mg} / \mathrm{kg}$, 
respectively. For the structural surrogate DBP there is very limited information supporting the TLVTWA, with some indication of respiratory tract irritation and headache in some workers exposed to DBP (unknown concentration/time) (ACGIH 2001g). In contrast, there are slightly more toxicity data available for TBP (ACGIH 2001aa). A 6-hour inhalation exposure of rats to TBP resulted in an $\mathrm{LC}_{50}$ of $123 \mathrm{ppm}$, and a 4- to 5-hour inhalation $\mathrm{LC}_{50}$ of $227 \mathrm{ppm}$ (as determined by the World Health Organization [WHO] in 1991). Workers exposed to $1.4 \mathrm{ppm}$ TBP have complained of nausea and headaches (ACGIH 2001aa); hence, the ACGIH recommended a TLV-TWA of $0.2 \mathrm{ppm}$ for TBP because it was less than the concentration reported to be associated with worker complaints.

\subsubsection{Conclusion}

The ACGIH has set the TLV-TWA for tributyl phosphate at $0.2 \mathrm{ppm}\left(2.29 \mathrm{mg} / \mathrm{m}^{3}\right)$ based primarily by analogy with triphenyl phosphate and reports of worker complaints at $1.4 \mathrm{ppm}$ exposure. Based on the uncertainty associated with chemical and toxicological differences between dibutyl butylphosphonate and TBP, a 9-fold factor is applied to the TBP TLV-TWA to establish an AOEL of $\mathbf{0 . 0 2} \mathbf{~ p p m}$ for dibutyl butylphosphonate. A 3-fold factor was used to account for the lack of a robust toxicity data set, and an additional 3-fold factor used to account for structural differences between dibutyl butylphosphonate and TBP. 


\subsection{Alkyl Nitriles and Alkene Nitriles}

\subsubsection{Propanenitrile (CAS \#107-12-0), Butanenitrile (CAS \# 109-74-0), 2-Methylene butanenitrile (CAS\#1647-11-6), Pentanenitrile (CAS\# 110-59-8), Hexanenitrile (CAS \# 628-73-9), Heptanenitrile (CAS\# 629-08-3), Octanenitrile (CAS \# 124-12-9), Nonanenitrile (CAS \#2243-27-8), Decanenitrile (CAS \# 1975-78-6)and 3-Butenenitrile (CAS\# 109-75-1), and 2,-4-Pentadienenitrile (CAS\# 1615-70-9)}

AOELs are proposed for a family of saturated alkyl nitriles with two to nine carbon alkyl side-chains and unsaturated alkenes with three to four carbon side-chains, based on a comprehensive review of the available toxicology literature. The principal toxic effects of these nitriles have been proposed to be mediated by metabolically released cyanide. The chemical in this family with the most robust toxicological data set is propanenitrile. The proposed AOELs for these compounds range from 0.3 to $8 \mathbf{~ p p m}$ and are based on toxicity information and pre-existing exposure guidelines from acceptable private and government agencies for the nitriles of interest and structurally similar compounds. An additional margin of safety was added, where appropriate, for the compounds in this class without pre-existing guidelines.

\subsubsection{Methodology}

To identify and access available toxicity data on alkyl and alkene nitriles, a number of Internet data bases, including PUBMED, TOXNET, TOMES, EPA-IRIS, and the IARC were searched, and summary toxicity profiles were obtained and primary references identified. These toxicology summaries were then reviewed to identify the most critical data sets that could be used to establish the toxicity profile and for the development of the AOEL. Primary references for the most relevant toxicology endpoints were obtained for review.

\subsubsection{Available Guidelines}

Guidelines have been proposed for propanenitrile and butanenitrile (see Table 5.4). Guidelines have also been proposed for related alkyl nitriles and alkene nitriles (see Tables 5.4 and 5.5). For many of these nitrile compounds, skin notations, but no classifications as carcinogens, have also been recommended.

\subsubsection{Toxicology Summary}

The $\mathrm{LC}_{50} \mathrm{~s}$ for butanenitrile and propanenitrile are similar (see Table 5.6). The endpoint of concern for developing an AOEL based on animal toxicity studies is likely to be developmental effects. At high exposure concentrations, embryolethality was observed; at lower concentrations, fetotoxicity was observed (Saillenfait et al. 1993). The NOELs for developmental effects are very similar between butanenitrile propanenitrile and pentanenitrile (see Table 5.6). 
Table 5.4. $\quad$ Exposure Limit Values Alkyl Nitriles

\begin{tabular}{|c|c|c|c|}
\hline Nitrile & Agency & Description & Limit (ppm) \\
\hline Acetonitrile & $\begin{array}{c}\text { ACGIH }^{\circledR} \\
\text { EPA }\end{array}$ & $\begin{array}{c}\text { TLV }^{\circledR} \text {-TWA } \\
\text { AEGL3 (8-hr) }\end{array}$ & $\begin{array}{r}20 \\
100\end{array}$ \\
\hline Butanenitrile & NIOSH & REL & 8 \\
\hline Propanenitrile & $\begin{array}{l}\text { NIOSH } \\
\text { EPA }\end{array}$ & $\begin{array}{c}\text { REL } \\
\text { AEGL3 (8-hr) }\end{array}$ & $\begin{array}{l}6 \\
1.4\end{array}$ \\
\hline \multicolumn{4}{|c|}{$\begin{array}{l}\text { REL = Recommended exposure limit } \\
\text { TLV = Threshold limit value } \\
\text { TWA = Time-weighted average } \\
\text { AEGL }{ }^{(a)}=\text { Acute Exposure Guideline Levels, once-in-a-lifetime, or rare, exposure to airborne chemicals. } \\
\text { The AEGLs for acetonitrile and propanenitrile are under review and do not have technical support } \\
\text { documentation available at this time. } \\
\text { (a) AEGL Levels } 1-3 \text {. AEGL Level } 1 \text { is an exposure at which an individual may have some discomfort. Level } 3 \text { is } \\
\text { the level at which an individual could experience life-threatening effects. Level } 2 \text { is the action level, the level at } \\
\text { which an individual may experience long-lasting effects. }\end{array}$} \\
\hline
\end{tabular}

Table 5.5. Acute or Subchronic $\mathrm{LD}_{50} \mathrm{~S}$ and OELs for Alkene Nitriles

\begin{tabular}{||l|l|l|l|l||}
\hline \multicolumn{1}{|c|}{ Nitrile } & C \# & \multicolumn{1}{c|}{ Species } & $\begin{array}{c}\text { LD }_{50}{ }^{(a)} \\
(\mathrm{mmol} / \mathrm{kg})\end{array}$ & \multicolumn{1}{|c||}{ Exposure Limit: Agency } \\
\hline \hline Acrylonitrile & 2 & Mouse & 0.73 & $\begin{array}{l}2 \text { ppm: OSHA PEL } \\
1 \text { ppm: NIOSH REL }\end{array}$ \\
\hline Methacrylonitrile & 3 & Mouse & 0.26 & 1 ppm: NIOSH REL \\
\hline 3-Butenenitrile & 3 & Mouse & 1.0 & -- \\
\hline $\begin{array}{l}\text { OSHA = Occupational Health and Safety Administration } \\
\text { PEL = Permissible exposure limit } \\
\text { (a) All LD }\end{array}$ values are from Tanii and Hashimoto (1984a). \\
\hline
\end{tabular}

Acetonitrile, pentanenitrile, and propanenitrile were all negative in genotoxicity assays conducted by the NTP of the NIEHS. ${ }^{\text {(a) }}$ Lifetime inhalation exposures to the structurally related acetonitrile did not result in increased incidences of cancers in rats (NTP 1996).

Toxicity of these saturated alkyl nitriles and unsaturated alkene nitriles is most likely mediated through metabolically released cyanide (Willhite and Smith 1981; Tanii and Hashimoto 1984b). All of these nitriles contain alkyl or alkene chains with nine carbons or less and a nitrile functional group ( $\mathrm{R}-\mathrm{C} \equiv \mathrm{N})$. The EPA Office of Pollution Prevention and Toxics has accepted a proposal from Eastman Kodak Co. and Solutia, Inc. to combine alkyl nitriles with up to three carbons (C-3) for the purposes of addressing data gaps. ${ }^{\text {(a) }}$ For the purpose of developing AOELs, nitriles with longer side-chains are also considered within this family.

(a) Assay information can be found online:

http://ntp.niehs.nih.gov/ntpweb/index.cfm?objectid=123DED4A-F1F6-975E-7CB19C212F28F788.

(a) See EPA's comments to the proposal online: http://www.epa.gov/chemrtk/alkyntrl/c14860ct.htm. 
Table 5.6. Acute or Subchronic NOELs and $\mathrm{LC}_{50}$ s for Alkyl Nitriles

\begin{tabular}{|c|c|c|c|c|c|c|}
\hline Nitrile & $\begin{array}{c}\mathrm{C} \\
\#^{(\mathrm{a})}\end{array}$ & Species & $\begin{array}{c}\mathrm{LC}_{50} \\
(\mathrm{ppm})\end{array}$ & $\begin{array}{l}\mathrm{LD}_{50}{ }^{(\mathrm{b})} \\
(\mathrm{mg} / \mathrm{kg})\end{array}$ & NOEL & Reference \\
\hline Acetonitrile & 1 & $\begin{array}{l}\text { Rat/Developmental } \\
\text { Mouse }\end{array}$ & $\begin{array}{l}-- \\
2673\end{array}$ & $\begin{array}{l}-- \\
6.6\end{array}$ & $\begin{array}{l}190 \mathrm{mg} / \mathrm{kg} \\
--\end{array}$ & $\begin{array}{l}\text { Johannsen et al. } 1986 \\
\text { Willhite et al. } 1981\end{array}$ \\
\hline Propanenitrile & 2 & $\begin{array}{l}\text { Rat/Developmental } \\
\text { Rat/Developmental } \\
\text { Mouse }\end{array}$ & $\begin{array}{l}-- \\
-- \\
163\end{array}$ & $\begin{array}{l}-- \\
-- \\
0.65\end{array}$ & $\begin{array}{l}50 \mathrm{ppm} \\
20 \mathrm{mg} / \mathrm{kg} \\
--\end{array}$ & $\begin{array}{l}\text { Saillenfait et al. } 1993 \\
\text { Johannsen et al. } 1986 \\
\text { Willhite et al. } 1981\end{array}$ \\
\hline Butanenitrile & 3 & $\begin{array}{l}\text { Mouse } \\
\text { Rat/Developmental }\end{array}$ & $\begin{array}{l}249 \\
--\end{array}$ & $\begin{array}{l}0.56 \\
--\end{array}$ & $50 \mathrm{ppm}$ & $\begin{array}{l}\text { Willhite et al. } 1981 \\
\text { Saillenfait et al. } 1993\end{array}$ \\
\hline Pentanenitrile & 4 & $\begin{array}{l}\text { Rat/Developmental } \\
\text { Mouse }\end{array}$ & -- & $\begin{array}{l}-- \\
2.3\end{array}$ & $30 \mathrm{mg} / \mathrm{kg}$ & Munley et al. 2001 \\
\hline Hexanenitrile & 5 & Mouse & -- & 4.8 & -- & \\
\hline Heptanenitrile & 6 & NA & -- & -- & -- & \\
\hline Octanenitrile & 7 & Mouse & -- & 14.1 & -- & \\
\hline Nonanenitrile & 8 & Mouse & -- & 14.8 & -- & \\
\hline Decanenitrile & 9 & NA & -- & -- & -- & \\
\hline \multicolumn{7}{|c|}{ 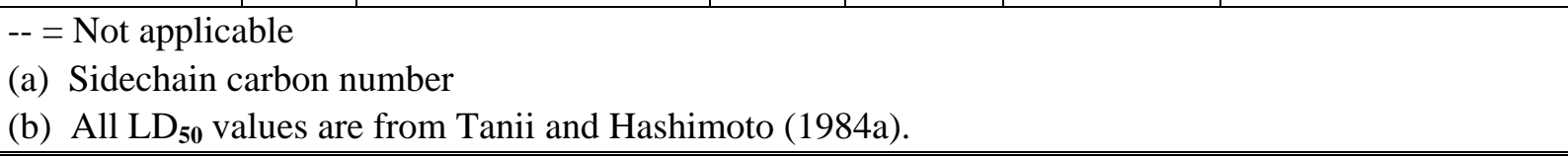 } \\
\hline
\end{tabular}

Toxicity data for most of these chemicals are limited. The decision to include the alkyl and alkene nitriles as a family was driven by the comparable available data, the similarity of the compounds, and the common active group $(\mathrm{C} \equiv \mathrm{N})$. The research reported by Tanii and Hashimoto (1984a 1984b) found cyanide metabolism in all the tested members of this family. The $\mathrm{LD}_{50}$ values determined by Tanii and Hashimoto (1984a) formed the basis for the proposed AOELs for chemicals in this family that currently lack AOELs (see Tables 5.5 and 5.6).

\subsubsection{Data Analysis}

NIOSH has set exposure guidelines for two of the four short-chain nitriles of interest (i.e., butanenitrile and pentanenitrile) and ACGIH has set exposure guidelines for the structurally similar acetonitrile (see Table 5.4). The TLV for acetonitrile is about three-fold higher than the NIOSH-recommended exposure limits (RELs) for the other nitriles. Likewise, the NOELs for developmental effects are about eight-fold higher for acetonitrile than propanenitrile and pentanenitrile (see Table 5.5). The $\mathrm{LD}_{50}$ values follow a similar trend, indicating toxicity of acetonitrile is less than alkyl and alkene nitriles with C-2 to C-5 chains. Alkyl nitriles with chains longer than seven carbons have increased $\mathrm{LD}_{50}$ values (decreased toxicity) compared to the shorter-chain nitriles (see Tables 5.5 and 5.6; Figure 5.1). 


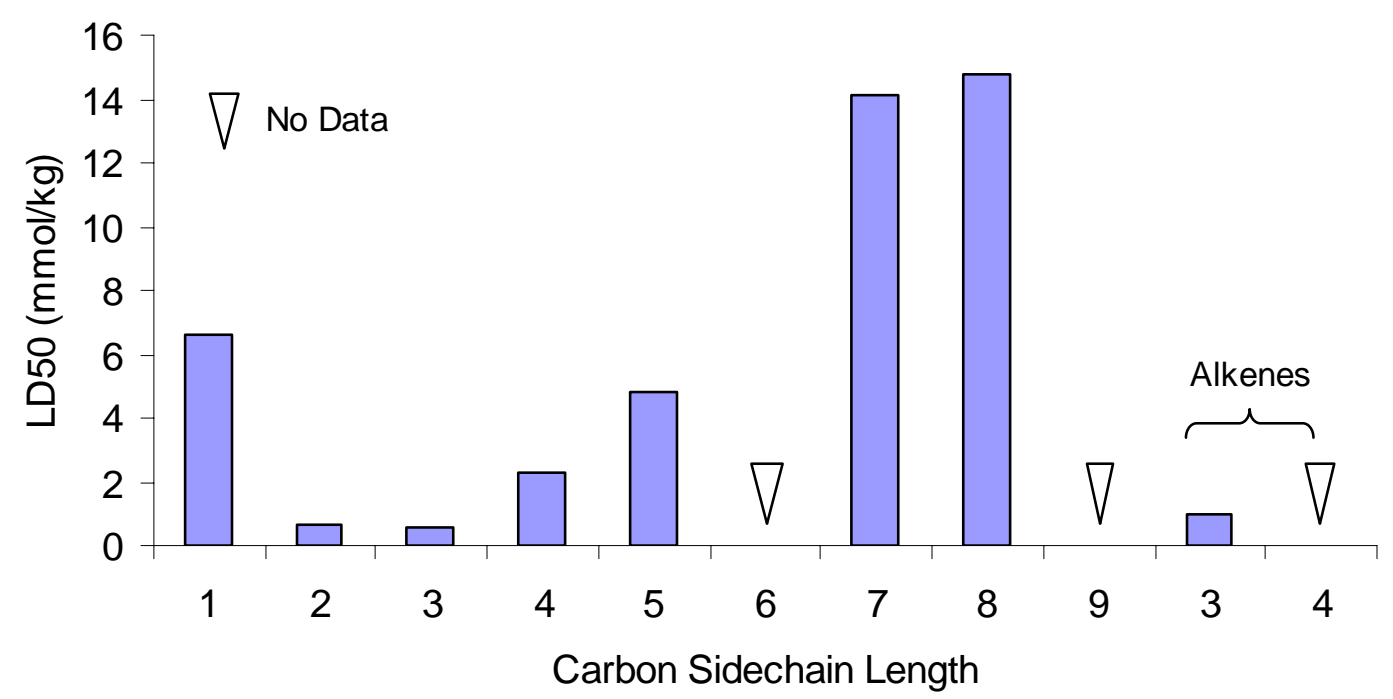

Figure 5.1. Comparison of Mice $\mathrm{LD}_{50}$ Values (Tanii and Hashimoto 1984a) Based on Carbon Length

To determine reasonable AOELs, the guidelines for propanenitrile (6 ppm: NIOSH REL) and butanenitrile (8 ppm: NIOSH REL) have been compared to the toxicity data available for the family of compounds in the literature. For alkyl nitriles with toxicity data below those of propanenitrile, an AOEL of $6 \mathrm{ppm}$ is proposed. NIOSH has recommended RELs for the structurally similar acrylonitrile and methacrylonitrile. The toxicity data indicate similar $\mathrm{LD}_{50} \mathrm{~S}$ for the alkene nitriles (see Table 5.5) and an AOEL of 1 ppm is proposed for 3-butenenitrile, for which toxicity data are available, and 0.3 ppm for 2,4-pentadienenitrile and for 2-methylene butanenitrile, which lack toxicity data. Table 5.7 summarizes the AOELs for each nitrile in this family.

It is unclear why the EPA Acute Exposure Guideline Level $3^{(a)}$ (AEGL3) for propanenitrile is lower than the NIOSH REL (see Table 5.4). At this time, no documentation is available to assess the derivation of the AEGL3. As additional new data become available for nitriles, it would be reasonable to reassess the appropriateness of this proposed AOEL.

\subsubsection{Conclusion}

The nitriles are structurally similar and consist of an alkyl or alkene side-chain and a nitrile functional group. Toxicity is most likely mediated though the cyanide metabolite. The known NOELs for developmental effects and $\mathrm{LD}_{50} \mathrm{~s}$ are similar for this class of chemicals. The proposed AOELs for this family of nitriles are based on the NIOSH RELs for nitriles, with an additional safety factor when toxicity data are not available. The proposed AOELs of 0.3 to 8 ppm are comparable to the NIOSH RELs for propanenitrile and butanenitrile.

(a) The EPA proprionitrile results are available online: http://www.epa.gov/oppt/aegl/results27.htm. 
Table 5.7. Proposed AOELS

\begin{tabular}{|l|l|l|l||}
\hline \multicolumn{1}{|c|}{ Nitrile } & Carbon \# & $\begin{array}{l}\text { AOEL } \\
(\mathrm{ppm})\end{array}$ & \multicolumn{1}{c|}{ Basis } \\
\hline $\begin{array}{l}\text { Propanenitrile } \\
\text { (CAS \#107-12-0) }\end{array}$ & 2 & 6 & NIOSH \\
\hline $\begin{array}{l}\text { Butanenitrile } \\
\text { (CAS \# 109-74-0) }\end{array}$ & 3 & 8 & NIOSH \\
\hline $\begin{array}{l}\text { 3-Butenenitrile } \\
\text { (CAS\# 109-75-1) }\end{array}$ & 3 & 1 & $\begin{array}{l}\text { Methacrylonitrile Surrogate: NIOSH REL, ACGIH } \\
\text { TLV }\end{array}$ \\
\hline $\begin{array}{l}\text { 2-Methylene } \\
\text { butanenitrile } \\
\text { (CAS\#1647-11-6) }\end{array}$ & 3 & 0.3 & $\begin{array}{l}\text { Methacylonitrile Surrogate: NIOSH REL, ACGIH } \\
\text { TLV, with UF of 3 due to lack of toxicity data }\end{array}$ \\
\hline $\begin{array}{l}\text { Pentanenitrile } \\
\text { (CAS\# 110-59-8) }\end{array}$ & 4 & 6 & Propanenitrile \\
\hline $\begin{array}{l}\text { Hexanenitrile } \\
\text { (CAS \# 628-73-9) }\end{array}$ & 5 & 6 & Propanenitrile \\
\hline $\begin{array}{l}\text { Heptanenitrile } \\
\text { (CAS\# 629-08-3) }\end{array}$ & 6 & 6 & Propanenitrile \\
\hline $\begin{array}{l}\text { Octanenitrile } \\
\text { (CAS \# 124-12-9) }\end{array}$ & 7 & 6 & Propanenitrile \\
\hline $\begin{array}{l}\text { Nonanenitrile } \\
\text { (CAS \#2243-27-8) }\end{array}$ & 8 & 6 & Propanenitrile \\
\hline $\begin{array}{l}\text { Decanenitrile } \\
\text { (CAS \# 1975-78-6) }\end{array}$ & 9 & 6 & Propanenitrile \\
\hline $\begin{array}{l}\text { 2,-4-Pentadienenitrile } \\
\text { (CAS\# 1615-70-9) }\end{array}$ & 4 & $\begin{array}{l}\text { Methacylonitrile Surrogate: NIOSH REL, ACGIH } \\
\text { TLV, with UF of 3 due to lack of toxicity data }\end{array}$ \\
\hline
\end{tabular}




\subsection{Amines and Amides}

\subsubsection{Acetamide (CAS \#60-35-5)}

In the interest of protecting the health of tank farm workers at DOE's Hanford Site, chemicals found within tank headspaces that the IARC lists as "possibly carcinogenic to humans" (2B) are being evaluated. The evaluation process will determine if there is a need to establish an AOEL for worker exposure based on a review of all available exposure and toxicological data as described in Sections 2.0 4.0. IARC assigned acetamide a 2B carcinogen classifications based on a paper by Fleischman et al. (1980) in which a diet of $2.36 \%$ acetamide resulted in hepatocarcinomas in male and female rats, and diets of 1.18 and $2.36 \%$ resulted in malignant lymphomas in male mice (Table 5.8). Only IARC and California EPA have assigned a carcinogen classification for acetamide; neither the EPA nor OSHA has made such a designation. The NTP investigated the mutagenic potential of acetamide in drosophila and salmonella and the results were negative. The bioassay results from the NTP were "inconclusive and not reportable” (http://ntp.niehs.nih.gov/index.cfm?objectid=07058954-ED59-D6FE-

5E91CDDBC78C556E).

There are more data available for the related chemicals N,N-dimethylacetamide and formamide (Figure 5.2). N,N-Dimethylacetamide is metabolized to acetamide in the liver. Acetamide and formamide are very similar, but acetamide is metabolized more slowly. The ACGIH, OSHA, and NIOSH have all set exposure limits for N,N-dimethylacetamide at $10 \mathrm{ppm}$ TWA. The ACGIH recommended AOEL for formamide is also $10 \mathrm{ppm}$. Neither formamide nor dimethylacetamide have been assigned possible human carcinogen status.

Acetamide, dimethylacetamide, formamide, and dimethylformamide all cause progressive hepatotoxicity (Kennedy 1986). The hepatocellular carcinomas observed by Fleischman et al. (1980) may have been due to hepatocellular cytotoxicity and concomitant compensatory cellular regeneration, which would have a threshold effect. Also, the ACGIH TLV of $10 \mathrm{ppm}$ for demethylacetamide should provide a good estimate for an acetamide TLV, and even after application of a 10x safety factor, the margin of exposure for acetamide (and related compounds, see Table 5.9) should be sufficient (estimated OEL of 1 ppm compared to tank headspace concentration of $0.0032 \mathrm{ppm}$ ). Therefore, no OEL is proposed for acetamide at this time. As additional new data become available for acetamide, it would be reasonable to reassess the appropriateness of not assigning an OEL based on the potential carcinogenicity.

Table 5.8. Incidence of Cancers in Rats and Mice Fed Diets Containing Acetamide

\begin{tabular}{|c|c|c|c|c|}
\hline Species & Acetamide (\%) & Endpoint & Incidence & Control \\
\hline Rat (male) ${ }^{(a)}$ & 2.36 & $\begin{array}{l}\text { Hepatocellular } \\
\text { Carcinomas }\end{array}$ & $441 / 47$ & $0 / 50$ \\
\hline Mouse (male) & 1.18 & Malignant lymphoma & $7 / 50$ & $0 / 79$ \\
\hline Mouse (male) & 2.36 & Malignant lymphoma & $7 / 46$ & $0 / 79$ \\
\hline
\end{tabular}

(a) Male and female rats were dosed, with similar outcomes, but male rats had slightly higher incidence and quicker time to tumor development Fleischman et al. (1980). 
Table 5.9. Acetamide and Related Chemicals

\begin{tabular}{|l|l|l|l|l|l|l||}
\hline $\begin{array}{c}\text { CAS or } \\
\text { TWINS } \\
\text { Number }\end{array}$ & \multicolumn{1}{|c|}{ Chemical } & $\begin{array}{c}\text { Max. Conc. } \\
(\mathrm{ppm})\end{array}$ & \multicolumn{1}{|c|}{ Surrogate } & $\begin{array}{c}\text { Surrogate } \\
\text { OEL } \\
\text { Source }\end{array}$ & $\begin{array}{c}\text { Safety } \\
\text { Factor }\end{array}$ & $\begin{array}{c}\text { Screening } \\
\text { Value } \\
(\mathrm{ppm})\end{array}$ \\
\hline $60-35-5$ & Acetamide & 0.0032 & N,N-Dimethylacetamide & TLV & 1000 & 0.01 \\
\hline $79-16-3$ & N-Methylacetamide & 0.00037 & N,N-Dimethylacetamide & TLV & 100 & 0.1 \\
\hline $541-35-5$ & Butanamide & 0.020 & N,N-Dimethylacetamide & TLV & 100 & 0.1 \\
\hline $10264-17-2$ & N-Hexylbutanamide & 0.000052 & N,N-Dimethylacetamide & TLV & 100 & 0.1 \\
\hline
\end{tabular}<smiles>CC(N)=O</smiles>

Acetamide<smiles>NC=O</smiles>

Formamide

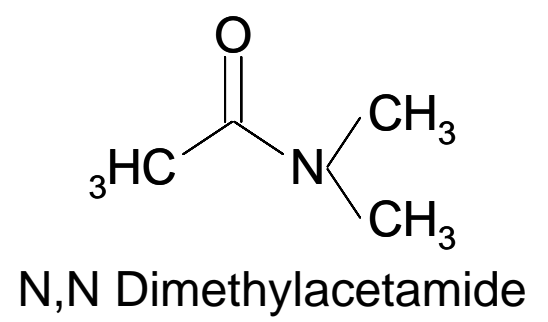<smiles>CN(C)C=O</smiles>

N,N Dimethylformamide

Figure 5.2. $\quad$ Acetamide and Related Compounds

\subsubsection{N-Methylaziridine (CAS\# 1072-44-2)}

An AOEL is proposed for N-methylaziridine. Aziridines are 3 membered heterocyclic compounds with an amine group. N-Methylaziridine has a methyl group bound to the ring nitrogen. Aziridines have highangle strains due to the tight nature of the 3-member ring compared to larger ring structures. No toxicological data were found for $\mathrm{N}$-methylaziridine, but it is similar to ethylenimine and propyleneimine, which have ACGIH-recommended TLVs of 0.5 and 2 ppm, respectively. These ACGIH TLVs are intended to minimize respiratory tract irritation. Ethylenimine and propyleneimine are confirmed animal carcinogens. The proposed AOEL for $\mathbf{N}$-methylaziridine is $\mathbf{0 . 0 5} \mathbf{p p m}$ based on the ACGIH TLVs for the closely relate compound ethylenimine with an UF of 10 .

\subsubsection{Methodology}

The procedures described in Sections 2.0 - 4.0 were used as a guide for developing this AOEL. To identify and access available toxicity data on N-methylaziridine, a number of Internet data bases including PUBMED, TOXNET, and TOMES were searched, and summary toxicity profiles were obtained and primary references identified. In addition, ACGIH documentation was reviewed for relevant surrogate chemicals. These toxicology summaries were then reviewed to identify the most critical data sets that could be used to establish the toxicity profile and develop the AOEL. 


\subsubsection{Available Guidelines}

No OEL for N-methylaziridine has been proposed by the OSHA or ACGIH. The ACGIH has proposed TLVs of 0.5 and 2 ppm for ethylenimine and propylenimine, structurally similar compounds. In addition, OSHA has assigned a Permissible Exposure Limit (PEL) of 2 ppm, and NIOSH has assigned an Immediately Dangerous to Life or Health (IDLH) of $100 \mathrm{ppm}$ for propylenimine. Skin notations have been recommended for these aziridines.

\subsubsection{Toxicology Summary}

Aziridines are reactive due to the ring strain, and they interact readily with nucleophiles. The substituted polyethylenimine is not mutagenic in salmonella strains. Aziridine and aziridines with smaller substitutions (i.e., propylenimine) are mutagenic and carcinogenic in laboratory animals. Aziridines are irritating to mucous membranes, skin, eyes, and lungs. Acute exposures of laboratory animals have resulted in congestion of the respiratory tract, edema, hemorrhage, and kidney damage. The 10-minute $\mathrm{LC}_{50}$ for aziridine is $2200 \mathrm{ppm}$, but exposures of 4 or more hours to as low as $25 \mathrm{ppm}$ has resulted in death in rats and guinea pigs. Embryotoxicity (decreased body weights, hematomas, decreased live births) have been observed with inhalation exposure concentrations as low as 0.6 ppm (NTP). Although animal studies to low concentrations result in serious effects, exposures in humans have resulted in less notable outcomes. Vapor exposures in human studies have resulted in no ill-effects for up to 3 hours. After 3 hours, vomiting and eye and nose irritation was reported. Acute dermal or inhalation exposures have resulted in central nervous system effects, fluid in the lungs, and damage to liver and kidneys (ACGIH 2001l).

Propylenimine has less potent toxicity than aziridine. The physiological action of propylenimine, however, resembles that of aziridine (ACGIH 2001z). The LCL0 for rats is $500 \mathrm{ppm}$ for a 4-hour exposure. N-Aziridineethanol is an $\mathrm{N}$-substituted aziridine with an ethanol group. Like the other azeridines, $\mathrm{N}$-aziridineethanol is an eye and skin irritant that also has limited data indicating it is an animal carcinogen (National Institutes of Health [NIH]).

\subsubsection{Data Analysis}

The most data were available for the unsubstituted aziridine. The ACGIH has recommended TLV-TWAs of 0.5 and 2 ppm for aziridine and propylenimine, respectively. The toxicity and carcinogenicity of aziridines with substitutions smaller than three carbons is similar. Due to the ring strain, these compounds are reactive. The primary endpoint of concern is irritation of skin, eyes, and lungs, and, for some aziridines, kidney damage. The ACGIH TLV for aziridine is four-times lower than for propylenimine due to the decreased toxicity for that substituted aziridine over the unsubstituted ring. The $\mathrm{N}$-substitute aziridine is not likely to result in significant decrease in ring strain.

\subsubsection{Conclusion}

Based on the lack of toxicological data for N-methylaziridine, it is proposed that the ACGIH TLV of 0.5 ppm be used with an UF of 10 to propose an OEL for $\mathbf{N}$-methylaziridine of $\mathbf{0 . 0 5} \mathbf{~ p p m}$. As additional new data become available for the $\mathrm{N}$-methylaziridine, it would be reasonable to reassess the appropriateness of basing the AOEL upon the WEEL for substituted pyridines. 


\subsection{Nitrites and Nitrates}

\subsubsection{Short-Chain Alkyl Nitrites: n-Butyl nitrite (CAS\# 544-16-9), Ethyl nitrite (CAS\# 109-95-5), and Methyl nitrite (CAS\# 624-91-1)}

The principal toxic effect of exposures to volatile organic nitrites results from methemoglobinemia. Evidence indicates that the methemoglobinemia is mediated by the nitrite ion after the organic nitrite is oxidized; therefore, it should be possible to set an AOEL for the family of organic nitrites of interest. The ACGIH has suggested a TLV of 1 ppm for the related organic volatile nitrite, isobutyl nitrite. Using the TLV for isobutyl nitrite and applying a safety margin for chemical differences, the proposed AOEL for the nitrite family is $0.1 \mathrm{ppm}(100 \mathrm{ppb})$.

\subsubsection{Toxicology Summary}

Nitrate $\left(\mathrm{NO}_{2}{ }^{-}\right)$is a naturally occurring inorganic ion. Nitrites react with the iron $\left(\mathrm{Fe}^{2+}\right)$ of deoxyhemoglobin and form methemoglobin, resulting in iron incapable of transporting oxygen $\left(\mathrm{Fe}^{3+}\right)$. The principal toxicology of nitrite exposures stems from methemoglobinemia and includes cyanosis, cardiac dysrhythmias, hemolytic anemia, circulatory failure, and progressive central nervous system effects. Children are especially at risk from oral exposures.

Volatile organic nitrites (e.g., butyl and amyl nitrite) are in medications and drugs of abuse. Production of nitric oxide from exposures to several nitrites has been observed (Cederqvist et al. 1994), and is likely to represent a common mechanism between chemicals of this class. Cyanosis is the major effect seen in animals following inhalation exposures to butyl nitrite. In rats, the $\mathrm{LC}_{50} \mathrm{~s}$ for the primary three nitrites of interest were 176, 160, and 420 ppm/4 hours for methyl, ethyl, and butyl nitrite, respectively (Klonne et al. 1987). No reports on chronic effects from nitrite exposures were found.

The potential of nitrites to cause cancer in humans is unknown. Isobutyl nitrite vapor was mutagenic in the Ames assay (Mirvish et al. 1993) and in salmonella tests (NTP 1996). Several nitrites have been shown to be mutagenic in vitro, including n-butyl, isobutyl, iso-amyl, sec-butyl, and n-propyl in mice lymphoma cells (Dunkel et al. 1989), and methyl nitrite (with and without an S9 activating system) in Salmonella (Tornqvist et al. 1983).

Although no in vivo animal carcinogenicity studies were identified for n-butyl, ethyl, or methyl nitrites, a two-year bioassay with the structurally similar isobutyl nitrite was reported (NTP 1996). In the two-year inhalation studies, there was "clear evidence" of increased incidences of alveolar and bronchiolar adenomas and carcinomas in rats, and some evidence of carcinogenic activity in B6C3F1 mice (NTP 1996). Based on the results of this study, ACGIH has recommended that isobutyl nitrite be given the notation of Confirmed Animal Carcinogen with Unknown Relevance to Humans (A3).

\subsubsection{Conclusion}

The most robust set of toxicological data were for butyl nitrite. A single study did show that the $\mathrm{LC}_{50}$ for nitrites was lowest, with the smaller side chains (methyl $\approx$ ethyl $<$ butyl). In reviewing the available exposure guidelines for organic nitrites, only an ACGIH guideline for isobutyl nitrite was found. An additional safety factor of 10 is proposed to account for chemical differences between isobutyl nitrite and methyl- or ethyl- nitrite. Since the TLV for isobutyl nitrite has been set by ACGIH at 1 ppm, a proposed 
AOEL for the family of short-chain alkyl nitrites (such as methyl, ethyl, and butyl) is $0.1 \mathrm{ppm}$. As additional and appropriate new data become available for nitrites, it would be reasonable to reassess the appropriateness of basing the alkyl nitrite's AOEL upon isobutyl nitrite.

\subsubsection{Short-Chain Alkyl Nitrates Methyl Nitrate (CAS \#598-58-3), Ethyl Nitrate (CAS \# 625-58-1), Butyl Nitrate (CAS \# 120-92-3), and Propyl Nitrate (CAS \# 627-13-4)}

An AOEL is proposed for the short-chain alkyl nitrates (methyl, ethyl, and butyl) based on a comprehensive review of the available toxicology literature. These four nitrates are structurally similar and consist of a one- to four-carbon alkyl side-chain and a nitrite functional group. The principal toxic effects of exposures to volatile short-chain alkyl nitrates result from methemoglobinemia. Nitrates are converted to nitrites, and the toxicity is mediated by the nitrite ion after the organic nitrite is oxidized; therefore, it should be possible to set an AOEL for the family of short-chain alkyl nitrates of interest. Although the organic nitrate identified with the most available data is propyl nitrate, the nitrates of interest are methyl and ethyl nitrate. A TLV of 25 ppm has been assigned by ACGIH for n-propyl nitrate. Based on the uncertainty associated with chemical differences between propyl nitrate and methyl and ethyl nitrate, an AOEL of 8 ppm is proposed for these nitrates.

\subsubsection{Methodology}

To identify and access available toxicity data on organic nitrates, a number of Internet data bases including PUBMED, TOXNET, TOMES, the EPA-IRIS, and IARC were searched, and summary toxicity profiles were obtained and primary references identified. These toxicology summaries were then reviewed to identify the most critical data sets that could be used to establish the toxicity profile to develop the AOEL. Primary references for the most relevant toxicology endpoints were obtained for review.

\subsubsection{Available Guidelines}

No OEL for ethyl, methyl, or butyl nitrate has been proposed by OSHA or ACGIH. However, NIOSH, OSHA, and ACGIH have all set OELs for propyl nitrate (see Table 5.10). From 1971 to 2001, the TLVs have not changed and are 25 or 40 ppm, depending on the length of exposure, for all agencies.

\subsubsection{Toxicology Summary}

Organic nitrates are used in the synthesis of other compounds as a room deodorizer propellant and in rocket propellants. Butyl nitrate and the related amyl nitrate are in the inhalant drugs of abuse known as Poppers and, therefore, exposures to these nitrates can be high. Butyl nitrate is a degradation product of tributyl phosphate (Tashiro et al. 2000). Environmental contamination with nitrates often stems from nitrogen-containing fertilizers. In the environment, organic nitrogen is converted to nitrite and nitrate by microbes, and nitrite is oxidized to nitrate so nitrate is found in high levels in groundwater. Worldwide, nitrate-contaminated groundwater is common, especially around farming communities where nitrogencontaining fertilizers are used. Epidemiological studies indicate that nitrate contamination of water supplies may be associated with risk of Type I diabetes, but only at concentrations greater than 10 to 25 mg/L (Van Maanen et al. 2000). 
Table 5.10. Exposure Limit Values for Propyl Nitrate

\begin{tabular}{|c|c|c|c|}
\hline Agency & Description & Value (ppm) & Date $^{(\mathrm{a})}$ \\
\hline ACGIH & TLV-STEL & 40 & 2001 \\
\hline ACGIH & TLV-TWA & 25 & 2001 \\
\hline $\mathrm{CDC}^{2}$ & IDLH & 500 & 1994 \\
\hline NIOSH & STEL & 40 & 1994 \\
\hline NIOSH & REL & 25 & 1994 \\
\hline OSHA & PEL-STEL & 40 & 1989 \\
\hline OSHA & PEL-TWA & 25 & 1994 \\
\hline \multicolumn{4}{|c|}{$\begin{array}{l}\text { (a) The date listed is the most recent found; in son } \\
\text { (b) See NTIS (1995). } \\
\text { IDLH = Immediately dangerous to life or health. } \\
\text { PEL = Permissible exposure limit. } \\
\text { REL = Recommended exposure limit. } \\
\text { STEL = Short-term Exposure Limit. } \\
\text { TWA = Time-weighted Average. }\end{array}$} \\
\hline
\end{tabular}

Nitrate $\left(\mathrm{NO}_{3}{ }^{-}\right)$and nitrite $\left(\mathrm{NO}_{2}^{-}\right)$are naturally occurring inorganic ions. Nitrates are converted to nitrites by intestinal bacteria. Nitrites, in turn, react with the iron $\left(\mathrm{Fe}^{2+}\right)$ of deoxyhemoglobin and form methemoglobin, resulting in iron incapable of transporting oxygen $\left(\mathrm{Fe}^{3+}\right)$. The principal toxicity of nitrate exposures stems from methemoglobinemia and includes cyanosis, cardiac dysrhythmias, hemolytic anemia, circulatory failure, and progressive central nervous system effects. Children are especially at risk from oral exposures. The EPA has derived a reference dose (RfD) of $1.6 \mathrm{mg} / \mathrm{kg} / \mathrm{day}$ for inorganic nitrate (IRIS 2002); a RfC has not been derived.

Orally, nitrates are rapidly absorbed from the small intestine. Regardless of exposure route, nitrates are delivered to the intestine via blood circulation and converted, primarily by bacterial oxidation, to the more reactive nitrites; therefore, nitrites are expected to have lower $\mathrm{LD}_{50}$ and $\mathrm{LC}_{50}$ values than nitrates (Bruning-Fann and Kaneene 1993). The $\mathrm{LC}_{50}$ value for methyl nitrate in rats is $1275 \mathrm{ppm} / 4 \mathrm{hr}$; the $\mathrm{LC}_{50}$ for the corresponding nitrite is seven times lower $(176 \mathrm{ppm} / 4 \mathrm{hr}){ }^{\left({ }^{a}\right)}$ Organic nitrites are rapidly converted in the liver to inorganic nitrite. The toxic mechanism of action leading to methemoglobinemia proceeds through either direct oxidation of the heme iron by the nitrite, or through production of NO from the nitrite (Cederqvist et al. 1994). Production of nitric oxide from exposures to several nitrites and nitrates has been observed (Cederqvist et al. 1994) and is likely to represent a common mechanism among chemicals of this class. The risk of methemoglobinemia from exposure of nitrate depends on the dose of nitrate and on the number and type of enteric bacteria.

The potential of nitrates to cause cancer in humans is unknown. Nitrates can react with amino acids to form nitrosamines, which can cause cancer in animals. An epidemiological study in workers exposed to nitrate fertilizers has shown a slight increase in stomach cancer incidence, but no increase in total cancer (Zandjani et al. 1994). Other studies have shown no relationship between occupation exposures to nitrate containing dust and any cancers (Fraser et al. 1982, 1989).

(a) Refer to the Hazardous Substances Data Bank online: http://csi.micromedex.com/assm.asp?HS7197. 


\subsubsection{Data Analysis}

No guidelines have been established for methyl, ethyl, or butyl nitrate (C-1, C-2, and C-4 side-chains, respectively). Exposure-level guidelines have been established by several agencies for propyl nitrate (see Table 5.10). The ACGIH TLVs were recommended based on acute and subchronic animal studies. Propyl nitrate causes sensory irritation at exposure levels much lower than needed to produce measurable methemoglobinemia (Rinehart et al. 1958). Therefore, there were no relevant human studies identified by the ACGIH. The TLV was based on the acute inhalation exposure $\mathrm{LC}_{50}$ in dogs (2000 to $2500 \mathrm{ppm}$ ) with a "reasonable uncertainty" factor. The $\mathrm{LD}_{50}$ for methyl nitrate in rats is about two times lower than the $\mathrm{LC}_{50}$ value reported for propyl nitrate in dogs. Due to the potential increase in toxicity of the shorterchain nitrates and the uncertainty associated with chemical differences, an additional uncertainty factor of 10 is recommended for the proposed AOEL for propyl nitrate, which results in an AOEL of 2.5 ppm. The ACGIH also concluded that there is insufficient data to warrant skin or carcinogenicity notations for propyl nitrate.

\subsubsection{Conclusion}

The most robust set of toxicological data were for propyl nitrate. The $\mathrm{LC}_{50}$ for acute inhalation of methyl nitrate in rats is $1275 \mathrm{ppm} / 4$ hours, the acute $\mathrm{LC}_{50}$ for propyl nitrate in dogs is 2000 to $2500 \mathrm{ppm} /$ 4 hours. Several agencies have established OELs for propyl nitrate, and these values were used to propose an AOEL for methyl and ethyl nitrate. An additional safety factor of 3 is proposed to account for chemical differences between propyl nitrate and the shorter-chain nitrates. Since the TLV for propyl nitrate has been set by ACGIH, OSHA, and NIOSH at 25 ppm (TWA), a proposed AOEL for the family of short-chain alkyl nitrates (methyl and ethyl) is $\mathbf{8 ~} \mathbf{~ p p m}$. As additional new data become available for nitrates, it would be reasonable to reassess the appropriateness of basing the alkyl nitrate's AOEL upon propyl nitrate.

\subsubsection{Dinitrates: 1,3-Propanediol, dinitrate (CAS \# 3457-90-7), 1,4-Butanediol, dinitrate (CAS \# 3457-91-8), 1,5-Pentanediol, dinitrate (CAS \# 3457-92-9), and 1,2,3-Propantriol, 1,3-dinitrate (CAS \# 623-87-0)}

An AOEL is proposed for the dinitrates, based on a comprehensive review of the available toxicology literature. The principal toxic effects of exposures to nitrates result from methemoglobinemia. Dinitrates are also vasodilators, but the mechanism of action is incompletely understood. The development of proposed AOELs for the dinitrates are based on short-chain aliphatic nitrites, propylene glycol dinitrate, and nitroglycerine. Nitrates are converted to nitrites, and the methemoglobinemia is mediated by the nitrite ion after the organic nitrite is oxidized. The ACGIH has assigned TLVs of $0.05 \mathrm{ppm}$ for ethylene glycol dinitrate, propylene glycol dinitrate, and nitroglycerine. The ACGIH TLV has already considered the incomplete understanding of the mechanism of action and the use of surrogate chemicals, therefore, an AOEL of $\mathbf{0 . 0 5} \mathbf{~ p p m}$ is proposed for these dinitrates.

\subsubsection{Methodology}

To identify and access available toxicity data on dinitrates, a number of Internet data bases, including PUBMED, TOXNET, TOMES, the EPA-IRIS, and IARC were searched, and summary toxicity profiles were obtained and primary references identified. These toxicology summaries were then reviewed to 
identify the most critical data sets that could be used to establish the toxicity profile and develop the AOEL. Primary references for the most relevant toxicology endpoints were obtained for review.

\subsubsection{Available Guidelines}

No OELs are available for the dinitrates found in the tank waste headspace. The ACGIH has set TLVs of $0.05 \mathrm{ppm}$ for the related dinitrates propylene glycol dinitrate, (ACGIH 2001y), ethylene glycol dinitrate (ACGIH 2001k) and the trinitrate, nitroglycerine (ACGIH 2001t). The TLVs for all of these compounds are based on assessment of propylene glycol dinitrate (ACGIH 2001y). OSHA and NIOSH have also set REL and PELs for propylene glycol at a TWA of 0.05 ppm, respectively.

\subsubsection{Toxicology Summary}

Very little data were found concerning the toxicity of these dinitrates. By analogy with propylene glycol dinitrate, and other nitrates, a probable toxicity profile can be estimated. When ingested orally, nitrates are rapidly absorbed from the small intestine. Regardless of exposure route, nitrates are delivered to the intestine via blood circulation and converted, primarily by bacterial oxidation, to more reactive nitrites. Organic nitrites are rapidly converted in the liver to inorganic nitrite. The toxic mechanism of action leading to methemoglobinemia proceeds through either direct oxidation of the heme iron by the nitrite or through production of NO from the nitrite (Cederqvist et al. 1994). Production of nitric oxide from exposures to several nitrites and nitrates has been observed (Cederqvist et al. 1994) and is likely to represent a common mechanism among chemicals of this class. The risk of methemoglobinemia from exposure of nitrate depends on the dose of nitrate and on the number and type of enteric bacteria.

The related compound with the most available toxicological information is propylene glycol dinitrate (CAS\# 6423-43-4). The primary toxicological endpoints of concern for propylene glycol dinitrate exposures are its effects on the cardiovascular and central nervous systems. Human exposures have led to symptoms of dizziness, eye irritation, nasal congestion, heart palpitations, and chest pain. Dizziness has been reported for inhalation exposures as low as $1.5 \mathrm{ppm}$, and the threshold for mild headache was 0.5 ppm (reviewed in: National Research Council 2001).

\subsubsection{Data Analysis}

No guidelines have been established for the dinitrates within the tank waste headspace. The ACGIH has set TWA-TLV of $0.05 \mathrm{ppm}$ for related dinitrates based primarily on the data available for propylene glycol dinitrate. This TLV is 500-fold lower than the ACGIH TWA for n-propyl nitrate (see Section 5.9.2). Due to the vasodilation effects from exposures to dinitrates and potential increase in toxicity of the dinitrates over the nitrates, it is proposed that the AOEL of $\mathbf{0 . 0 5} \mathbf{~ p p m}$ set by ACGIH for propyl glycol dinitrate, ethyl glycol dinitrate, and nitroglycerine be applied to the dinitrates within the tank waste headspace.

\subsubsection{Conclusion}

The most robust set of toxicological data were for propylene glycol dinitrate. The ACGIH has used this dataset to base AOELs for other di- and tri-nitrates. By analogy with the short-chain aliphatic mononitrates, this AOEL of $0.05 \mathrm{ppm}$ is conservative for these dinitrates. As additional new data become available for dinitrates, it would be reasonable to reassess the proposed AOEL. 


\subsubsection{1-Nitrate 1,2,3-propanetriol (CAS \# 624-43-1)}

An AOEL is proposed for 1-nitrate 1,2,3-propanetriol based on a comprehensive review of the available toxicology literature. 1-Nitrate 1,2,3-propanetriol consists of a nitrate functional group and a glycerol sidechain. The principal toxic effects of exposures to nitrates result from methemoglobinemia. Nitrates are converted to nitrites, and the methemoglobinemia is mediated by the nitrite ion after the organic nitrite is oxidized. Very high exposures to glycerol mist may result in hemolysis, hemoglobinuria, and renal failure. The ACGIH has assigned TLVs of 2.65 and 25 ppm for glycerin mist and n-propyl nitrate vapor, respectively. Following metabolism in the intestine and liver, the likely metabolites will be inorganic nitrite and propylene glycol. Since propylene glycol is relatively non-toxic, the proposed AOEL for 1-nitrate 1,2,3-propanetriol is based on the $25 \mathrm{ppm}$ OEL for n-propyl nitrate with a safety factor of 3 for uncertainties between chemical differences. The proposed AOEL for 1-nitrate 1,2,3-propanetriol is 8 ppm.

\subsubsection{Methodology}

To identify and access available toxicity data on 1-nitrate 1,2,3-propanetriol, a number of Internet data bases, including PUBMED, TOXNET, TOMES, and IARC were searched, and summary toxicity profiles were obtained and primary references identified. These toxicology summaries were then reviewed to identify the most critical data sets that could be used to establish the toxicity profile and develop the AOEL. Primary references for the most relevant toxicology endpoints were obtained for review.

\subsubsection{Available Guidelines}

No OEL for 1-nitrate 1,2,3-propanetriol has been proposed by either OSHA or ACGIH. NIOSH, OSHA, and ACGIH have all set 25 ppm TWA OELs for propyl nitrate. Likewise, OSHA and ACGIH have both set an OEL of $10 \mathrm{mg} / \mathrm{m}^{3}$ (2.65 ppm) for glycerin particulate exposures.

\subsubsection{Toxicology Summary}

Very little data were found concerning the toxicity of 1-nitrate 1,2,3-propanetriol. By analogies with propyl nitrate, nitroglycerine, glycerin, and propylene glycol, a probable toxicity profile can be estimated. When ingested orally, nitrates are rapidly absorbed from the small intestine. Regardless of exposure route, nitrates are delivered to the intestine via blood circulation and converted, primarily by bacterial oxidation, to more reactive nitrites. Organic nitrites are rapidly converted in the liver to inorganic nitrite. The toxic mechanism of action leading to methemoglobinemia proceeds through either direct oxidation of the heme iron by the nitrite, or through production of NO from the nitrite (Cederqvist et al. 1994).

Production of nitric oxide from exposures to several nitrites and nitrates has been observed (Cederqvist et al. 1994) and is likely to represent a common mechanism among chemicals of this class. The risk of methemoglobinemia from exposure of nitrate depends on the dose of nitrate and on the number and type of enteric bacteria.

\subsubsection{Data Analysis}

No guidelines have been established for 1-nitrate 1,2,3-propanetriol. Exposure level guidelines have been established by several agencies for propyl nitrate (see alkyl nitrates AOEL). The ACGIH TLVs were recommended based on acute and subchronic animal studies. Propyl nitrate causes sensory irritation at 
exposure levels much lower than needed to produce measurable methemoglobinemia (Rinehart et al. 1958). Propylene glycol is relatively non-toxic, and human ingestion of up to $100 \mathrm{ml}$ primarily leads to gastrointestinal upset. Due to the uncertainty associated with chemical differences, an additional uncertainty factor of 3 is recommended for the proposed AOEL for 1-nitrate 1,2,3-propanetriol, which results in an AOEL of 8 ppm. The proposed AOEL for glycerol is based on mist exposures, rather than vapor, and is therefore not applicable for vapors in the tank waste headspace.

\subsubsection{Conclusion}

The most likely active moiety of 1-nitrate 1,2,3-propanetriol will be the nitrite following metabolism in the gastrointestinal tract and liver and leaving inorganic nitrite and propylene glycol. Alternative metabolism may lead to the production of glycerin. Inorganic nitrite and glycerin have more toxicity associated with exposures than does propylene glycol. Based on the supposition that the metabolism will follow that typical for alkyl nitrates, an AOEL of $8 \mathbf{~ p p m}$, based on n-propyl nitrate is proposed. As additional new data become available for 1-nitrate 1,2,3-propanetriol, it would be reasonable to reassess the proposed AOEL. 


\subsection{Nitro Compounds}

\subsubsection{2-Nitro-1-propanol (CAS\# 2902-96-7), 2-nitro-methylpropane (CAS\# 594-70-7), and 1-nitrobutane (CAS\# 627-05-4)}

The principal toxic effects that stem from exposures to nitro compounds are irritation of eyes and respiratory tract and liver damage. Because no OELs are available for the nitro compounds of concern, 2-nitropropane (branched) and 1-nitropropane (unbranched) were chosen as surrogates with the most data and available OELs. The branched surrogate nitro compounds are more potent hepatotoxicants than the non-branched. Likewise, 2-nitropropane is an animal hepatocarcinogen, probably due to cellular damage and compensatory proliferation. The ACGIH has recommended TLVs of 10 and 25 ppm for 2nitropropane (branched) and 1-nitropropane, respectively. 1-Nitrobutane is an unbranched nitro compound with a longer side chain than 1-nitropropane, the recommended OEL for 1-nitrobutane is 2.5 ppm and was based on the OEL for 1-nitropropane with an uncertainty factor of 10 for minor structural differences and limited data. 2-Nitro-methylpropane is a branched nitro compound, with 1 more methyl group than 2-nitropropane, the recommended OEL for 2-nitro-methylpropane is $\mathbf{0 . 3}$ ppm and was based on the OEL for 2-nitropropane with an uncertainty factor of 10 for structural differences and 3 for limited toxicity data. 2-Nitro-1-propanol has an $\mathrm{OH}$ group that the other two chemicals of concern do not have. The recommended OEL for 2-nitro-1-propanol is $\mathbf{0 . 8} \mathbf{~ p p m}$ based on the OEL for 1-nitropropane with an uncertainty factor of 10 for structural differences and an additional UF of 3 for limited data.

\subsubsection{Methodology}

The procedures described in Sections 2.0 - 4.0 for were used as a guide for developing this AOEL. To identify and access available toxicity data on 2-nitro-1-propanol, 2-nitro-methylpropane, and 1nitrobutane, a number of Internet data bases including PUBMED, TOXNET, and TOMES were searched, and summary toxicity profiles were obtained and primary references identified. In addition, ACGIH documentation was reviewed for nitroethane, 2-nitropropane, and 1-nitropropane and relevant surrogate chemicals. These toxicology summaries were then reviewed to identify the most critical data sets that could be used to establish the toxicity profile and develop the AOEL.

\subsubsection{Available Guidelines}

No OELs have been proposed by OSHA or ACGIH for 2-nitro-1-propanol, 2-nitro-methylpropane, or 1nitrobutane. However, ACGIH has assigned a TLV-TWA for the structural surrogates, nitroethane, 2nitropropane, and 1-nitropropane. 1-Nitropropane is structurally very similar to 1-nitrobutane, differing only in one carbon. Likewise, 2-nitropropane is comparable to 2-nitro-methylpropane, differing in the side-chains; the former is secondary and the latter is a tertiary structure (Table 5.11). The ACGIH documentation for 1-nitropropane indicates that human exposures to $100 \mathrm{ppm}$ or more caused irritation to the eyes and recommended a TLV of $25 \mathrm{ppm}$ to minimize the potential of irritation to eyes and respiratory tract (ACGIH 2001u). The branched 2-nitropropane causes liver damage in laboratory animals, and hepatocellular carcinomas were noted in rats necropsied after 6 months of exposures to $207 \mathrm{ppm}$. For shorter exposure durations, progressive liver damage was observed, suggesting that the hepatocellular carcinomas were a consequence of cellular regeneration and proliferation secondary to damage. ACGIH recommended a TLV of 10 ppm for 2-nitropropane (ACGIH 2001v). 
Table 5.11. Structure and Proposed OELS for Nitro Compounds

\begin{tabular}{|lll|} 
Basis \\
\hline 1-Nitropropane
\end{tabular}

\subsubsection{Toxicology Summary}

No toxicity data were found for any of these nitro compounds, necessitating analysis based solely on structurally similar surrogates. For 2-nitro-methylpropane and 1-nitrobutane, the structural similarities to 2-nitropropane and 1-nitropropane, respectively, results in a reasonable level of confidence in using these surrogates. Structural differences for 2-nitro-1-propanol compared to the surrogates are more extensive (discussed in more detail below).

The surrogate for 1-nitrobutane, 1-nitropropane was not mutagenic in Salmonella tester strains. The primary endpoint of concern for 1-nitropropane exposures is irritation of the eyes and respiratory tract (ACGIH 2001u). Acute (1-3 hours) inhalation exposures in rats to 10,000 ppm resulted in conjuntival irritation, lacrimation, and slowed respiration. Rats exposed via inhalation for 7 hours/day, 5 days/week for $\sim 22$ months showed no gross or histopathological effects of the liver upon necropsy, and there was also no effect of exposure on organ or body weights or hematology (Table 5.12). 
Table 5.12. Comparative Toxicity Parameters for Nitro Compound Surrogates

\begin{tabular}{|c|c|c|c|c|}
\hline & NOEL $^{(a)}$ & $\begin{array}{l}\mathrm{LC}_{50} \\
(\mathrm{ppm})\end{array}$ & $\begin{array}{c}\mathrm{LD}_{50} \\
(\mathrm{mg} / \mathrm{kg})\end{array}$ & Other \\
\hline $\begin{array}{l}\text { Surrogates } \\
\text { 2-methyl-2-nitro-1-propanol }\end{array}$ & & & $844-1480$ & \\
\hline 1-nitropropane & $101 \mathrm{ppm}$ & & & $\begin{array}{l}\text { LC100 }=5000 \mathrm{ppm} / 3 \mathrm{hr} \\
\mathrm{LClo}=714-4622 \mathrm{ppm} / 4.5 \mathrm{hr}\end{array}$ \\
\hline $\begin{array}{l}\text { 2-nitropropane1 } \\
\text { nitroethane }\end{array}$ & $\begin{array}{l}27 \mathrm{ppm} \\
500 \mathrm{ppm}\end{array}$ & 400 & $500-750$ & \\
\hline
\end{tabular}

The endpoint of concern for 2-nitropropane is liver damage. The acute lethality of 2-nitropropane was less than the non-branched 1-nitropropane (See Table 5.12). Rats exposed to 2-nitropropane at $207 \mathrm{ppm}$ for 7 hours/day, 5 days/week, for 6 months developed hepatocellular carcinomas. 2-Nitropropane was also positive for genotoxicity in the Ames test but not in other in vitro genotoxicity studies (i.e., Drosophilia recessive assay). Worker exposures to 20-45 ppm resulted in nausea, vomiting, diarrhea, anorexia, and headache.

2-Nitro-1-propanol is a branched nitro compound with a hydroxyl (-OH) group; no surrogate with these structural features and an OEL proposed by ACGIH or OSHA was identified. Some acute toxicity data for a structural analogue, 2-methyl-2-nitro-1-propanol (CAS\# 76-39-1) was identified (See structure in Table 5.12). 2-Methyl-2-nitro-1-propanol is produced by the reaction of nitroparaffin with formaldehyde and is used in the production of other alkanolamines. The Dow Chemical Company has assessed the acute toxicity of 2-methyl-2-nitro-1-propanol as a part of its High Production Volume Chemical Challenge Test Plan (http://www.epa.gov/chemrtk/nitroalc/c14355tp.pdf) and reports an $\mathrm{LD}_{50}$ of 845$1480 \mathrm{mg} / \mathrm{kg}$ in rats. 2-Methyl-2-nitro-1-propanol was not genotoxic in the Ames assay. The primary toxicological effects seen in laboratory animals following exposures to 2-methyl-2-nitro-1-propanol is eye irritation.

\subsubsection{Conclusion}

In reviewing the available toxicity data bases on nitro compounds with similar structures to 2-nitro1-propanol, 2-nitro-methylpropane, and 1-nitrobutane the most robust data were found for 2-nitropropane and 1-nitropropane, which differ from 2-nitro-methylpropane and 1-nitrobutane by the addition of an extra carbon group, respectively. The ACGIH-recommended TWA-TLVs for 2-nitropropane and 1-nitropropane are 10 and 25 ppm, respectively. An UF of 10 is recommended to extrapolate a recommended OEL for 2 nitro-methylpropane from 2-nitropropane due to the structural differences inherent with the $3^{\circ}$ branching of the sidechain compared to the $2^{\circ}$ branching of the surrogate, which may result in metabolic and/or toxicological differences. Thus, the recommended OEL for 2-nitro-

methylpropane is $\mathbf{0 . 3} \mathbf{~ p p m}$. An UF of 10 is recommended to extrapolate a recommended OEL for 
1-nitrobutane from 1-nitropropane due to the lack of data for 1-nitrobutane. The structural differences between the non-branched compounds are less extreme than for the branched nitro compounds. Thus, the recommended OEL for 1-nitrobutane is $2.5 \mathbf{~ p p m}$.

2-Nitro-1-propanol is a nitro alcohol and therefore structurally different from the surrogates. Several nitro alcohols are used in high quantities in the manufacture of alkanolamines (The Dow Chemical Company 2002). The acute $L D_{50}$ for 2-methyl-2-nitro-1-propanal is higher than the acute $L D_{50}$ for the 2nitropropane and 1-nitropropane surrogates. The recommended OEL for 2-nitro-1-propanol is $0.8 \mathrm{ppm}$ based on the TLV-TWA for 1-nitropropane with an UF of 10 for structural differences and an additional UF of 3 for limited data. 1-Nitropropane was used as the surrogate due to the listed toxicological endpoint of concern for the surrogate, 2-methyl-2-nitro-1-propanal, of sensory irritation, which was more similar to 1-nitropropane than 2-nitropropane. 


\subsection{Heterocyclics}

\subsubsection{Furan (CAS \# 110-00-9)}

An AOEL is proposed for furan based on a comprehensive review of the available toxicology literature. The most sensitive and relevant toxicological endpoint for establishing an AOEL for furan is the observed hepatic billiary tract hyperplasia (13-week sub-chronic study) leading to carcinogenicity following oral administration in rats and mice. Based on the available experimental data, the dose-response for both the hyperplasia and tumor response was very steep (i.e., near maximal response at all dose levels) with no experimentally determined NOEL. The results from the 13-week sub-chronic study were used to extrapolate from an observed $70 \%$ incidence at $4 \mathrm{mg} / \mathrm{kg} /$ day to a dose that would produce a $0.01 \%$ incidence $\left(1 \times 10^{-4}\right)$. The AOEL calculated for furan assumed a human inhalation rate of $10 \mathrm{~m}^{3} /$ day, and $100 \%$ of the inhaled furan was absorbed systemically. The proposed AOEL for furan based on this analysis is $\sim \mathbf{4} \mathbf{~} \mathbf{g} / \mathbf{m}^{3}$ or $\mathbf{1} \mathbf{~ p p b}$.

\subsubsection{Methodology}

To identify and access available toxicity data on furan, a number of Internet data bases including PUBMED, TOXNET, TOMES, EPA-developed IRIS, and one by IARC were searched, and summary toxicity profiles were obtained and primary references identified. These toxicology summaries were then reviewed to identify the most critical data sets that could be used to establish the toxicity profile and to help identify or establish NOEL that could be used to develop the AOEL. Primary references for the most relevant toxicology endpoints were obtained for review.

\subsubsection{Available Guidelines}

A review of the literature indicates that no documented OELs have been established by ACGIH, OSHA, or state regulatory agencies. In reviewing the Registry of Toxic Effects of Chemical Substances, in was noted that Russia had set a short-term exposure limit (STEL) of $0.5 \mathrm{mg} / \mathrm{m}^{3}$ with a skin notation in January 1993; however, specific documentation was unavailable to evaluate how this STEL was established. In 1989, EPA established an oral reference dose (RfD) of $0.001 \mathrm{mg} / \mathrm{kg} /$ day based on sub-chronic studies in mice using a NOEL of $1.4 \mathrm{mg} / \mathrm{kg} /$ day for hepatic lesions (cellular necrosis), with a 1000-fold uncertainty factor applied (10x extrapolation sub-chronic to chronic; 10x interspecies; 10x for added protection sensitive subpopulation). This EPA assessment did not consider the results obtained from NTP chronic bioassay for furan (NTP 1993).

\subsubsection{Toxicology Summary}

Furan is the parent compound for a broad class of structurally related compounds. IARC has classified furan as a possible carcinogen to humans (Group 2B), and it is a known animal carcinogen based on the observed carcinogenic response following oral administration in both mice and rats (NTP 1993). In rats, sub-chronic exposure to furan produced a high incidence of hepatic billiary tract hyperplasia and cholangiofibrosis in both male and females. In rats, chronic furan exposure produced hepatocellular adenomas in both male and female rats, and hepatocellular carcinomas in males. A very high incidence ( $100 \%$ ) of cholangiocarcinomas was also observed in both genders. The incidence of mononuclear-cell leukemia was also increased. Mice, likewise, showed an increased incidence of hepatocellular adenomas 
and carcinomas in both genders. The cholangiocarcinomas showed the steepest dose-response. There is some suggestion that furan is bioactivated to a reactive metabolite that can readily alkylate proteins, resulting in significant cytotoxicity.

\subsubsection{Data Analysis}

The most sensitive and relevant toxicological endpoint for establishing an AOEL for furan is the observed carcinogenicity following oral administration in rats and mice. In assessing the carcinogenic doseresponse, the observed cholangiocarcinoma response in both male and female rats demonstrated the steepest dose-response and represents the most conservative data set for extrapolation. However, the data for this effect lacked an adequate dose-response to fully evaluate. Therefore, the most sensitive and relevant toxicological endpoint for establishing an AOEL for furan is the observed hepatic billiary tract hyperplasia leading to carcinogenicity following oral administration in rats and mice. The non-neoplastic hepatic hyperplasia response in male and female rats following oral sub-chronic exposure to furan is presented in Table 5.13. In assessing the hepatic non-neoplastic dose-response in rats the billiary tract hyperplasia response in the females is the most sensitive, with a $70 \%$ compared to a $40 \%$ response in males at the lowest dose (4 mg/kg/day). In assessing the carcinogenic dose-response, the observed cholangiocarcinoma response in both male and female rats demonstrated the steepest dose-response. The observed tumor incidence is presented in Table 5.14. Both genders demonstrated reasonably comparable responses; females had slightly more tumors at the low dose ( $2 \mathrm{mg} / \mathrm{kg} /$ day) than males (49 vs. 43, respectively).

Table 5.13. Hepatic Non-Neoplastic Response: Number of Animals with Lesion/Total Number of Animals (NTP 1993)

\begin{tabular}{|c|c|c|}
\hline \multirow{2}{*}{$\begin{array}{c}\text { Dose } \\
\text { (mg/kg/day) }\end{array}$} & \multicolumn{2}{|c|}{ Billiary Tract Hyperplasia } \\
\cline { 2 - 3 } & $\begin{array}{c}\text { Male } \\
\text { (w/Hyperplasia/Total) }\end{array}$ & $\begin{array}{c}\text { Female } \\
\text { (w/ Hyperplasia /Total) }\end{array}$ \\
\hline \hline 0 & $0 / 10$ & $0 / 10$ \\
4 & $4 / 10$ & $7 / 10$ \\
8 & $9 / 10$ & $10 / 10$ \\
15 & $10 / 10$ & $10 / 10$ \\
30 & $10 / 10$ & $10 / 10$ \\
60 & $10 / 10$ & $10 / 10$ \\
\hline
\end{tabular}

Table 5.14. Tumor Response: Number of Animals with Tumors/Total Number of Animals (NTP 1993)

\begin{tabular}{||c|c|c||}
\hline \multirow{2}{*}{$\begin{array}{c}\text { Dose } \\
(\mathrm{mg} / \mathrm{kg} / \text { day) }\end{array}$} & \multicolumn{2}{|c|}{ Cholangiocarcinoma } \\
\cline { 2 - 3 } & $\begin{array}{c}\text { Male } \\
\text { (w/Tumors/Total) }\end{array}$ & $\begin{array}{c}\text { Female } \\
\text { (w/Tumors/Total) }\end{array}$ \\
\hline \hline 0 & $0 / 50$ & $0 / 50$ \\
2 & $43 / 50$ & $49 / 50$ \\
4 & $48 / 50$ & $50 / 50$ \\
8 & $49 / 50$ & $49 / 50$ \\
\hline \hline
\end{tabular}


The steep dose-response curves for both the pre-neoplastic and carcinogenic responses are very comparable and consistent with a non-genotoxic mode of carcinogenic action (i.e., tumors are secondary to cytotoxicity). The lack of observable tumors in the control groups also indicates that this response in the Fisher 344 (F344) rat is of a low spontaneous frequency; yet, a near-maximum tumor response is observed in both genders following chronic exposure to the low $2 \mathrm{mg} / \mathrm{kg} /$ day dose level. The lack of a clearly definable NOEL for either the pre-neoplastic or carcinogenic response does makes it difficult to establish with confidence a point of departure for calculating an AOEL for furan.

\subsubsection{Conclusion}

Initial evaluation of the data were done with the hope of applying a BMD calculation to establish an appropriate NOEL as a POD for calculating a cancer slope factor (CSF) for furan. Benchmark dose software developed by EPA was used (http://cfpub.epa.gov/ncea/cfm/recordisplay.cfm?deid=20167). This software was developed as a tool to facilitate the application of BMD methods to EPA hazardous pollutant risk assessments. However, due to the lack of a clear dose-response for the chronic bioassay (Table 5.14) there was some concern about using a BMD approach since there was substantial uncertainty concerning the calculated POD. A second approach attempted to conduct a similar evaluation of the dose-response for the non-neoplastic hepatic response (Table 5.13); however, these results likewise demonstrated a poor dose-response over the range evaluated. Hence, it was decided that since it was not satisfying to apply the BMD model to either the 13-week or chronic experimental data, a simple linear extrapolation approach would be utilized.

This extrapolation was based on the observed dose-response in female rats for billiary tract hyperplasia, where a $70 \%$ response (7 out of 10 animals) was observed following 13-weeks of oral exposure to $4 \mathrm{mg} / \mathrm{kg} /$ day. Based on this dose-response ratio, it was possible to calculate the dose associated with a $0.01 \%$ response as noted in equation 5.1 .

$$
\operatorname{dose}(\mathrm{mg} / \mathrm{kg} / \text { day })=\frac{(0.01 \% * 4 \mathrm{mg} / \mathrm{kg} / \text { day })}{70 \%}
$$

The calculated oral dose for a $0.01 \%$ response $(1$ x 10-4) was 5.71 x $10-4 \mathrm{mg} / \mathrm{kg} / \mathrm{day}$ or $0.571 \mu \mathrm{g} / \mathrm{kg} / \mathrm{day}$. Assuming a human weighed $65 \mathrm{~kg}$, the daily oral equivalent dose would be $\sim 37 \mu \mathrm{g} /$ day. To convert the oral dose $(\mu \mathrm{g} / \mathrm{kg})$ to an equivalent inhalation dose $\left(\mu \mathrm{g} / \mathrm{m}^{3}\right)$, it was assumed that an average human would inhale $\sim 10 \mathrm{~m}^{3} /$ day of air, using equation 2 .

$$
\mu g / m 3=\frac{\mu g / \text { day }}{10 m 3 / \text { day }}
$$

These calculations also assumed that $100 \%$ of the inhaled furan would be absorbed systemically through the respiratory system. Using these assumptions, the proposed AOEL for furan based on this analysis is $\sim 4 \mathbf{~} \mathrm{g} / \mathbf{m}^{3}$ or $1 \mathbf{~ p p b}$. An AOEL of $1 \mathrm{ppb}$ inhalation (equivalent to $\sim 0.5 \mu \mathrm{g} / \mathrm{kg} / \mathrm{day}$ oral) is reasonably comparable to the $1 \mu \mathrm{g} / \mathrm{kg} /$ day proposed as an oral RfD for furan. 


\subsubsection{Furan Family: Substituted Furans 2-methylfuran (CAS\# 534-22-5), 2-5- dihydrofuran and 2-propylfuran (CAS\# 4229-91-8) and Others}

For the broad class of furan-based chemicals, there is strong experimental evidence suggesting that observed toxicity in several target organs, including the lung and liver, involves the formation of a chemically reactive metabolite. The weight of evidence suggests there is a high probability that a broad range of chemicals containing the unsaturated furan nucleus will be metabolized in animals and humans to a highly reactive and toxic furan epoxide metabolite. For these reactive furans, toxicity is observed in organ systems like the liver and lung, which are capable of CYP450 metabolic activation. In the absence of any substantial toxicity data to fully evaluate the range of substituted furans, the most rational and defensible approach is to set an AOEL for all unsubstituted furans based upon the results obtained with furan itself. Therefore, the proposed AOEL for the substituted furans based on this analysis is $\sim \mathbf{4} \mathbf{\mu g} / \mathbf{m}^{\mathbf{3}}$ or 1 ppb.

\subsubsection{Toxicology Summary}

The furans are a class of chemicals that have as their core a common 5-member, oxygen-containing, unsaturated heterocyclic ring. A number of chemicals that contain the furan heterocyclic ring structure have been identified as occurring naturally or being used as industrial intermediates. For the broad class of furan-based chemicals, there is strong experimental evidence suggesting that observed toxicity in several target organs, including the lung and liver, involves the formation of a chemically reactive metabolite. Boyd (1980) has published several reviews on the role of metabolic activation and chemicalinduced lung injury and has reviewed a number of furan-based derivatives including furan, 2methylfuran, 3-methylfuran, and other substituted furans such as 4-ipomeanol. The review provides strong evidence that CYP450 metabolism in microsomes prepared from both the liver and lung of rats and humans appears to mediate the in vitro and in vivo formation of reactive chemical species that were shown to alkylate microsomal proteins. Through the use of metabolic inhibitors, it has also been shown that in the absence of metabolism, there was insufficient reactivity of the parent furan to alkylate tissue proteins. Additional support for the important role of metabolism was gleaned by showing that alkylation was not observed in non-metabolically active tissues (e.g., blood, heart, skeletal muscle) following exposure to 4-ipomeanol.

Important to the assessment of the potential toxicological significance for the broad range of furan chemistry was the observation that when the furan ring of 4-ipomeanol was replaced by phenyl or methyl, there was no evidence of covalent binding in the rat lung or liver microsomes in vitro (Boyd et al. 1978a). In addition, neither of these analogs became covalently bound to the rat lung or liver in vivo, and they were relatively non-toxic at doses $>800 \mathrm{mg} / \mathrm{kg}$ (Boyd and Burka 1978). As noted by Boyd (1980), data from several other laboratories have suggested that a highly reactive and toxic furan epoxide metabolite can be formed due to the metabolism of the unsaturated furan ring. Evidence for this pathway was shown with the formation of an epoxide of the dihydrofuran moiety of aflatoxin B1 and the metabolic activation of the furan ring of the diuretic, furosemide (Swenson et al. 1974; Mitchell et al. 1976; McMurtry and Mitchell 1977). The importance of the unsaturated furan ring as a prerequisite for toxicity was demonstrated by Wirth et al. (1976), who reported that a furosemide analog that had a fully saturated tetrahydrofuran group could not be metabolized to a reactive epoxide and did not become covalently bound to liver microsomes. There is evidence that both 3-methy and 2-methylfuran are also converted by CYP450 metabolism to highly reactive metabolites that are covalently bound to protein (Ravindranath et al. 1986; Boyd et al. 1978b). Boyd (1980) noted that a number of other furan derivatives, including 
1-ipomeanol, 1,4-ipomeanol, ipomeanine, 2-methylfuran, and 2-furamide, as well as furan have been reported to cause pulmonary and/or hepatic necrosis in mice. In all cases, each of these chemicals contained an unsaturated furan ring. Further, while studies have not been conducted with all these substituted furans to determine whether they are metabolized to reactive metabolites, it is reasonable to speculate that they have the potential for such metabolism.

The weight of evidence suggests that a broad range of chemicals containing the unsaturated furan nucleus have a high probability to be metabolized in animals and humans to a highly reactive and toxic furan epoxide metabolite. For these reactive furans, toxicity is observed in organ systems like the liver and lung, which are capable of CYP450 metabolic activation.

\subsubsection{Conclusion}

In reviewing the available toxicity data bases on furan and substituted furans, the most robust data were found for the parent furan and includes a 2-year oral gavage bioassay conducted in rats and mice (NTP 1993). In rats, sub-chronic exposure to furan produced a high incidence of hepatic billiary tract hyperplasia and cholangiofibrosis in both males and females, and chronic furan exposure produced hepatocellular adenomas in both males and females, and hepatocellular carcinomas in males. A very high incidence ( $100 \%$ ) of cholangiocarcinomas was also observed in both genders. There is some suggestion that furan is bioactivated to a reactive metabolite that can readily alkylate proteins, resulting in significant cytotoxicity. (See Section 5.11.1). Hence, there is some suggestion that furan's mode of carcinogenic action is non-genotoxic (i.e., tumors are secondary to cytotoxicity). In the absence of any substantial toxicity data to fully evaluate the range of substituted furans, the most rationale and defensible approach is to set the AOEL for all unsubstituted furans based upon the results obtained with furan itself. When assessing the potential exposures of workers to furan, the ambient furan concentrations should be taken into account. As additional and appropriate new data become available for substituted furans, it would be reasonable to reassess the appropriateness of basing that chemical's AOEL upon furan.

\subsubsection{2,4-Dimethylpyridine (CAS\# 108-47-4)}

An AOEL is proposed for 2,4-dimethylpyridine. Toxicological data for 2,4-dimethylpyridine are minimal, but it is structurally similar to pyridine, 3-picoline, and 5-ethyl-2-picoline, for which more data are available. 2,4-Dimethylpyridine is a food additive recognized as having "no safety concern" by the WHO. Repeated exposure to high concentrations of a mixture of pyridine derivatives can cause central nervous system and gastrointestinal disturbances, facial paralysis, ataxia, and anisocoria (unequal pupils). A Temporary Exposure Limit (TEEL) of 0.5 ppm has been recommended by DOE for 2,4dimethylpyridine, ACGIH has recommended TLVs of 1 ppm for pyridine, and the AIHA has recommended WEELs of 2 ppm for 2-methylpyridine, 3-methylpyridine, and 4-methylpyridine. The

proposed AOEL for 2,4-Dimethylpyridine is $0.5 \mathbf{~ p p m}$, based on the DOE TEEL-1 and consistent with ACGIH TLVs and AIHA WEELs for closely related compounds.

\subsubsection{Methodology}

To identify and access available toxicity data on 2,4-dimethylpyridine, a number of Internet data bases including PUBMED, TOXNET, TOMES, EPA-IRIS, and the IARC were searched, and summary toxicity profiles were obtained, and primary references were identified. These toxicology summaries were then 
reviewed to identify the most critical data sets that could be used to establish the toxicity profile and develop the AOEL. Primary references for the most relevant toxicology endpoints were obtained for review.

\subsubsection{Available Guidelines}

No OEL for 2,4-dimethylpyridine has been proposed by the OSHA or ACGIH. A TLV of 1 ppm has been proposed by the ACGIH for pyridine, a structurally similar compound. The AIHA has proposed WEELs of 2 ppm for 2-methylpyridine, 3-methylpyridine, and 4-methylpyridine.

Other available guidelines include the DOE Subcommittee on Consequence Assessment and Protective Actions (SCAPA) TEELs. The TEELs are designed to serve as temporary guidance for chemicals needing guidelines for hazard assessment and safety analysis for DOE personnel and general public adjacent to DOE sites. These TEELs are assigned to chemicals on a temporary basis until they can be replaced with AEGLs or emergency response planning guidelines, which require additional documentation and assessment. The protocol used to consider available OEL and toxicological data in the development of TEELs has been published (Craig et al. 2000). Four levels of TEELs (TEEL-0, TEEL-1, TEEL-2, TEEL-3) are calculated as fractions based on set criteria. TEEL-1 is defined as "the maximum airborne concentration below which it is believed that nearly all individuals could be exposed without experiencing other than mild transient adverse health effects or perceiving a clearly defined, objectionable odor.” When a PEL-STEL or TLV-STEL is available, TEEL-1 should be lower (more protective) than the STEL. Although not specifically stated, TEEL-1 is usually based on a 1-hour TWA. The DOE SCAPA-recommended TEEL-1 for 2,4-dimethylpyridine is $0.5 \mathrm{ppm}$. TEEL-3, defined as "the maximum airborne concentration below which it is believed that nearly all individuals could be exposed without experiencing or developing life-threatening health effects,” is $20 \mathrm{ppm}$.

\subsubsection{Toxicology Summary}

Repeated industrial exposure to mixtures of pyridine derivatives, which include 2,4-dimethylpyridine, have resulted in central nervous system and gastrointestinal disturbances, facial paralysis, ataxia, and anisocoria. Short-term exposures to high levels of pyridine mixes can cause a burning sensation, coughing, dizziness, drowsiness, headache, labored breathing, nausea and sore throat. The $\mathrm{LD}_{50}$ for 2,4-dimethylpyridine in rats was $200 \mathrm{mg} / \mathrm{kg}$. The WHO has commented that there is no safety concern with 2,4-dimethylpyridine as a food additive (WHO 2005).

Exposures to the surrogate, pyridine, result in irritation. Repeated exposures can also result in kidney and liver damage. The acute $\mathrm{LD}_{50}$ for pyridine in rats and mice ranges from 900-1500 mg/kg (ACGIH 2004). The NOEL in rats and mice in 28-day drinking water exposures was 7-15 mg/kg/day. Pyridine is not mutagenic in bacteria or $\mathrm{CHO}$ cells. Human exposure assessment in a chemical plant indicated that repeated exposures to 6-12 ppm resulted in headache, temporary vertigo, nervousness, and sleeplessness. The recommended ACGIH TLV for pyridine is $1 \mathrm{ppm}$ based on minimizing the potential for nasal irritation and liver and kidney toxicity.

2,4-Dimethylpyridine is a substituted pyridine, with slightly higher acute toxicity than pyridine; therefore, a substituted pyridine surrogate was sought to assess the potential for higher toxicity in substituted pyridines. 5-Ethyl-2-picoline was the closest surrogate with sufficient toxicity data identified. The NOEL for 5-ethyl-2-picoline was $30 \mathrm{mg} / \mathrm{kg} /$ day in a 28-day oral study in mice. 


\subsubsection{Data Analysis}

2,4-Dimethylpyridine and mixed pyridine exposures occur in industrial settings. The most data were available for the unsubstituted pyridine. The ACGIH first assigned an OEL of $10 \mathrm{ppm}$ for pyridine in 1956; this value has been changed twice and is $1 \mathrm{ppm}$ as of 2004. A comparison of acute toxicity between pyridine, methylpyridine, and 5-ethyl-2-picoline suggests that the substitutions do not result in increased toxicity. The primary endpoint of concern for 5-ethyl-2-picoline is likely due to its corrosive properties and therefore nasal irritation. The AOEL of $1 \mathrm{ppm}$ for pyridine, and the TEEL-1 for 2,4-dimethylpyridine of 0.5 ppm are similar.

\subsubsection{Conclusion}

Based on the comparison of acute and subchronic effects of 5-ethyl-2-picoline, pyridine, and 2,4-dimethylpyridine in laboratory animals and the effects from human exposures to pyridine mixtures, it is proposed that the DOE TEEL-1 of $0.5 \mathrm{ppm}$ be adopted as the AOEL for 2,4-dimethylpyridine. TEEL-1 is similar to the ACGIH TLV of 1 ppm for pyridine and the AIHA WEEL of 2 ppm for 2-methylpyridine, 3-methylpyridine, and 4-methylpyridine. Based on the WHO's recognition of 2,4-dimethylpyridine as having "no safety concern" for oral exposures, this is a very conservative TLV, and TEEL-1 may be based on route-dependent irritation. As additional new data become available for the 2,4-dimethylpyridine, it would be reasonable to reassess the appropriateness of basing the AOEL upon the DOE SCAPA TEEL-1.

\subsubsection{1,2,3,6-Tetrahydropyridine (CAS\# 694-05-3)}

An AOEL is proposed for 1,2,3,6-tetrahydropyridine. No toxicological data were found for 1,2,3,6-tetrahydropyridine but it is structurally similar to both pyridine or piperidine, for which more data are available. Repeated exposures to high concentrations of a mixture of pyridine derivatives can cause central nervous system and gastrointestinal disturbances, facial paralysis, ataxia, and anisocoria. ACGIH has recommended TLVs of $1 \mathrm{ppm}$ for pyridine, and the AIHA has recommended WEELs of $2 \mathrm{ppm}$ for 2-methylpyridine, 3-methylpyridine, and 4-methylpyridine. Piperidines are used as nonsedating antihistamines since they do not readily cross the blood-brain barrier. The AIHA has recommended a WEEL of 1 ppm for piperidine. The proposed AOEL for 1,2,3,6-tetrahydropyridine is $0.1 \mathrm{ppm}$ based on the AIHA WEEL for surrogate piperidine with an UF of 10 for the lack of data and structural differences. This proposed OEL is also consistent with the ACGIH TLVs of 1 ppm for pyridine and 0.1 for the piperidine derivative, phenylhydrazine.

\subsubsection{Methodology}

To identify and access available toxicity data on 1,2,3,6-tetrahydropyridine, a number of Internet data bases, including PUBMED, TOXNET, TOMES, EPA-IRIS, and the IARC, were searched and summary toxicity profiles were obtained, including the identification of primary references. These toxicology summaries were then reviewed to identify the most critical data sets that could be used to establish the toxicity profile and used for the development of the AOEL. Primary references for the most relevant toxicology endpoints were obtained for review. 


\subsubsection{Available Guidelines}

No OEL for 1,2,3,6-tetrahydropyridine has been proposed by the OSHA or ACGIH. A TLV of 1 ppm has been proposed by the ACGIH for pyridine and $0.1 \mathrm{ppm}$ for phenylhydrazine, which are structurally similar compounds. The AIHA has proposed WEELs of 2 ppm for 2-methylpyridine, 3-methylpyridine, and 4-methylpyridine. The structurally similar piperidine has an AIHA-recommended WEEL of 1 ppm with a skin notation.

\subsubsection{Toxicology Summary}

Repeated industrial exposure to mixtures of pyridine derivatives have resulted in central nervous system and gastrointestinal disturbances, facial paralysis, ataxia, and anisocoria (unequal pupils). Short-term exposures to high levels of pyridine mixes can cause a burning sensation, coughing, dizziness, drowsiness, headache, labored breathing, nausea and sore throat. Piperidines are nasal and dermal irritants. 1,2,3,6-Tetrahydropyridine is also explosive.

Exposures to the surrogate, pyridine, result in irritation. Repeated exposures can also result in kidney and liver damage. The acute $\mathrm{LD}_{50}$ for pyridine in rats and mice ranges from 900-1500 mg/kg (ACGIH 2004). The NOEL in rats and mice in 28-day drinking water exposures was $7-15 \mathrm{mg} / \mathrm{kg} / \mathrm{day}$. Pyridine is not mutagenic in bacteria or $\mathrm{CHO}$ cells. Human exposure assessment in a chemical plant indicated that repeated exposures to 6-12 ppm resulted in headache, temporary vertigo, nervousness, and sleeplessness. The recommended ACHGIH TLV for pyridine is $1 \mathrm{ppm}$ based on minimizing the potential for nasal irritation and liver and kidney toxicity.

\subsubsection{Data Analysis}

The most data were available for the unsubstituted pyridine. The ACGIH first assigned an OEL of $10 \mathrm{ppm}$ for pyridine in 1956; this value has been changed twice and is $1 \mathrm{ppm}$ as of 2004 . The primary endpoint of concern is likely due to corrosive properties and therefore nasal irritation. The AOEL of 1 ppm for pyridine, and the WEELs for other pyridines of 2 ppm are similar.

\subsubsection{Conclusion}

Based on the lack of toxicological data for 1,2,3,6-tetrahydropyridine, it is proposed that the AIHA WEEL of 1 ppm for piperidine be used with an UF of 10 to propose an OEL for 1,2,3,6-

tetrahydropyridine of $\mathbf{0 . 1} \mathbf{~ p p m}$. As additional new data become available for the 1,2,3,6tetrahydropyridine, it would be reasonable to reassess the appropriateness of basing the AOEL upon the WEEL for substituted pyridines. 


\subsection{Chlorinated Compounds}

\subsubsection{Polychlorinated Biphenyls (PCBs)}

An AOEL is proposed for a family of polychlorinated biphenyls (PCBs). There are 209 different congeners of PCBs that vary in the extent and position of chlorination on the aromatic rings. They are not naturally occurring and primarily come from industrial manufacture of such items as capacitors and transformers. They persist in the environment and fat stores in the body. Exposures to high concentrations can lead to skin lesions (rashes and acne). High chronic concentrations can lead to liver damage, anemia, and potentially to adverse reproductive effects. The toxic potential of PCBs is dependent upon the extent and location of chlorine substation on the aromatic rings. The PCB congeners found in the tank waste headspace are much more similar to the PCBs with lower percentages of chlorine, and the proposed AOEL for these PCBs is $0.03 \mathrm{mg} / \mathrm{m}^{3}(\sim 0.003 \mathrm{ppm})$ based on the ACGIH TLV for $42 \%$ chlorinated PCBs with an UF of 3 to account for uncertainty associated with the exact mixture of PCBs in the tank and the potential for chloracne.

\subsubsection{Methodology}

To identify and access available toxicity data on polychlorinated biphenols, a number of Internet data bases, including PUBMED, TOXNET, TOMES, EPA-IRIS, and IARC were searched, and summary toxicity profiles were obtained and primary references identified. These toxicology summaries were then reviewed to identify the most critical data sets that could be used to establish the toxicity profile and develop the AOEL. Primary references for the most relevant toxicology endpoints were obtained for review.

\subsubsection{Available Guidelines}

ACGIH has proposed guidelines for PCBs with $42 \%$ (Aroclor $1242^{\circledR}$ ) or $54 \%$ (Aroclor $1254^{\circledR}$ ) chlorine. Aroclor 1242 and 1254 are mixtures of different congeners of chlorobiphenyl. The environmental fate, potential carcinogenicity, and toxicity of PCBs is dependant upon the degree of chlorination (ACGIH 2001c; ACGIH 2001d; Chana et al. 2002). The ACGIH assigned an A3 - Confirmed Animal Carcinogen with Unknown Relevance to Humans notation for the mixture of PCBs containing 54\% chlorine, but stated there are insufficient data to assign cancer or skin notations for Aroclor 1242 (42\% chlorine).

Other available guidelines include the OSHA PEL, which matches the ACGIH TLV of 1 or $0.5 \mathrm{mg} / \mathrm{m}^{3}$ depending on the level of chlorination; the NIOSH REL, which is $1 \mu \mathrm{g} / \mathrm{m}^{3}$; and the NIOSH IDLH, which is $5 \mathrm{mg} / \mathrm{m}^{3}$. The IDLH is based on acute inhalation toxicity data of PCBs in humans and animals and is not specific for the chlorine content. The $1 \mu \mathrm{g} / \mathrm{m}^{3}$ NIOSH REL is based on potential carcinogenicity and is not specific for chlorine content. The IARC has given PCBs a 2A Carcinogens status irrespective of the amount of chlorine substitution.

The EPA has calculated CSFs for different mixtures of PCBs based on their associated risks and persistence. For PCBs with the lowest risk and persistence (congeners with more than four chlorines on less than one-half of the total PCBs in the mixture, which includes the PCBs in the tank waste headspace) the upper-bound CSF is 0.07 per $\mathrm{mg} / \mathrm{kg} / \mathrm{day}$, and the central estimate CSF is $0.04 \mathrm{per} \mathrm{mg} / \mathrm{kg} / \mathrm{day}$ ). 
Applying the EPA slope factors for upper and central estimate slope factors for PCBs of the type found in the tank waste headspace, estimated OELs are 26 and $45 \mu \mathrm{g} / \mathrm{m}^{3}$, respectively (for calculation methodology, see Section 5.11.1).

\subsubsection{Conclusion}

The use of the ACGIH TLV-TWA of $1 \mathrm{mg} / \mathrm{m}^{3}$ based on exposures to $42 \%$ chlorine PCB to propose an AOEL for the tank waste PCB headspace content results in a conservative guideline (Table 5.16). The PCB congeners in this population are generally predicted to have relatively low toxicities based on the number and location of chlorine substitutions (see Table 5.16), and the percentage of chlorine in the tank waste headspace will be lower than the $42 \%$ in the ACGIH assessment. The proposed AOEL for the PCBs in the tank waste headspace is therefore $\mathbf{0 . 0 3} \mathbf{~ m g} / \mathbf{m}^{3}$ and includes an UF of 30 to account for

Table 5.16. $\quad$ PCBs in Tank Waste

\begin{tabular}{|c|c|c|c|c|c|c|}
\hline Tank Name & Chemical Name & $\begin{array}{c}\text { Molecular } \\
\text { Weight }\end{array}$ & Chemical Id & Conc. $\left(\mathrm{mg} / \mathrm{m}^{3}\right)$ & $\begin{array}{l}\text { Conc. } \\
(\mathrm{PPM})\end{array}$ & $\begin{array}{c}\mathrm{TLV} / \mathrm{Max} \\
\mathrm{HS}^{(\mathrm{a})} \\
\end{array}$ \\
\hline 241-AX-102 & 1,1`-Biphenyl, 2-chloro- & 188.7 & $2051-60-7$ & 0.0063 & 0.0008 & 158 \\
\hline 241-B-103 & 1,1`-Biphenyl, 3-chloro- & 188.7 & 2051-61-8 & 0.033 & 0.0043 & 30 \\
\hline 241-BY-103 & 1,1`-Biphenyl, 2-chloro- & 188.7 & 2051-60-7 & 0.0078 & 0.0010 & 128 \\
\hline 241-BY-104 & $\begin{array}{l}\text { 1,1`-Biphenyl, 2,6-dichloro } \\
\text { and siloxane }\end{array}$ & 223.1 & MRHUSI0-01 & 0.0092 & 0.0010 & 109 \\
\hline 241-BY-112 & 1,1`-Biphenyl, 2,2`-dichloro- & 223.1 & 13029-08-8 & 0.0057 & 0.0006 & 176 \\
\hline 241-S-105 & Chloro-1,1`-Biphenyl & 188.7 & URH000-03 & 0.023 & 0.0030 & 44 \\
\hline $241-S-111$ & 1,1`-Biphenyl, 2-chloro- & 188.7 & 2051-60-7 & 0.0016 & 0.0002 & 641 \\
\hline 241-TX-105 & $\begin{array}{l}\text { 1,1`-Biphenyl, 2,3,4`,6- } \\
\text { tetrachloro- }\end{array}$ & 292.0 & $52663-58-8$ & 0.0023 & 0.0002 & 442 \\
\hline \multicolumn{7}{|c|}{ Tanks with More than 1 PCB Detected } \\
\hline 241-TX-118 & 1,1`-Biphenyl, 3,3`-dichloro- & 223.1 & $2050-67-1$ & 0.0069 & 0.0008 & \\
\hline \multirow[t]{2}{*}{ 241-TX-118 } & 1,1`-Biphenyl, 3-chloro- & 188.7 & 2051-61-8 & 0.0064 & 0.0008 & \\
\hline & & & Total & 0.013 & & 75 \\
\hline 241-TY-101 & $\begin{array}{l}\text { 1,1`-Biphenyl, 2,3,3`,5`- } \\
\text { tetrachloro- }\end{array}$ & 292.0 & $41464-49-7$ & 0.0045 & 0.0004 & \\
\hline \multirow[t]{2}{*}{ 241-TY-103 } & 1,1`-Biphenyl, 2-chloro- & 188.7 & 2051-60-7 & 0.035 & 0.0045 & \\
\hline & & & Total & 0.039 & & 25 \\
\hline 241-TY-104 & 1,1`-Biphenyl, 2,2`-dichloro- & 223.1 & 13029-08-8 & 0.0011 & 0.0001 & \\
\hline 241-TY-104 & 1,1`-Biphenyl, 2,3-dichloro- & 223.1 & $16605-91-7$ & 0.0010 & 0.0001 & \\
\hline 241-TY-104 & $\begin{array}{l}\text { 1,1`-Biphenyl, 2,4`,5- } \\
\text { trichloro- }\end{array}$ & 257.5 & $16606-02-3$ & 0.0035 & 0.0003 & \\
\hline 241-TY-104 & 1,1`-Biphenyl, 4,4`-dichloro- & 223.1 & $2050-68-2$ & 0.0037 & 0.0004 & \\
\hline 241-TY-104 & 1,1`-Biphenyl, 2-chloro- & 188.7 & 2051-60-7 & 0.0037 & 0.0005 & \\
\hline 241-TY-104 & 1,1`-Biphenyl, 4-chloro- & 188.7 & 2051-62-9 & 0.0026 & 0.0003 & \\
\hline 241-TY-104 & 1,1`-Biphenyl, trichloro- & 257.5 & 25323-68-6 & 0.0032 & 0.0003 & \\
\hline 241-TY-104 & 1,1`-Biphenyl, 2,6-dichloro- & 223.1 & $33146-45-1$ & 0.0032 & 0.0004 & \\
\hline 241-TY-104 & 1,1`-Biphenyl, 2,5-dichloro- & 223.1 & $34883-39-1$ & 0.0009 & 0.0001 & \\
\hline 241-TY-104 & $\begin{array}{l}\text { 1,1`-Biphenyl, 2,3,3`,5`- } \\
\text { tetrachloro- }\end{array}$ & 292.0 & $41464-49-7$ & 0.0026 & 0.0002 & \\
\hline 241-TY-104 & $\begin{array}{l}\text { 1,1`-Biphenyl, 2,3,4`,6- } \\
\text { tetrachloro- }\end{array}$ & 292.0 & 52663-58-8 & 0.0006 & 0.00005 & \\
\hline \multicolumn{7}{|c|}{$\begin{array}{l}\text { (a) The total concentration of PCBs in the Headspace }\left(\mathrm{mg} / \mathrm{m}^{3} \text { ) compared to the ACGIH TLV of } 1 \mathrm{mg} / \mathrm{m}^{3} \text {. Only } 3 \text { tanks had }\right. \\
\text { headspace concentrations with a margin of exposure less than } 50 \text { (in bold). }\end{array}$} \\
\hline
\end{tabular}


uncertainty associated with the precise composition of the tank waste PCBs and to protect against chloracne. In addition, $0.03 \mathrm{mg} / \mathrm{m}^{3}$ also approximates the OEL achieved using the EPA cancer slope factor calculation. As additional new data become available for these PCBs, it would be reasonable to reassess the appropriateness of basing the AOEL upon Aroclor 1242. 


\subsection{Summary of Proposed AOELs}

The AOEL development process described in Sections 2.0 - 4.0 was applied to 57 tank headspace chemicals. Proposed AOELs for four chemicals were based on OELs established by U.S. or foreign government agencies. These are listed in Table 6.1, along with the source of the established OEL. For the remaining 53 chemicals without established OELs, epidemiological and toxicological information were reviewed to identify potential hazards, select critical effects, and estimate dose-response to determine exposure levels expected to present no health risks. When information on the chemical itself was insufficient to develop an AOEL, the proposed AOEL was based on one or more structurally related chemicals (surrogates) for which sufficient data were available. Surrogates with close structural and pharmacological activity with established OELs (ACGIH or OSHA) were preferentially selected. Of these 53 chemicals, 47 were assigned proposed AOELs and six were determined to not warrant complete AOEL development, based on expected low potential for adverse health effects. Table 6.2 lists the 47 proposed AOELs, and Table 6.3 lists the six chemicals for which no AOEL was deemed necessary.

Table 6.1. $\quad$ Proposed AOELs for Chemicals with Limits from NIOSH, AIHA or MAK

\begin{tabular}{||l|c|c|l||}
\hline \multicolumn{1}{|c|}{ Chemical } & $\begin{array}{c}\text { CAS } \\
\text { Number }\end{array}$ & $\begin{array}{c}\text { Proposed } \\
\text { AOEL }(\mathrm{ppm})\end{array}$ & $\begin{array}{c}\text { OEL } \\
\text { Source }\end{array}$ \\
\hline \hline Propanenitrile & $107-12-0$ & 6 & NIOSH REL \\
\hline 2-Ethyl-1-hexanol & $104-76-7$ & 20 & MAK \\
\hline Butanal & $123-72-8$ & 25 & AIHA WEEL \\
\hline Butanenitrile & $109-74-0$ & 8 & NIOSH REL \\
\hline
\end{tabular}

Table 6.2. Summary of Proposed AOELs

\begin{tabular}{|c|c|c|}
\hline Chemical & CAS Number & $\begin{array}{l}\text { Proposed AOEL } \\
\text { (ppm) }\end{array}$ \\
\hline \multicolumn{3}{|l|}{ HALOCARBONS } \\
\hline 2-Fluoropropene & $1184-60-7$ & 0.1 \\
\hline \multicolumn{3}{|l|}{ ALCOHOLS } \\
\hline Cyclopentanol & $96-41-3$ & 5 \\
\hline \multicolumn{3}{|l|}{ ETHERS } \\
\hline 1-Methoxybutane & $628-28-4$ & 17 \\
\hline \multicolumn{3}{|l|}{ ALDEHYDES } \\
\hline 2-Methylbut-2-enal & 1115-11-3 & 0.03 \\
\hline 2-Ethylhex-2-enal & $645-62-5$ & 0.1 \\
\hline \multicolumn{3}{|l|}{ KETONES } \\
\hline 4-Methyl-2-hexanone & $105-42-0$ & 0.5 \\
\hline 3-Hexanone & $589-38-8$ & 67 \\
\hline 6-Methyl-2-heptanone & 928-68-7 & 8 \\
\hline 2-Nonanone & $821-55-6$ & 17 \\
\hline 3-Dodecanone & $1534-27-6$ & 17 \\
\hline 2-Tridecanone & $593-08-8$ & 17 \\
\hline 3-Tridecanone & $1534-26-5$ & 17 \\
\hline 5-Methyl-2-(1-methylethenyl) cyclohexanone & $89-82-7$ & 2.5 \\
\hline
\end{tabular}


Table 6.2. (contd)

\begin{tabular}{|c|c|c|}
\hline Chemical & CAS Number & $\begin{array}{l}\text { Proposed AOEL } \\
\text { (ppm) }\end{array}$ \\
\hline 4,7,7-Trimethyl bicyclo[4.1.0]heptan-3-one & $4176-04-9$ & 0.7 \\
\hline 3-Methyl-3-buten-2-one & $814-78-8$ & 0.02 \\
\hline \multicolumn{3}{|l|}{ ESTERS } \\
\hline Dibutyl butylphosphonate & $78-46-6$ & 0.02 \\
\hline \multicolumn{3}{|l|}{ NITRILES } \\
\hline 2-Methylene butanenitrile & $1647-11-6$ & 0.3 \\
\hline Pentanenitrile & $110-59-8$ & 6 \\
\hline Hexanenitrile & $628-73-9$ & 6 \\
\hline Heptanenitrile & $629-08-3$ & 6 \\
\hline Octanenitrile & $124-12-9$ & 6 \\
\hline Nonanenitrile & $2243-27-8$ & 6 \\
\hline Decanenitrile & $1975-78-6$ & 6 \\
\hline 3-Butenenitrile & $109-75-1$ & 1 \\
\hline 2,4-Pentadienenitrile & $1615-70-9$ & 0.3 \\
\hline \multicolumn{3}{|l|}{ AMINES \& AMIDES } \\
\hline N-Methylaziridine & $1072-44-2$ & 0.05 \\
\hline \multicolumn{3}{|l|}{ NITRITES \& NITRATES } \\
\hline Methyl nitrite & $624-91-9$ & 0.1 \\
\hline Ethyl nitrite & 109955 & 0.1 \\
\hline Butyl nitrite & $544-16-1$ & 0.1 \\
\hline Methyl nitrate & $598-58-3$ & 8 \\
\hline Ethyl nitrate & $625-58-1$ & 8 \\
\hline Butyl nitrate & $928-45-0$ & 8 \\
\hline 1,3-Propanediol, dinitrate & $3457-90-7$ & 0.05 \\
\hline 1,4-Butanediol, dinitrate & $3457-91-8$ & 0.05 \\
\hline 1,5-Pentanediol, dinitrate & $3457-92-9$ & 0.05 \\
\hline 1,2,3-Propanetriol, 1,3-dinitrate & $623-87-0$ & 0.05 \\
\hline 1,2,3-Propanetriol, 1-nitrate & $624-43-1$ & 8 \\
\hline \multicolumn{3}{|l|}{ NITRO COMPOUNDS } \\
\hline 2-Nitro-1-propanol & 2902-96-7 & 0.8 \\
\hline 2-Nitro-2-methylpropane & $594-70-7$ & 0.3 \\
\hline 1-Nitrobutane & $627-05-4$ & 2.5 \\
\hline \multicolumn{3}{|l|}{ HETEROCYCLICS } \\
\hline Furan & $110-00-9$ & 0.001 \\
\hline 2-Methylfuran & $534-22-5$ & 0.001 \\
\hline 2-Propylfuran & 4229-91-8 & 0.001 \\
\hline 2-Ethyl-5-methylfuran & $1703-52-2$ & 0.001 \\
\hline 2,5-Dihydrofuran & $1708-29-8$ & 0.001 \\
\hline alpha-Propylfuranacetaldehyde & $31681-26-2$ & 0.001 \\
\hline 2,4-Dimethylpyridine & $108-47-4$ & 0.5 \\
\hline
\end{tabular}


Table 6.3. Chemicals For Which No AOEL is Recommended

\begin{tabular}{||l|c|}
\hline \multicolumn{1}{|c|}{ Chemical } & CAS Number \\
\hline 1-Hexadecanol & $36653-82-4$ \\
\hline 1-Octadecanol & $112-92-5$ \\
\hline 1-Methylethyl tetradecanoate & $110-27-0$ \\
\hline Butyl tetradecanoate & $110-36-1$ \\
\hline 1-Methylethyl hexadecanoate & $142-91-6$ \\
\hline Acetamide & $60-35-5$ \\
\hline
\end{tabular}




\subsection{References}

Abou-Donia, MB, DM Lapadula, and G Campbell. 1985. “The Synergism of N-Hexane-Induced Neurotoxicity by Methyl Isobutyl Ketone Following Subchronic (90 Days) Inhalation in Hens: Induction of Hepatic Microsomal Cytochrome P-450.” Toxicol. Appl. Pharmacol., 81:1-16.

ACGIH. 2005a. ACGIH Operations Manual. Threshold Limit Values For Chemical Substance Committee. American Conference of Governmental Industrial Hygienists, Cincinnati, Ohio. http://www.acgih.org/TLV/OpsManual.pdf

ACGIH. 2005a. ACGIH Operations Manual. Threshold Limit Values For Chemical Substance Committee. American Conference of Governmental Industrial Hygienists, Cincinnati, Ohio. http://www.acgih.org/TLV/OpsManual.pdf

ACGIH. 2005b TLVs and BEIs: Threshold Limit Values for Chemical Substances and Physical Agents, American Conference of Governmental Industrial Hygienists, Cincinnati, Ohio.

ACGIH. 2004. Pyridine, American Conference of Governmental Industrial Hygienists, Cincinnati, Ohio.

ACGIH. 2003. Methyl n-butyl ketone . BEI. American Conference of Governmental Industrial Hygienists, Cincinnati, Ohio.

ACGIH. 2002a. Methyl tert-butyl ether. American Conference of Governmental Industrial Hygienists, Cincinnati, Ohio.

ACGIH. 2002b. Propionaldehyde. American Conference of Governmental Industrial Hygienists, Cincinnati, Ohio.

ACGIH. 2001a. Acrolein. In: Documentation of the Threshold Limit Values and Biological Exposure Indices, 7th edition, American Conference of Governmental Industrial Hygienists (Eds.), Cincinnati, Ohio.

ACGIH. 2001b. Camphor, Synthetic. In: Documentation of the Threshold Limit Values and Biological Exposure Indices, 7th edition, American Conference of Governmental Industrial Hygienists (Eds.), Cincinnati, Ohio.

ACGIH. 2001c. Chlorodiphenyl - 42\% Chlorine. In: Documentation of the Threshold Limit Values and Biological Exposure Indices, 7th edition, American Conference of Governmental Industrial Hygienists (Eds.), Cincinnati, Ohio.

ACGIH. 2001d. Chlorodiphenyl -54\% Chlorine. In: Documentation of the Threshold Limit Values and Biological Exposure Indices, 7th edition, American Conference of Governmental Industrial Hygienists (Eds.), Cincinnati, Ohio.

ACGIH. 2001e. Crotonaldehyde. In: Documentation of the Threshold Limit Values and Biological Exposure Indices, 7th edition, American Conference of Governmental Industrial Hygienists (Eds.), Cincinnati, Ohio. 
ACGIH. 2001f. Cyclohexanol. In: Documentation of the Threshold Limit Values and Biological Exposure Indices, 7th edition, American Conference of Governmental Industrial Hygienists (Eds.), Cincinnati, Ohio.

ACGIH. 2001g. Dibutyl phosphate. In: Documentation of the Threshold Limit Values and Biological Exposure Indices, 7th edition, American Conference of Governmental Industrial Hygienists (Eds.), Cincinnati, Ohio.

ACGIH. 2001h. Diethyl ketone. In: Documentation of the Threshold Limit Values and Biological Exposure Indices, 7th edition, American Conference of Governmental Industrial Hygienists (Eds.) Cincinnati, Ohio.

ACGIH. 2001i. Ethyl amyl ketone. In: Documentation of the Threshold Limit Values and Biological Exposure Indices, 7th edition, American Conference of Governmental Industrial Hygienists (Eds.), Cincinnati, Ohio.

ACGIH. 2001j. Cyclohexanone. In: Documentation of the Threshold Limit Values and Biological Exposure Indices, 7th edition, American Conference of Governmental Industrial Hygienists (Eds.), Cincinnati, Ohio.

ACGIH. 2001k. Ethylene glycol dinitrate. In: Documentation of the Threshold Limit Values and Biological Exposure Indices, 7th edition, American Conference of Governmental Industrial Hygienists (Eds.), Cincinnati, Ohio.

ACGIH. 2001l. Ethylenimine. In: Documentation of the Threshold Limit Values and Biological Exposure Indices, 7th edition, American Conference of Governmental Industrial Hygienists (Eds.), Cincinnati, Ohio.

ACGIH. 2001m. Methyl n-butyl ketone. In: Documentation of the Threshold Limit Values and Biological Exposure Indices, 7th edition, American Conference of Governmental Industrial Hygienists (Eds.), Cincinnati, Ohio.

ACGIH. 2001n. Flouroethylene; chloroethylene; bromoethylene. In: Documentation of the Threshold Limit Values and Biological Exposure Indices, 7th edition, American Conference of Governmental Industrial Hygienists (Eds.), Cincinnati, Ohio.

ACGIH. 20010. Glycerin. In: Documentation of the Threshold Limit Values and Biological Exposure Indices, 7th edition, American Conference of Governmental Industrial Hygienists (Eds.), Cincinnati, Ohio.

ACGIH. 2001p. Isooctyl alcohol. In: Documentation of the Threshold Limit Values and Biological Exposure Indices, 7th edition, American Conference of Governmental Industrial Hygienists (Eds.) Cincinnati, Ohio.

ACGIH. 2001q. Methyl n-amyl ketone. In: Documentation of the Threshold Limit Values and Biological Exposure Indices, 7th edition, American Conference of Governmental Industrial Hygienists (Eds.), Cincinnati, Ohio. 
ACGIH. 2001r. Methyl propyl ketone. In: Documentation of the Threshold Limit Values and Biological Exposure Indices, 7th edition, American Conference of Governmental Industrial Hygienists (Eds.) Cincinnati, Ohio.

ACGIH. 2001s. Methyl vinyl ketone. In: Documentation of the Threshold Limit Values and Biological Exposure Indices, 7th edition, American Conference of Governmental Industrial Hygienists (Eds.), Cincinnati, Ohio.

ACGIH. 2001t. Nitroglycerine. In: Documentation of the Threshold Limit Values and Biological Exposure Indices, 7th edition, American Conference of Governmental Industrial Hygienists (Eds.), Cincinnati, Ohio.

ACGIH. 2001u. 1-Nitropropane. In: Documentation of the Threshold Limit Values and Biological Exposure Indices, 7th edition, American Conference of Governmental Industrial Hygienists (Eds.), Cincinnati, Ohio.

ACGIH. 2001v. 2-Nitropropane. In: Documentation of the Threshold Limit Values and Biological Exposure Indices, 7th edition, American Conference of Governmental Industrial Hygienists (Eds.), Cincinnati, Ohio.

ACGIH. 2001w. N-propyl nitrate. In: Documentation of the Threshold Limit Values and Biological Exposure Indices, 7th edition, American Conference of Governmental Industrial Hygienists (Eds.), Cincinnati, Ohio.

ACGIH. 2001x. Phenylhydrazine. In: Documentation of the Threshold Limit Values and Biological Exposure Indices, 7th edition, American Conference of Governmental Industrial Hygienists (Eds.), Cincinnati, Ohio.

ACGIH. 2001y. Propylene glycol dinitrate. In: Documentation of the Threshold Limit Values and Biological Exposure Indices, 7th edition, American Conference of Governmental Industrial Hygienists (Eds.), Cincinnati, Ohio.

ACGIH. 2001z. Propylenimine. In: Documentation of the Threshold Limit Values and Biological Exposure Indices, 7th edition, American Conference of Governmental Industrial Hygienists (Eds.) Cincinnati, Ohio.

ACGIH. 2001aa. Tributyl phosphate. In: Documentation of the Threshold Limit Values and Biological Exposure Indices, 7th edition, American Conference of Governmental Industrial Hygienists (Eds.), Cincinnati, Ohio.

ACGIH. 2001bb. Vinyl chloride and vinyl bromide. In: Documentation of the Threshold Limit Values and Biological Exposure Indices, 7th edition, American Conference of Governmental Industrial Hygienists (Eds.), Cincinnati, Ohio.

Albro, PW. 1975. “The Metabolism of 2-ethylhexanol in Rats.” Xenobiotica, 5(10):626-636. 
Anthony, DC, K Boekelhede, and DG Graham. 1983. "The Effect of 3,4-dimethyl Substitution on the Neurotoxicity of 2,5-Hexanedione. I. Accelerated Clinical Neuropathy is Accompanied by More Proximal Axonal Swelling.” Toxicol. Appl. Pharmacol., 71(3):362-371.

Arnow, R. 1976. “Camphor Poisoning.” JAMA 235:1260.

Bailey WH. 2002. "Dealing with Uncertainty in Formulating Occupational and Public Exposure Limits." Health Phys., 83(3):402-408.

BASF. 1991. Report on the Study of Oncogenic Potential of 2-ethylhexanol in Mice After Administration By Gavage (Aqueous Emulsion) for 18 Months. Department of Toxicology of BASF, Submitted to WHO by the Flavor and Extract Manufacturers” Association of the United States, Washington, D.C.

BASF. 1992. Report on the Study of Oncogenic Potential of 2-Ethylhexanol in Rats After Administration by Gavage (Aqueous Emulsion) by 24 Months. Department of Toxicology of BASF, Submitted to WHO by the Flavor and Extract Manufacturers” Association of the United States, Washington, D.C.

Benya, TJ, WM Busey, and MA Dorato. 1982. "Inhalation Carcinogenicity Bioassay of Vinyl Bromide in Rats.” Toxicol. Appl. Pharmacol., 64:367-379.

Bevan, C, TL Neeper-Bradley, and RW Tyl. 1997. "Two-Generation Reproduction Study of MTBE in Rats.” J. Appl. Toxicol., (S1):S13-S19.

Bogdanffy, MS, CR Kee, DP Kelly, MC Carakostas, and GP Sykes. 1990. “Subchronic Inhalation Study With Vinyl Fluoride: Effects on Hepatic Cell Proliferation and Urinary Fluoride Excretion.” Fund. Appl. Toxicol., 15(2):394-406.

Bogdanffy, MS, GT Makovec, and SR Frames. 1995. "Inhalation Oncogenicity Bioassay in Rats and Mice with Vinyl Fluoride.” Fund. Appl. Toxicol., 26:223 - 238.

Boyd, MR. 1980. "Biochemical Mechanisms in Chemical-Induced Lung Injury: Role of Metabolic Activation CRC.” Critical Rev. in Toxicol. 103-176.

Boyd, MR and LT Burka. 1978. "In Vitro Studies on the Relationship Between Target Organ Alkylation and the Pulmonary Toxicity of a Chemically Reative Metabolite of 4-ipomeanol.” J. Pharmacol. Exp. Therap. 207:687.

Boyd, MR, LT Burka, BJ Wilson, and HA Sasame. 1978a. "In vitro Studies on the Metabolic Activation of the Pulmonary Toxin, 4-ipomeanol, by Rat Lung and Liver Microsomes." J. Pharmacol. Exp. Therap., 207:677.

Boyd, MR, C Statham, R Franklin, and JR Mitchell. 1978b. "Pulmonary Bronchiolar Alkylation and Necrosis by 3-methylfuran, a Naturally Occurring Potential Atmospheric Contaminant.” Nature. 272:270.

Bruning-Fann, CS and JB Kaneene. 1993. "The Effects of Nitrate, Nitrite and N-Nitroso Compounds on Human Health: a Review.” Vet Human Toxicol. 35, 521-538. 
Burleigh-Flayer, HD, JS Chun, and WJ Kintigh. 1992. "Methyl tertiary butyl ether: Vapor Inhalation Oncogenicity Study in CD-1 Mice. Study \# 91N0013A.” Union Carbide Corporation, Bushy Run Research Center, Export Pennsylvania.

Caprino, L, and GI Togna. 1998. "Potential Health Effects of Gasoline and Its Constituents: a Review of Current Literature (1990-1997) on Toxicological Data.” Environ. Health Perspect., 106:115-125.

Cederqvist, B, MG Persson, and LE Gustafsson. 1994. "Direct Demonstration of NO Formation In Vivo from Organic Nitrites and Nitrates, and Correlation to Effects on Blood Pressure and to In Vitro Effects." Biochem. Pharmacol. 47, 1047-1053.

Chana, A, MA Concejero, FM de, MJ Gonzalez, and B Herradon. 2002. “Computational Studies on Biphenyl Derivatives. Analysis of the Conformational Mobility, Molecular Electrostatic Potential, and Dipole Moment of Chlorinated Biphenyl: Searching for the Rationalization of the Selective Toxicity of Polychlorinated Biphenyls (PCBs).” Chem. Res Toxicol. 15(12), 1514-1526.

Chun, JS, HD Burleigh-Flayer, and WJ Kintigh. 1992. "Methyl Tertiary Butyl Ether: Vapor Inhalation Oncogenicity Study in F-344 Rats. Study \# 91N0013B.” Union Carbide Corporation, Bushy Run Research Center, Export Pennsylvania.

Clayton, Jr, JW. 1967. “Fluorocarbon Toxicity and Biological Action.” Fluorine Chem. Rev., 1: 197-252.

Clayton, GD and FE Clayton. 1982. Patty's Industrial Hygiene and Toxicology: Volume 2A, 2B, 2C: Toxicology $3^{\text {rd }}$ ed., John Wiley Sons, New York. pp. 4740.

CLS 2000. Commission on Life Sciences (CLS), Subcommittee on Spacecraft Maximum Allowable Concentrations, Committee on Toxicology Board on Environmental Studies and Toxicology. National Research Council. National Academy Press, Washington, D.C.

Cometto-Muniz, JE, WS Cain, and MH Abraham. 1998. "Nasal Pungency and Odor of Homologous Aldehydes and Carboxylic Acids.” Exp. Brain Res 118(2), 180-188.

Conaway, CC, RE Schroeder, and NK Snyder. 1985. “Teratology Evaluation of Methyl Tertiary Butyl Ether in Rats and Mice.” J. Toxicol. Environ. Health, 16:797-809.

Craig, DK, JS Davis, DJ Hansen, AJ Petrocchi, TJ Powell, and TE Tuccinardi, Jr. 2000. "Derivation of Temporary Emergency Exposure Limits (TEELs).” J. Appl. Toxicol. 20(1), 11-20.

Crump KS. 1984. “A New Method for Determining Allowable Daily Intakes.” Fund. Appl. Toxicol., 4:854-871.

Daughtrey, WC, MW Gill, IM, Pritts, JF Douglas, JJ Kneiss, and LS Andrews. 1997.

“Neurotoxicological evaluation of methyl tertiary-butyl ether in rats.” J. Appl. Toxicol. 17, S57-S64

Deichman, WB and TJ LeBlanc. 1943. Determination of the Approximate Lethal Dose with About Six Animals.” J. Ind. Hyg. Toxicol., 25:415-417. 
Dorne JL and AG Renwick. 2005. "The Refinement of Uncertainty/Safety Factors in Risk Assessment by the Incorporation of Data on Toxicokinetic Variability in Humans.” Toxicol. Sci., 86(1):20 -26.

Dourson ML, RC Hertzberg, R Hartung, and K Blackburn. 1985. "Novel Methods for Estimation of Acceptable Daily Intake.” Toxicol. Ind., Health, 1:23-33.

Dow Chemical Company. 2002. High Production Volume (HPV) Chemical Challenge Program Test Plan. Submitted to the U.S. Environmental Protection Agency. http://www.epa.gov/chemrtk/nitroalc/c14355tp.pdf.

Duckett, S, N Williams, and S Francis. 1974. "Peripheral Neuropathy Associated with Inhalation of Methyl n-butyl ketone.” Experientia, 30:1283-1284.

Dunkel, VC, AM Rogers-Back, TE Lawlor, JW Harbell, and TP Cameron. 1989. "Mutagenicity of Some Alkyl Nitrites Used as Recreational Drugs.” Environ. Mol. Mutagen. 14(2), 115-122.

EPA. 2002. U.S. Environmental Protection Agency (EPA). A Review of the Reference Dose and Reference Conference Process. Final report. EPA/639/P-02/002F.

EPA. 2000. U.S. Environmental Protection Agency (EPA). Benchmark Dose Technical Guidance Document. EPA/630/R-00/001.

EPA. 1994. U.S. Environmental Protection Agency (EPA). Methods for Derivation of Inhalation Reference Concentration and Application Of Inhalation Dosimetry. EPA/600/8-90/066F.

EPA. 1989. U.S. Environmental Protection Agency. Butyraldehyde, Vapor Inhalation Study in Rats, with Letter 2/6/89. EPA/OTS, Doc. \#86-890000097. http://www.epa.gov/chemfact/butyr-sd.txt.

Fillipsson AF, S Sand, J Nilsson, and K Victorin. 2003. “The Benchmark Dose Method-Review Of Available Models, and Recommendations for Application in Health Risk Assessment.” Crit. Rev. Toxicol., 33(5):505-542.

Filser, JG, and HM Bolt. 1979. "Pharmacokinetics of Halogenated Ethylenes in Rats.” Arch. Toxicol., 42:123-136.

Fleischman, RW, JR Baker, M Hagopian, GG Wade, DW Hayden, ER Smith, JH Weisburger, and EK Weisburger. 1980. "Carcinogenesis Bioassay of Acetamide, Hexanamide, Adipamide, Urea and P-Tolylurea in Mice and Rats.” J. Environ. Pathol. Toxicol. 3(5-6), 149-170.

Fraser, P, C Chilvers, and P Goldblatt. 1982. "Census-Based Mortality Study of Fertiliser Manufactures.” Br. J. Ind. Med. 39, 323-329.

Fraser, P, C Chilvers, M Day, and P Goldblatt. 1989. "Further Results From a Census Based Mortality Study of Fertiliser Manufacturers.” Br. J. Ind. Med. 46, 38-42.

General Accounting Office (GAO). 2001. Chemical Risk Assessment, Selected Federal Agencies” Procedures, Assumptions and Policies. GAO-01-810. Washington, D.C. 
Gosselin, RE, RP Smith, and HC Hodge. 1984. Toxicology of Commercial Products, $5^{\text {th }}$ ed., Section III, pp. 84-86. Williams \& Wilkins, Baltimore, Maryland.

Gronka, PA, RL Bobkoskie, GJ Tomchick, and AB Rakow. 1969. "Camphor Exposures in a Packaging Plant.” Am. Ind. Hyg. Assoc. J., 30:276-279.

Gupta, PK, WH Lawrence, JE Turner, and J Autian. 1979. “Toxicological Aspects of Cyclohexanone.” Toxicol. Appl. Pharm., 49:525-533.

Haber LT and A Maier. 2002. "Scientific Criteria for the Development of Occupational Exposure Limits for Metals and Other Mining-Related Chemicals.” Reg. Toxicol. Pharmacol., 36:262-279.

Health Council of the Netherlands (HCN). 2000. Committee on Updating of Occupational Exposure Limits: Health-Based Reassessment of Administrative Occupational Exposure Limits. No.

2000/150SH/000. Health Council of the Netherlands.

International Agency for Research on Cancer (IARC). 1987. IARC Monographs on the Evaluation of Carcinogenic Risk to Humans. Supplement 7. World Health Organization, Lyon, France.

Ito, N, H Nagasaki, M Arai, S Makiura, S Sugihara, and K Hirao. 1973. "Histopathologic Studies on Liver Tumorigenesis Induced in Mice by Technical Polychlorinated Biphenyls and Its Promoting Effect on Liver Tumors Induced by Benzene Hexachloride.” J. Natl. Cancer Inst. 51(5), 1637-1646.

Ito, N, H Nagasaki, S Makiura, and M Arai. 1974. "Histopathological Studies on Liver Tumorigenesis in Rats Treated with Polychlorinated Biphenyls.” Gann 65(6), 545-549.

Johanson, G, A Nihlen, and A Lof. 1995. "Toxicokinetics and Acute Effects of MTBE and ETBE in Male Volunteers.” Toxicol. Lett., 82/83:713-718,

Johnson, BL, WK Anger, and JV Setzer. 1979. "Neurobehavioral effects of methyl n-butyl ketone and methyl n-amyl ketone in rats and monkeys: a summary of NIOSH investigations.” J. Environ. Pathol. Toxicol., 2:113-133

Johnson, BL, JV Setzer, TR Lewis, and RW Hornung. 1978. “An Electrodiagnostic Study of the Neorotoxicity of Methyl-n-amy-kentone.” Am. Ind. Hyg. Assoc. J., 39:866-872.

Katz, GV, JL O’Donoghue, GD DiVincenzo, and CJ Terhaar. 1980. “Comparative Neurotoxicity and Metabolism of Ethyl-n-butyl ketone and Methyl-n-butyl ketone in Rats.” Toxicol. Appl. Pharmacol., 52:153-158.

Kennedy, GL, Jr. 1986. "Biological Effects of Acetamide, Formamide, and their Monomethyl and Dimethyl Derivatives.” Crit Rev. Toxicol. 17(2), 129-182.

Klonne, DR, CE Ulrich, J Weissmann, and AK Morgan. 1987. “Acute Inhalation Toxicity of Aliphatic (C1-C5) Nitrites in Rats.” Fundam. Appl. Toxicol. 8(1), 101-106. 
Krasavage, WJ, JL O’Donoghue, and GD Divincenzo. 1982. In: Patty’s Industrial Hygiene and Toxicology, $3^{\text {rd }}$ Rev. Edition, Vol. 2C, Toxicology, Eds. GD Clayton and FE Clayton, John Wiley \& Sons, New York, pp. 4722-4764.

Lijinsky, W, and RMJ Kovatch. 1986. "Chronic Toxicity Study of Cyclohexanone in Rats and Mice.” Natl. Cancer Inst., 941-949.

Lington, AW, DF Dodd, and SA Ridlon. 1997. "Evaluation of 13-Week Inhalation Toxicity Study on MTBE in Fisher 344 Rats.” J. Appl. Toxicol., 17(Suppl 1):S37-S44.

MAK. 2000. Deutsche Forschungsgemeinschaft: Sensitizing Substances. In: List of MAK and BAT Values, pp 150-158. Commission for the investigation of health hazards of chemical compounds in the work area. Report No. 36. Wiley-VCH, Weinheim, Germany.

Maltoni, C, G LeFemine, A Ciliberti, G Cotti, and D Carretti. 1981. "Carcinogenicity Bioassays of Vinyl Chloride Monomer: a Model of Risk Assessment on an Experimental Basis.” Environ. Health Perspect., 41:3-29.

Marsh, DF and CD Leake. 1950. "The Comparative Anesthetic Activity of the Aliphatic Ethers.” Anaesthesiology 11:455-463.

McMurtry, RJ and JR Mitchell. 1977. "Renal and Hepatic Necrosis After Metabolic Activation of 2Substituted Furans and Thiophenes, Including Furosemide and Cephaloridine.” Toxicol. Appl.

Pharmacol. 42:285.

Mendell, JR, K Saida, and MF Ganansia. 1974. “Toxic Polyneuropathy Produced by Methyl n-butyl ketone.” Science, 185:787-789.

Mirvish, SS, J Williamson, D Babcook, and SC Chen. 1993. "Mutagenicity of Iso-Butyl Nitrite Vapor in the Ames Test and Some Relevant Chemical Properties, Including the Reaction of Iso-Butyl Nitrite with Phosphate.” Environ. Mol. Mutagen. 21(3), 247-252.

Mitchell, JR, SD Nelson, WZ Potter, HA Sasame, and DJ Jollow. 1976. "Metabolic Activation of Furosemide to a Chemically Reactive, Hepatotoxic Metabolite.” J. Pharmacol. Exp. Therap. 199:41.

National Academy of Sciences (NAS). 1994. National Research Council. Science and Judgment in Risk Assessment, National Academy Press, Washington, D.C.

National Academy of Sciences (NAS). 1983. Risk Assessment in the Federal Government: Managing the Process. National Academy Press, Washington, D.C..

National Research Council of the National Academies. 2001. Acute Exposure Guideline Levels for Selected Airoborne Chemicals, Volume 2. The National Academies Press, Washington, D.C. http://www.epa.gov/oppt/aegl/pubs/tsd154.pdf

Nelson, KW, JF Ege, Jr, and M Ross. 1943. “Sensory Response to Certain Industrial Solvent Vapors.” J. Ind. Hyg. Toxicol., 25:282-285. 
NIH. 2006. http://toxnet.nlm.nih.gov/cgi-bin/sis/search/f?./temp/ POO1ne:1:FULL

NIOSH. 1976. Registry of Toxic Effects of Chemical Substances. Eds. HE Christensen and EJ Fairchild. Entry: MP03500, p. 586, National Institute of Occupational Safety and Health, Washington D.C.

NTIS. 1995. Documentation for Immediately Dangerous to Life or Health Concentrations (IDLH): NIOSH Chemical Listing and Documentation of Revised IDLH Values (as of 3/1/95). NTIS Publication No. PB-94-195047.

NTP. 1993. Toxicology and Carcinogenisis Studies of Furan in F344/n Rats and B6C3F1 Mice (Gavage). Technical Report 402. Health and Human Services, NIH, NIEHS/NTP. Research Triangle Park, North Carolina.

NTP. 2006. http://ntp.niehs.nih.gov/index.cfm?objectid=E87DF5FE-BDB5-82F8-E2743EDE7C9F8EA

OECD. 2004. Organization for Economic Co-operation and Development. Joint meeting of the chemical committee and the working party on chemicals, pesticides and biotechnology. Task force on harmonization of classification and labeling. Proposal for revision of chapter 3.1 on acute toxicity. ENV/JM/HCL(2004)7/REV.

Olefins Panel. 2004. http://www.epa.gov/chemrtk/c5ncyl/c12801rt3.pdf

Poet, TS, TJ Mast, and JL Huckaby. 2006. Screening Values for Non-Carcinogenic Hanford Waste Tank Vapor Chemicals that Lack Established Occupational Exposure Limits, PNNL-15640, Pacific Northwest National Laboratory, Richland, Washington.

Proctor, NH, JP Hughes, and ML Fishman. 1988. Chemical Hazards of the Workplace, $2^{\text {nd }}$ ed., pp. 114115. J. B. Lippincott, Philadelphia, Pennsylvania.

Ravindranath, V, MG McMenamin, JH Dees, and MR Boyd. 1986. "2-methylfuran Toxicity in RatsRole of Metabolic Activation In Vivo.” Toxicol. Appl. Pharmacol , 85(1):78-91.

Rinehart, WE, RC Garbers, EA Greene, and RM Stoufer. 1958. "Studies on the Toxicity of N-propyl nitrate Vapor.” Am. Ind. Hyg. Assoc. J. 19, 80-83

Saillenfait, AM, P Bonnet, JP Guenier, and J de Ceaurriz. 1993. "Relative Developmental Toxicities of Inhaled Aliphatic Mononitriles in Rats.” Fundam. Appl. Toxicol. 20(3), 365-375.

Scala, RA and EG Burtis. 1973. "Acute Toxicity of a Homologous Series of Branched-Chain Primary Alcohols.” Am. Ind. Hygiene Assoc. J., 34 (11):493-499.

Schaal, B, G Coureaud, D Langlois, C Ginies, E Semon, and G Perrier. 2003. "Chemical and Behavioural Characterization of the Rabbit Mammary Pheromone.” Nature 424, 68-72.

Schaper, M. 1993. "Development of a Data Base for Sensory Irritants and its Use in Establishing Occupational Exposure Limits.” Am. Ind. Hyg. Assoc. J., 54(9):488-544. 
Scientific Committee on Occupational Exposure Limits (SCOEL). 1999. Methodology for the Derivation of Occupational Exposure Limits: Key Documentation. European Union, Scientific Committee on Occupational Exposure Limits, Luxembourg.

Sklarew, DS and AV Mitroshkov. 2006. Review of Mass Spectroscopy Data from Waste Tank Headspace Analysis. PNNL-15673, Pacific Northwest National Laboratory, Richland, Washington.

Smyth, HF, Jr, CP Carpenter, CS Weil, UC Pozzani, JA Striegel, and JS Nycum. 1969. "Range-finding Toxicity Data: List VII.” Am. Indust. Hygiene Assoc. J., 30(5):470-476.

Smyth, HF Jr, CP Carpenter, and CS Weil. 1949. “Range-finding Toxicity Data. List III.” J. Ind. Hyg. Toxicol., 31:60-62.

Specht, H, JW Miller, PJ Valaer, and RR Sayers. 1940. Acute Response of Guinea Pigs to the Inhalation of Ketone Vapors. U.S. National Institute of Health Bulletin No., 176. U.S. Public Health Service, Washington, D.C.

Spencer, PW, HH Schaumberg, RL Raleigh, and CJ Terhaar. 1975. "Nervous System Degeneration Produced by the Industrial Solvent Methyl n-butyl ketone.” Arch. Neurol., 32:219-222.

Swenson, DH, EC Miller, and JA Miller. 1974. “Aflatoxin B1-2,3-oxide: Evidence for its Formation in Rat Liver In Vivo and by Human Liver Microsomes In Vitro.” Biochem, Biophys. Res. Commun. 60:1036.

Tanii, H, H Tsuji, H, and K Hashimoto. 1986. “Structure-toxicity Relationship of Monoketones.” Toxicol. Lett. 30:13-17.

Tashiro, Y, R Kodama, H Sugai, K Suzuki, and S Matsuoka. 2000. “Nonphosphate Degradation Products of Tributyl Phosphate and their Reactivities in Purex Media Under Extreme Conditions.” Nuclear Technology. 129, 93-100.

Tanii, H and K Hashimoto. 1984a. "Structure-toxicity Relationship of Aliphatic Nitriles.” Toxicol. Lett. 22(2), 267-272.

Tanii, H and K Hashimoto. 1984b. "Studies on the Mechanism of Acute Toxicity of Nitriles in Mice.” Arch. Toxicol. 55(1), 47-54.

Thorup, I, G Wurtzen, J Carstensen, and P Olsen. 1983. "Short Term Toxicity Study in Rats Dosed with Pulegone and Menthol.” Toxicol. Lett. 19(3):207-210.

Tice, R. 1998. Pulegone (89-82-7) and One of its Metabolites Menthofuran (494-90-6). Review of toxicology literature. Integrated Laboratory Systems, prepared for NIEHS. (http://ntp.niehs.nih.gov/ntp/htdocs/Chem_Background/ExSumPdf/Pennyroyal.pdf).

Tornqvist, M, U Rannug, A Jonsson, and L Ehrenberg. 1983. "Mutagenicity of Methyl Nitrite in Salmonella Typhimurium.” Mutat. Res. 117(1-2), 47-54. 
Treon, JF. 1963. Alcohols. In: Patty's Industrial Hygiene and Toxicology, $2^{\text {nd }}$ Edition, Volume 2, Patty, F. A. (ed.)., Interscience Publishers, New York.

Treon, JF, WE Crutchfield, and KV Kitzmiller. 1943. “The Physiological Response of Animals to Cyclohexane, Methylcyclohexane and Certain Derivatives of these Compounds. II. Inhalation.” J. Ind. Hyg. Toxicol., 25:323-347.

Van Maanen, JM, HJ Albering, TM de Kok, SG van Breda, DM Curfs, IT Vermeer, AW Ambergen, BH Wolffenbuttel, JC Kleinjans, and HM Reeser. 2000. "Does the Risk of Childhood Diabetes Mellitus Require Revision of the Guideline Values for Nitrate in Drinking Water?” Environ. Health Perspect. 108, 457-461.

Willhite, CC and RP Smith. 1981. "The Role of Cyanide Liberation in the Acute Toxicity of Aliphatic Nitriles.” Toxicol. Appl. Pharmacol. 59(3), 589-602.

Willhite, CC, VH Ferm, and RP Smith. 1981. “Teratogenic Effects of Aliphatic Nitriles.” Teratology. 23(3), 317-323.

Wirth, PJ, CJ Bettis, and WL Nelson. 1976. “Microsomal Metabolism of Furosemide. Evidence for the Nature of the Reactive Intermediate Involved in Covalent Binding.” Mol. Pharmacol. 12:759.

WHO. 2005. Evaluation of Certain Food Additives, WHO Technical Report Series \#928. Sixty-third report of the Joint FAO/WHO Expert Committee on Food Additives. World Health Organization, Geneva, Switzerland.

Zandjani, F, B Hogsaet, A Andersen, and S Langard. 1994. "Incidence of Cancer Among Nitrate Fertilizer Workers.” Int. Arch. Occup. Environ. Health. 66, 189-193. 


\section{Distribution}

No. of

Copies

\section{OFFSITE}

33 CH2M Hill Hanford Group

$\mathrm{T}$ Anderson (5)

DF Farler

JO Honeyman (20)

FM Ito

JE Meacham (2)

JM Molnaa

ML Zabel (2)

Correspondence Control

2 U.S. Department of Energy

Robert C. Barr (2)
No. of

$\underline{\text { Copies }}$

ONSITE

7 Pacific Northwest National Laboratory

S7-70

S7-70

H6-03

R2-50

R2-58

R2-50

S7-70

H6-08

JL Huckaby (3)

K7-15

TS Poet

P7-59

CA Timchalk

P7-59

Information Release (2)

H6-60

Distr.1 